\title{
SURGICAL TOOLING DESIGNED FOR THE DIRECT ANTERIOR APPROACH TO TOTAL HIP ARTHROPLASTY
}

\author{
A Thesis \\ presented to \\ the Faculty of California Polytechnic State University, \\ San Luis Obispo
}

\author{
In Partial Fulfillment \\ of the Requirements for the Degree \\ Master of Science in Biomedical Engineering
}

by

Jon-Peter Meckel

July 2013 
(C) 2013

Jon-Peter Meckel

ALL RIGHTS RESERVED 


\section{COMMITTEE MEMBERSHIP}

TITLE:

AUTHOR:

DATE SUBMITTED:

COMMITTEE CHAIR:

COMMITTEE MEMBER:

COMMITTEE MEMBER:
Surgical Tooling Designed for the Direct Anterior Approach to Total Hip Arthroplasty

Jon-Peter Meckel

July 2013
Dr. Scott Hazelwood, Associate Professor of

Biomedical Engineering

Dr. David Clague, Associate Professor of

Biomedical Engineering

Dr. Kristen O’Halloran Cardinal, Associate

Professor of Biomedical Engineering 


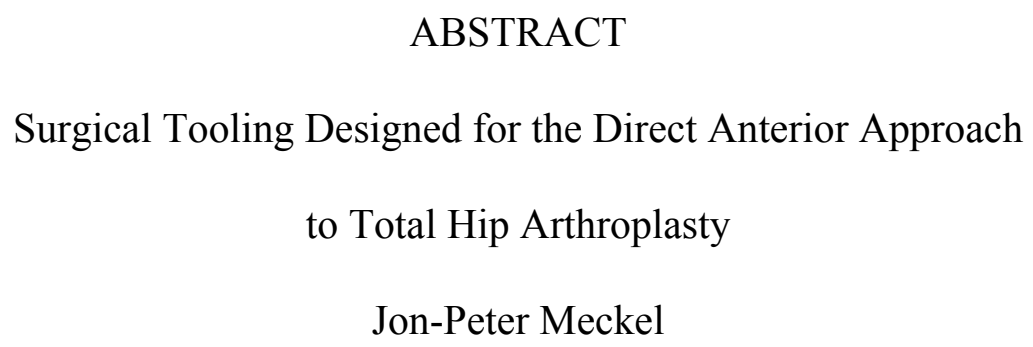

Total hip arthroplasty (THA) is becoming more and more common in the US as people continue to live longer and more active lives. The main reason that a THA is required is due to the "wear and tear" affliction of osteoarthritis, which in the year 2000 had at least $3 \%$ of the population over 30 showing symptoms ${ }^{8}$. A revitalized approach to THA is the direct anterior approach, or Smith-Petersen approach, which limits the amount of musculature affected by the surgery and creates a very stable joint post-operatively ${ }^{2}$. While this approach is showing great clinical success, it does require slightly unconventional patient positioning. The pioneers of this surgical approach include Dr. Joel Matta, who along with Mizuhosi (Union City, CA, USA) has created an impressive direct anterior approach surgical table to address the problems associated with getting patients in the right position. Unfortunately, this table is very expensive, gives no feedback on force application, and surgeons are being taught that it is required to perform the procedure. This thesis introduces a simple set of surgical tooling that facilitates the direct anterior approach very cost effectively, giving the surgeon the feedback lacking in the expensive Mizuhosi table, and the flexibility to attempt the approach without convincing his or her hospital to make such a large capital investment. A prototype was successfully developed and tested to show that a simple solution exists to make the direct anterior approach more feasible for surgeons to incorporate into their practice. 


\section{ACKNOWLEDGMENTS}

Thank you to the whole Cal Poly community for the support and education that has made me the man I am today. I couldn't have picked a better place to learn how to identify, dissect, and work through problems of any nature. Particular thanks are due to Dr. Hazelwood for allowing me the freedom to pursue my own project, and for encouraging me when it took longer than expected.

My family has always been there to console me after a tough test and celebrate after a good one. I love you all so much and can never express how important you are to me. Thank you Rachael for your unending support and understanding through this process. I love you and can't wait to start our lives together.

This project wouldn't exist without the ideas, encouragement, and funding of my brother Dr. Chris Meckel, and his colleague Dr. Phil Merritt. Thank you for trusting me to develop such an interesting project, and showing me a glimpse of the exciting field of Orthopedic Surgery. I look forward to following in your footsteps as I too go into the field of Medicine. 


\section{TABLE OF CONTENTS}

\section{Page}

LIST OF TABLES...........................................................iii

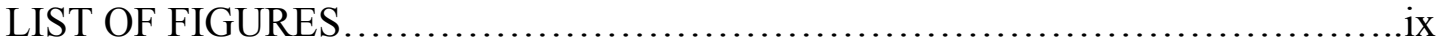

\section{CHAPTER}

I. INTRODUCTION ...................................................

Osteoarthritis........................................................

Total Hip Arthroplasty $\ldots \ldots \ldots \ldots \ldots \ldots \ldots \ldots \ldots \ldots \ldots \ldots \ldots \ldots \ldots \ldots \ldots$

Procedures...............................................................

History of the Direct Anterior Approach............................18

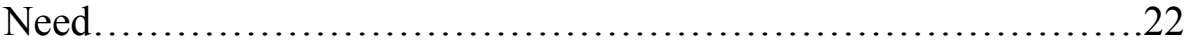

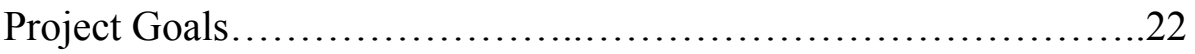

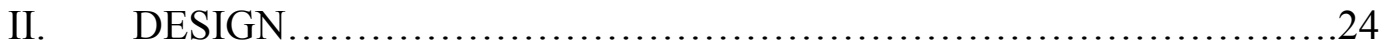

Overview.................................................................

Femoral Elevator Assembly ...................................27

Boot Assembly..................................................

Analysis............................................................ 34

III. MANUFACTURING AND TESTING .............................42

Overview..........................................................

Manufacturing ...................................................... 42

Completed Prototype............................................45

Prototype Testing............................................... 47 
IV. LIMITATIONS, IMPROVEMENT, FUTURE WORK, AND

CONCLUSIONS........................................................

Limitations.......................................................... 50

Improvements .................................................... 50

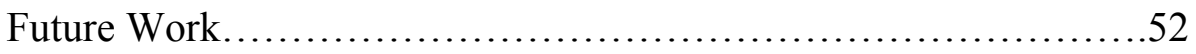

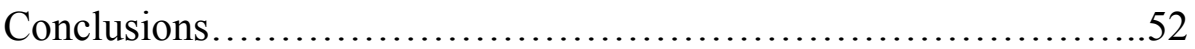

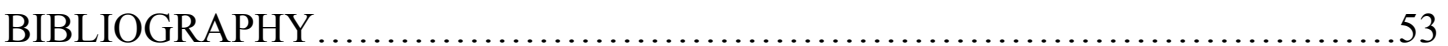

\section{APPENDICES}

A. Detailed Drawings.................................................56

B. Manufacturing Cost Estimate.................................... 86 


\section{LIST OF TABLES}

Table

Page

1. Musculature affected by the anterior approach to THA. Columns

highlighted in yellow indicate muscles cut/ligated....................... 14

2. Musculature affected by the posterior approach to THA. Columns

highlighted in yellow indicate muscles cut...........................14

3. Musculature affected by the lateral approach to THA. Columns

highlighted in yellow indicate muscles cut...........................15 


\section{LIST OF FIGURES}

$\begin{array}{lll}\text { Figure } & \text { Page }\end{array}$

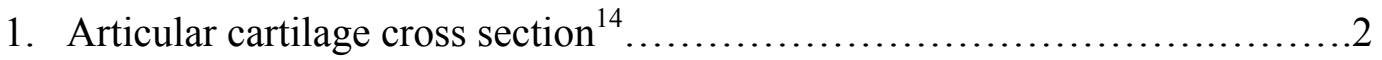

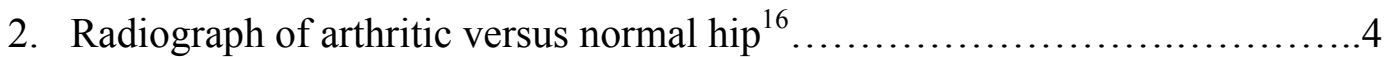

3. Arthroscopic debridement of severely damaged knee cartilage, healthy

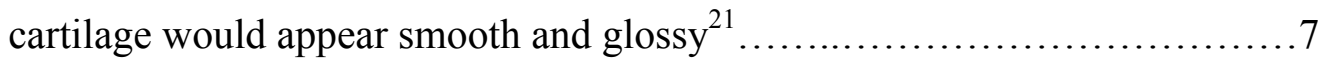

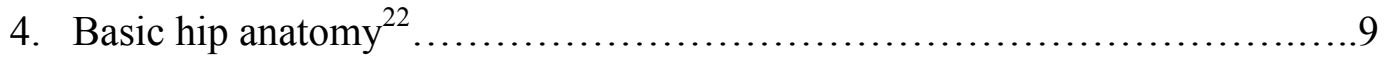

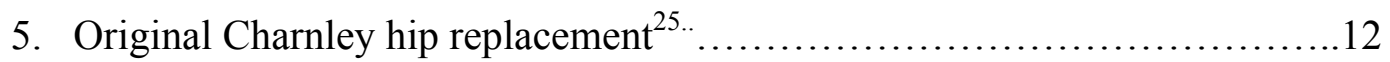

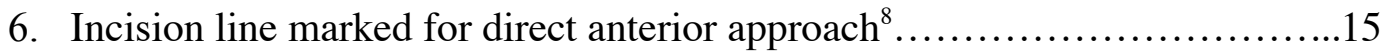

7. Patient positioning during the direct anterior approach ${ }^{8} \ldots \ldots \ldots \ldots \ldots \ldots \ldots$

8. Double osteotomy performed during direct anterior approach............... 17

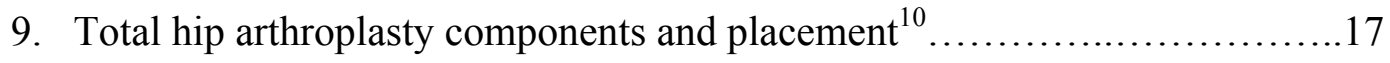

10. Smith-Petersen mold arthroplasty made of cobalt chrome ${ }^{12}$................19

11. Smith-Peterson mold arthroplasty X-ray image from $1949^{13} \ldots \ldots \ldots \ldots \ldots \ldots 19$

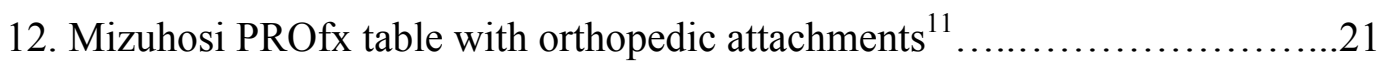

13. Full surgical attachment package shown on a representative table..........25

14. Surgical view of anterior THA. Note the external rotation of the leg undergoing procedure. Figure courtesy of Dr. Phil Merritt.................26

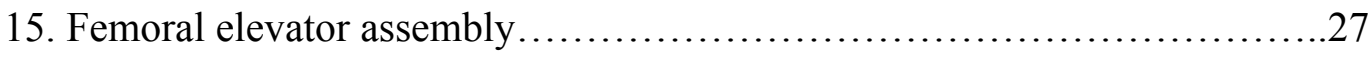

16. Exploded view of femoral elevator clamp...............................28

17. Exploded view of hook and pull rod assembly.........................29

18. Exploded view of femoral elevator rail clamp, designed to fit standard Skytron surgical tables..........................................29 
19. Boot assembly................................................. 31

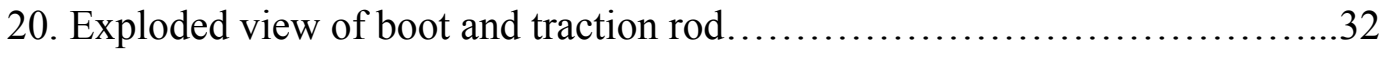

21. Exploded view of rail assembly..................................... 32

22. Simple rail clamp used to secure boot assembly to surgical table, designed to fit standard Skytron surgical tables....................................33

23. Track Slider Assembly........................................... 33

24. Femoral elevator with assumed forces.............................. 35

25. Blue arrow shows analysis point of interest of hook....................40

26. Femoral hook after initial forming and grinding ......................43

27. Prototype femoral elevator assembly..............................45

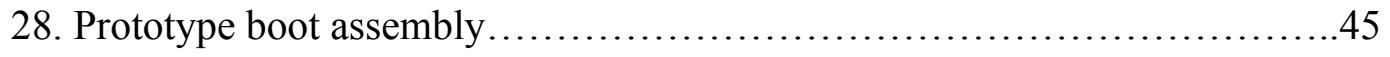

29. Patient on table with entire surgical package in place.....................48

30. Boot assembly strapped onto patient and rotated.......................49 


\section{CHAPTER 1}

\section{Introduction}

\section{Osteoarthritis}

Osteoarthritis is characterized by general joint pain, articular cartilage loss, osteophyte formation, and subchondral bone structural changes ${ }^{14}$. This can also be accompanied by inflammation of the joint, and damage to the soft tissue surrounding the joint. While it's thought that osteoarthritis is a "wear and tear" condition, there are clearly genetic, nutritional, weight, injury, and age related factors ${ }^{9}$. In the year $2000,3 \%$ of adults over the age of 30 in the US had symptomatic hip osteoarthritis ${ }^{9}$. This number has surely grown in the US as the population continues to grow older as we extend life expectancy.

\section{Articular Cartilage}

Articular cartilage is found within joints and provides a wear surface, cushioning for impact, and load dispersal throughout the joint. Articular cartilage is comprised of a structural extracellular matrix, water, chondrocytes, and a variety of other minor proteins and lipids ${ }^{14}$. The extracellular matrix is made up of mostly type II collagen, which provides the majority of the tensile strength for the structure, and proteoglycans. Proteoglycans are hydrophilic protein and sugar chains that attract water into the extracellular matrix, which in turn provides the compressive strength required for cartilage ${ }^{15}$. Chondrocytes are found throughout cartilage and are responsible for making new collagen, proteoglycans, and other collagen components. 
Articular cartilage is structured through alignment of the collagen fibers, whose orientation change based on the zone of cartilage in which they are found. Figure 1 shows a cross section of cartilage and how the fibers align within different regions.

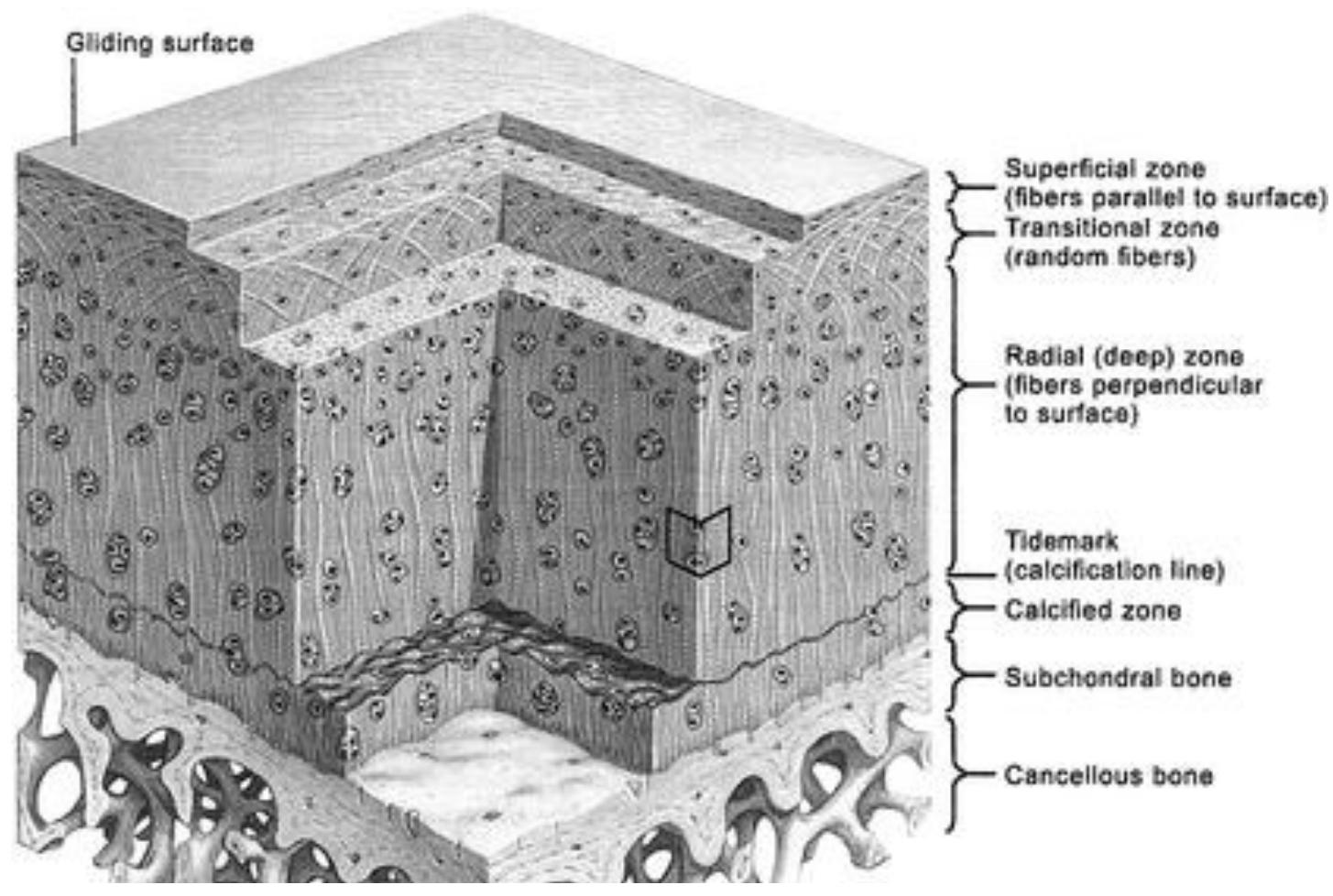

Figure 1. Articular cartilage cross section ${ }^{14}$.

The outermost zone, or superficial zone, experiences great shear stress as it must resist the mating joint sliding across its surface. Therefore, the collagen fibers are oriented to resist that stress and are parallel to the surface. The deeper layers of cartilage are also optimized for the loading they experience, with collagen fibers aligning perpendicular to the surface in the radial zone. The deepest layer of cartilage is the transition from a flexible structure to a rigid calcified zone, identified by the tidemark as seen in Figure 1. The calcified cartilage is anchored to subchondral bone, which provides the structural base for the cartilage. 


\section{Subchondral Bone}

Subchondral bone is the anchor for articular cartilage, but does much more than that alone. Mechanically, subchondral bone can actually attenuate up to $30 \%$ of the load applied to joints during impact in order to support the cartilage ${ }^{14}$. The interface between subchondral bone and cartilage is extremely important, as it is the source of nutrient exchange and waste removal for the cartilage. The subchondral bone and articular cartilage are linked in such a way that significant degradation in either will cause the other to degrade as well ${ }^{14}$.

\section{Effect of Osteoarthritis on Cartilage and Subchondral Bone}

Osteoarthritis is characterized by the degradation of articular cartilage and changes in subchondral bone. These changes are generally started through either injury or general breakdown of the tissues, which can be affected by a variety of factors. In the early stages of osteoarthritis chondrocytes are upregulated to produce more collagen and proteoglycans to replace the degrading tissues ${ }^{14}$. However, as the disease progresses the chondrocytes can no longer keep up with the growing demand for cartilage components. One of the theorized modes of osteoarthritis progression suggests that actual apoptosis of chondrocytes is triggered through cytokines so that there are fewer cells to rebuild components ${ }^{17}$. The loss of proteoglycans reduces the uptake of water into the extracellular matrix, decreasing the ability of cartilage to resist compression. The loads are then transferred more heavily to the subchondral bone, which is forced to remodel. 
This remodeling process creates thicker, more dense subchondral bone, which is less able to dampen the loads placed on the thinning articular cartilage. This causes even more degradation of the articular cartilage, and in severe cases it can be completely remodeled into a high-density sclerotic wear surface. Osteophytes can also develop which are bone spurs that occur along joints margins that cause irritation and further cartilage degradation. Throughout this process patients often experience inflammation and pain as tissue is irritated and degrades. A radiograph like that seen below in Figure 2 can quickly show both the decrease in cartilage thickness, and the densification of the subchondral bone.

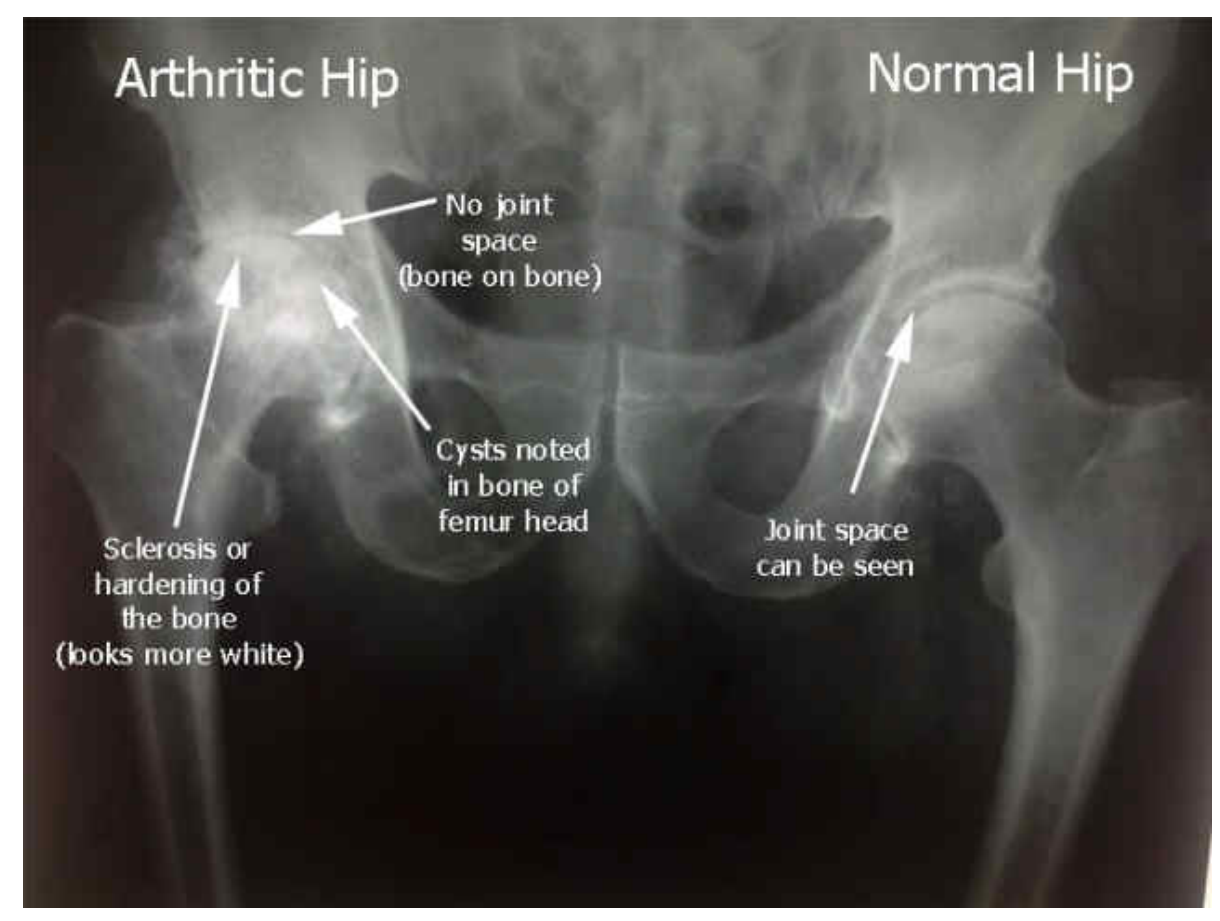

Figure 2. Radiograph of arthritic versus normal hip ${ }^{16}$. 


\section{Factors Affecting Osteoarthritis Development}

Osteoarthritis development can be affected by a multitude of factors including genes, nutrition, weight, injury, and age. Osteoarthritis is strongly genetically linked, with suspected genes being the vitamin D receptor gene, insulin-like growth factor I genes, cartilage oligomeric protein genes, and the HLA region'. Nutritionally, the onset of osteoarthritis appears to be slowed in those that consume large amounts of antioxidants and vitamin $\mathrm{C}^{9}$. These are thought to mitigate the harmful effects of the reactive oxygen species created by chondrocytes ${ }^{9}$. Obesity is thought to play a role in the development of osteoarthritis as the cartilage is forced to endure larger loads than an individual of normal weight. This requires greater maintenance levels of cartilage components, and especially as the load is generally magnified by $2-3$ times at the joint surface itself, small weight variations have a significant effect on joint loading ${ }^{16}$. Injury to cartilage can cause the onset of osteoarthritis in a few ways. Direct injury to the cartilage itself creates an area of high shear stress during joint articulation, as the surface is now compromised. This causes cartilage degradation and leads to chondrocyte remodeling of the cartilage. Injury to the joint that doesn't directly affect the cartilage can also cause issues if it causes a new loading pattern (a limp for example), which can put higher stresses on portions of the cartilage. Age is the strongest factor linked to osteoarthritis. As we age generally there is an associated loss in bone density and remodeling ability. This in turn reduces the ability of subchondral bone to share the load with articular cartilage, and the cartilage is broken down more quickly. Muscle tone and strength decreases with age as well, which puts greater stress on the cartilage during impacts and loading in general. 


\section{Treatment Options}

Osteoarthritis has no known cure, so the management of the condition is based on reduction in pain and increase in functionality for day-to-day tasks ${ }^{19}$. The first treatment used almost universally in the early stages of osteoarthritis is physical therapy along with acetaminophen, non-steroidal anti-inflammatory drugs, or COX-2 inhibitors ${ }^{2}$. The physical therapy is intended to increase muscle strength and support to the joint and to address gait issues that may be causing uneven stress on the cartilage. Exercise also lubricates the joint and facilitates nutrient and waste exchange throughout the cartilage. Non-steroidal anti-inflammatory drugs and COX2 inhibitors address pain and inflammation in the joint, but long-term use is linked to gastrointestinal issues and potentially hepatic and renal toxicity ${ }^{19}$.

If exercise and basic pharmacological interventions are unsuccessful, the next treatment for many patients is steroid injections ${ }^{2}$. These injections target specific areas of inflammation and are thought to give an inflamed joint the opportunity for some moderate repair with a reduced immune response. If repeated injections are unsuccessful, the final treatment modality to consider are surgical interventions. Specifically, the most common treatments are osteotomy, arthroscopic debridement, arthrodesis, and finally arthroplasty ${ }^{19}$. 
An osteotomy is a surgical procedure where a small portion of bone is either added or removed from a joint (commonly the knee) to alter the way the joint articulates in hopes of relieving an over-stressed portion of cartilage ${ }^{20}$. This is generally done in younger patients where a total arthroplasty is not yet recommended, and has varying effectiveness. Arthroscopic debridement is used in patients that have tears and inconsistencies in their cartilage (see Figure 3). The procedure is done by inflating the joint with carbon dioxide for viewing, inserting a camera and a cutting/effusion tool through cannulas, and trimming off the damaged cartilage.

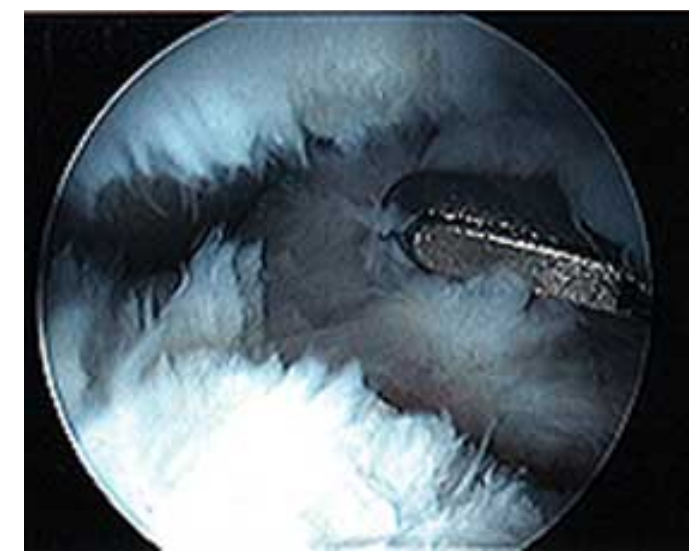

Figure 3. Arthroscopic debridement of severely damaged knee cartilage, healthy cartilage would appear smooth and glossy ${ }^{21}$.

Arthrodesis is the process of fusing a joint. This procedure is done almost exclusively in the spine and small joints of the hand and foot. Arthrodesis is completed by mechanical fixation of the joint through plates and screws, and in most cases completely eliminates the pain in that joint (but with the disadvantage of an immobile joint). Arthrodesis of a larger joint such as the knee or hip is only done as a salvage therapy for a limb that may otherwise be lost ${ }^{19}$. 
The final surgical intervention is joint arthroplasty, which involves the replacement of the articulation surfaces in the joint. Total joint arthroplasty is an extreme surgical intervention, but depending on the joint can have excellent clinical results. It is always considered the last resort for orthopedists, as joint arthroplasty requires removal of native structures that can never be restored. Also, total joint arthroplasty is generally reserved for older patients, as the intent is to have the joint last the remainder of the patient's life. Revision joint arthroplasties are challenging for surgeons and difficult on the body as there is less bone to work with and scarred tissue around the joint ${ }^{2}$.

\section{Total Hip Arthroplasty}

According to the CDC, there were 327,000 total hip arthroplasties (THA's) performed in the US in $2009^{1}$. This number is projected to grow exponentially as the US population continues to live longer and more active lives; the number of THA's per year is expected to be 572,000 by $2030^{3}$. The total hip arthroplasty of today involves cutting off the femoral head and replacing it with a metal ball and stem. The acetabulum is then reamed out to size and a metal cup is installed to hold a wear liner. This new wear surface between the metal ball and usually polymeric wear liner minimizes patient pain and restores range of motion. The most common reason for needing a joint replacement is osteoarthritis ${ }^{9}$. 


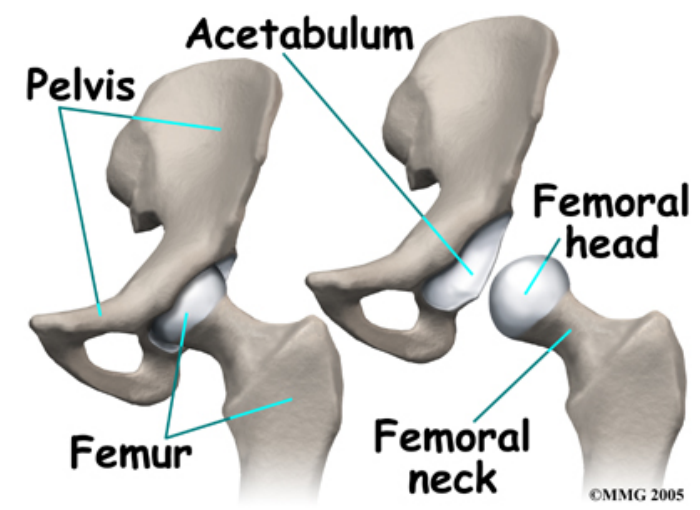

Figure 4. Basic hip anatomy ${ }^{22}$.

The hip joint articulates on the cartilage found on both the acetabulum and the femoral head. Figure 4 above shows the basic anatomy of this articulation. The ball and socket style joint is made of the femoral head mounted on the femur, and the acetabulum found on the pelvis. During a total hip replacement the neck and head of the femur are replaced, and the acetabulum is reamed and fitted with a cup and liner to create a new wear surface (see Figure 9 for specific component location and geometry).

\section{History}

The earliest hip arthroplasty procedures were not in fact replacements, but rather slightly modified semi-arthrodesis. In the early 1800's UK surgeons performed joint excision procedures where they would remove the joint capsule and cartilage. These surfaces would then scar and callus, partially seizing the joint and reducing the joint pain $^{23}$. While this may seem relatively barbaric, the alternative at the time was likely amputation and a significant risk of sepsis. The next main surgical procedure in the late 1800 's was interpositional arthroplasty. 
Leopold Ollier's work in Lyon, France (1880-1895) is generally credited as performing the pioneering work with adipose interpositional arthroplasty where adipose was inserted into the joint ${ }^{23}$. These procedures were ineffective at best, and dangerous at worst. However, the idea of interpositional arthroplasty was intriguing to many surgeons of the era and a variety of materials were attempted including metals, rubber, decalcified bones, wax, and pig bladder ${ }^{23}$. English surgeon Sir Robert Jones (1855-1933) reported a successful case of a patient who received a piece of gold foil as a wear surface in the hip that functioned properly over twenty years after implantation.

The first real ball and socket replacement recorded is credited to Berlin surgeon Themistocles Glück ${ }^{23}$. In 1891 Glück created an ivory ball and socket that was fixed to the femur and acetabulum using nickel-plated screws. While not very successful, his work sparked interest in the component design used now in modern hip replacement. Throughout the early 1900's a variety of hip replacements were developed using acrylic, glass, Vitallium, and stainless steel. The first true metal intramedullary stem was developed and implanted by Dr. Austin Moore and Harold R. Böhlman at John Hopkins Hospital in $1940^{23}$. They refined the stem to include bone-ingrowth fenestrations along the stem by 1953 . 
The man credited with being the father of the modern hip replacement is Sir John Charnley (1911-1982). Charnley was a UK born surgeon who trained as a general surgeon and held many prestigious positions throughout his career in both civilian and Army hospitals. Charnley was exposed to a military workshop while serving as a captain in the Royal Army, and there created a variety of surgical tooling and orthopedic bracing. This experience helped mold him as a designer and engineer, and he developed his first total hip arthroplasty in 1956 utilizing a PTFE acetabulum and femoral head liner ${ }^{24}$. PTFE wear was significantly higher in vivo than expected, and many patients developed severe reactions over time.

Early success with this combination quickly led to failure, and Charnley was inspired to develop a metal intramedullary prosthesis to mount the head, and utilize a different articulation material $^{24}$. He discovered ultra high molecular weight polyethylene, which at the time was being used for the impact bearing of mechanical looms. This material had much better wear characteristics than the PTFE in vivo, and did not cause the irritation seen with PTFE. Charnley was utilizing dental cement, polymethyl-methacrylate (PMMA), to fix his metal stem into the canal of the femur. Many orthopedists at the time used the same cement, however it was Charnley that realized and published a paper entitled Anchorage of the Femoral Head Prosthesis in the Shaft of the Femur in 1960 that explained that the cement itself was meant to be used as a grout, not an adhesive as was the popular thought at the time ${ }^{24}$. 
This momentous paper explained that the contact points of the bone and implant needed to be well supported with cement and compressed, or the bone would resorb leaving the implant unsupported and loose. See Figure 5 below for Charnley's most popular implant that is still the standard against which all other modern hip replacements are compared.

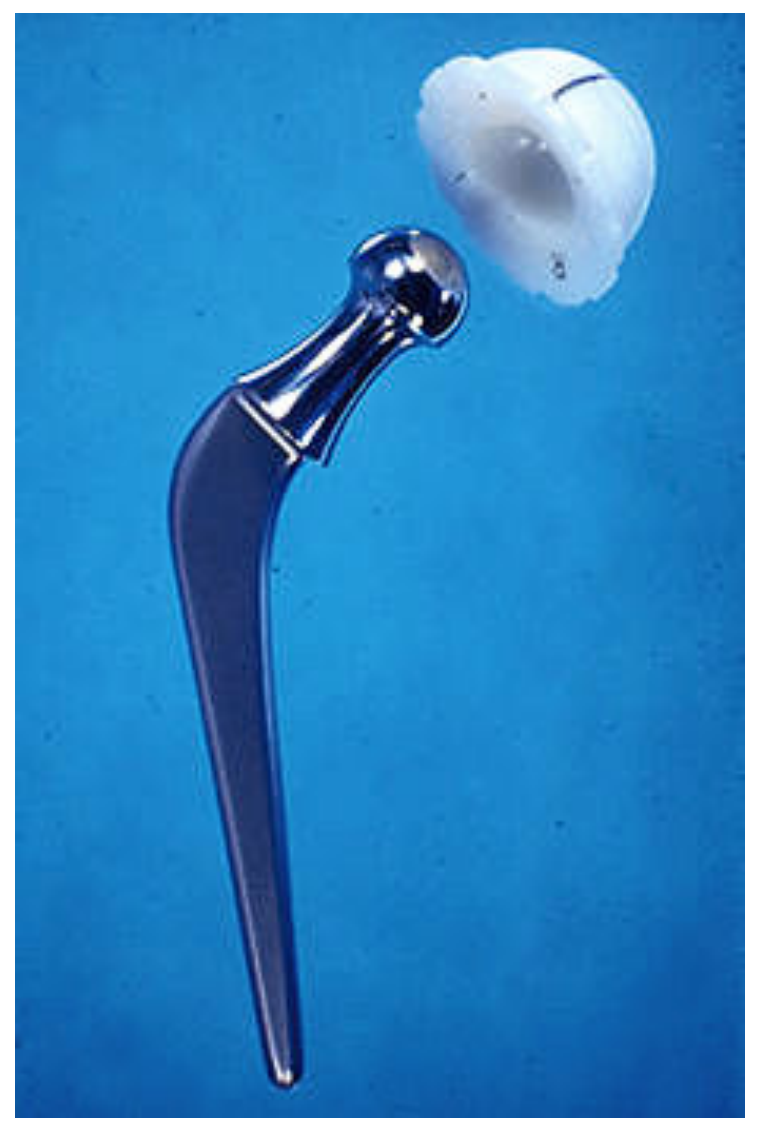

Figure 5. Original Charnley hip replacement ${ }^{25}$. 


\section{Procedures}

The traditional surgery uses either a posterior, or an anterolateral approach. The benefit to these approaches from a surgeon's perspective is a larger working area and easier anatomy identification ${ }^{3}$. However, from a rehabilitation and post-surgical stability standpoint neither approach is optimal. A new method gaining popularity is the direct anterior approach, which provides the best post-surgical stability and lowest incidence of dislocation ${ }^{2}$. A smaller incision is required for the procedure, and significantly less joint stabilizing muscle and fascia must be cut for access to the joint $^{2}$.

Tables 1, 2 and 3 below show in yellow the musculature that is affected with each of the three main approaches. The direct anterior approach clearly affects less musculature than the other approaches. However, the specific musculature that is affected is what's most important. The direct approach does not affect the muscles that cause abduction of the hip joint. These are the most important muscles for postsurgical stability, and allow patients that have undergone a direct anterior approach hip replacement to get up and walk the next day ${ }^{2}$. 
Table 1. Musculature affected by the anterior approach to THA. Columns highlighted in yellow indicate muscles cut/ligated.

\begin{tabular}{|l|l|l|l|l|l|}
\hline Flexion & $\underline{\text { Extension }}$ & $\underline{\text { Adduction }}$ & $\underline{\text { Abduction }}$ & $\underline{\text { ER }}$ & $\underline{\text { IR }}$ \\
\hline Iliacus & Glut. Max. & Adductors & Glut. Med. & Piriformis & $\begin{array}{l}\text { Tensor } \\
\text { FL }\end{array}$ \\
\hline Psoas & Glut Min. & Pectineus & Glut. Min. & $\begin{array}{l}\text { Obt. } \\
\text { Externis }\end{array}$ & $\begin{array}{l}\text { Glut. } \\
\text { Medius }\end{array}$ \\
\hline Sartorius & Glut. Med & Gracilis & Tensor FL & $\begin{array}{l}\text { Obt. } \\
\text { Internis }\end{array}$ & $\begin{array}{l}\text { Glut. } \\
\text { Min. }\end{array}$ \\
\hline $\begin{array}{l}\text { Rectus } \\
\text { Fem. }\end{array}$ & & & Glut. Max. & $\begin{array}{l}\text { Quad. } \\
\text { Fem. }\end{array}$ & \\
\hline Tensor FL & & & & $\begin{array}{l}\text { Glut. } \\
\text { Med/min }\end{array}$ & \\
\hline
\end{tabular}

Table 2. Musculature affected by the posterior approach to THA. Columns highlighted in yellow indicate muscles cut.

\begin{tabular}{|l|l|l|l|l|l|}
\hline Flexion & Extension & Adduction & Abduction & ER & IR \\
\hline Iliacus & Glut. Max. & Adductors & Glut. Med. & Piriformis & Tensor FL \\
\hline Psoas & Glut Min. & Pectineus & Glut. Min. & $\begin{array}{l}\text { Obt. } \\
\text { Externis }\end{array}$ & $\begin{array}{l}\text { Glut. } \\
\text { Medius }\end{array}$ \\
\hline Sartorius & Glut. Med & Gracilis & Tensor FL & $\begin{array}{l}\text { Obt. } \\
\text { Internis }\end{array}$ & Glut. Min. \\
\hline Rectus Fem. & & & Glut. Max. & Quad. Fem. & \\
\hline Tensor FL & & & & $\begin{array}{l}\text { Glut. } \\
\text { Med/min }\end{array}$ & \\
\hline
\end{tabular}


Table 3. Musculature affected by the lateral approach to THA. Columns highlighted in yellow indicate muscles cut.

\begin{tabular}{|l|l|l|l|l|l|}
\hline Flexion & Extension & Adduction & Abduction & ER & IR \\
\hline Iliacus & Glut. Max. & Adductors & Glut. Med. & Piriformis & Tensor FL \\
\hline Psoas & Glut Min. & Pectineus & Glut. Min. & $\begin{array}{l}\text { Obt. } \\
\text { Externis }\end{array}$ & $\begin{array}{l}\text { Glut. } \\
\text { Medius }\end{array}$ \\
\hline Sartorius & Glut. Med & Gracilis & Tensor FL & $\begin{array}{l}\text { Obt. } \\
\text { Internis }\end{array}$ & Glut. Min. \\
\hline Rectus Fem. & & & Glut. Max. & $\begin{array}{l}\text { Quad. } \\
\text { Fem. }\end{array}$ & \\
\hline Tensor FL & & & & $\begin{array}{l}\text { Glut. } \\
\text { Med/min }\end{array}$ & \\
\hline
\end{tabular}

\section{Direct Anterior Approach}

The procedure begins with the incision shown in Figure 6, starting approximately 2 $\mathrm{cm}$ posterior and distal to the ascending superior iliac spine and continuing $8-10 \mathrm{~cm}$ in a line towards the lateral edge of the patella ${ }^{8}$.

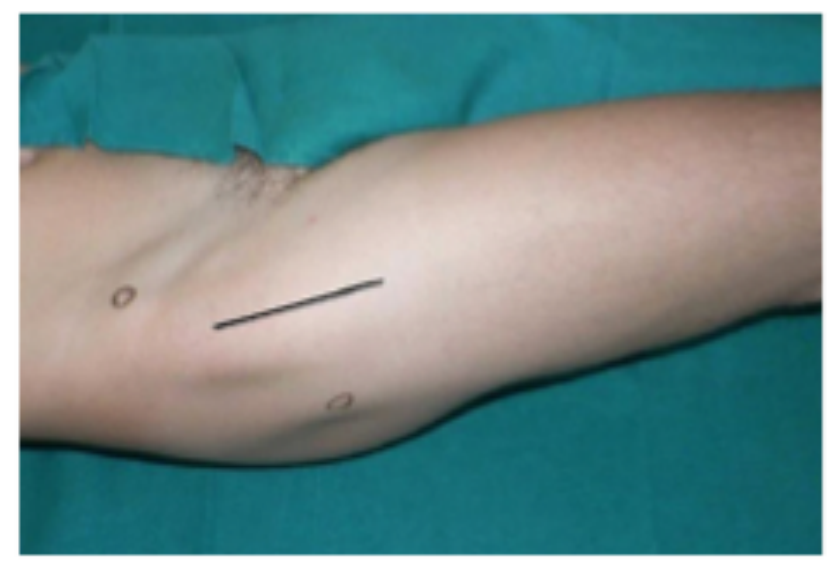

Figure 6. Incision line marked for direct anterior approach ${ }^{8}$. 
The dissection continues along the incision line of the skin, with muscles such as the sartorius and tensor fasciae latae being bluntly dissected and moved out of the way with retractors. In order to properly access the joint, it is necessary for the leg undergoing the procedure to be crossed over the non-procedure leg, externally rotated, and put into traction. Figure 7 shows the patient positioning required for this approach. This project is intended to replace 1-2 surgical assistants during the procedure.

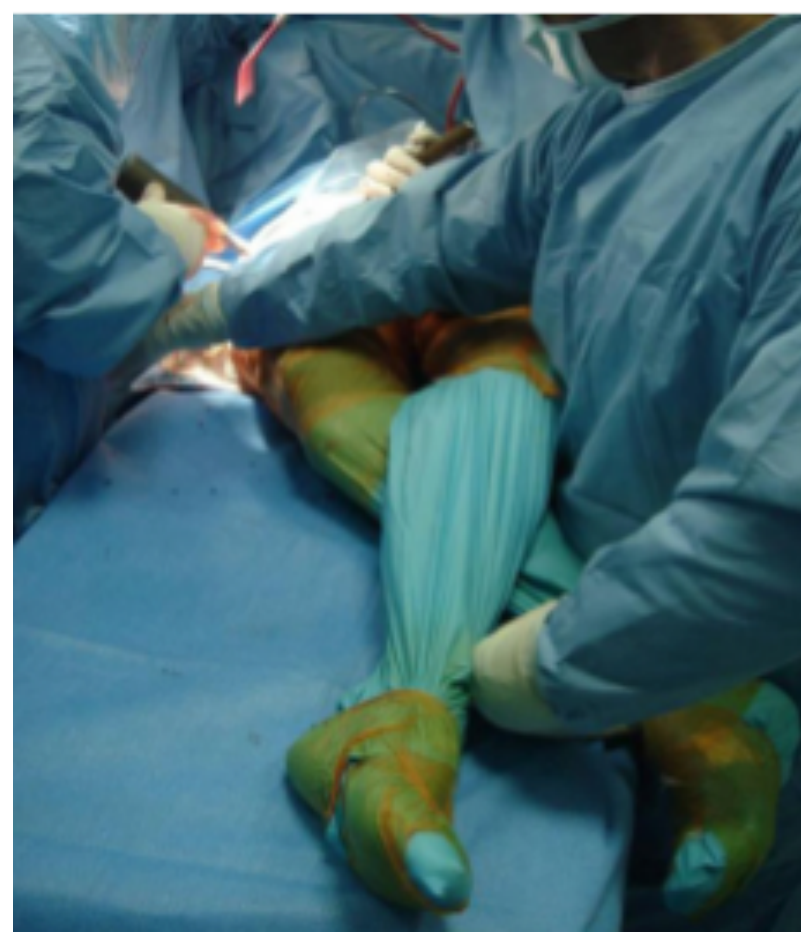

Figure 7. Patient positioning during the direct anterior approach ${ }^{8}$.

After putting the patient in this position the femur may be accessed as shown in Figure 7. Sometimes, a double osteotomy is performed to make removing the ball of the femur out of the smaller space easier (as shown in Figure 8). 


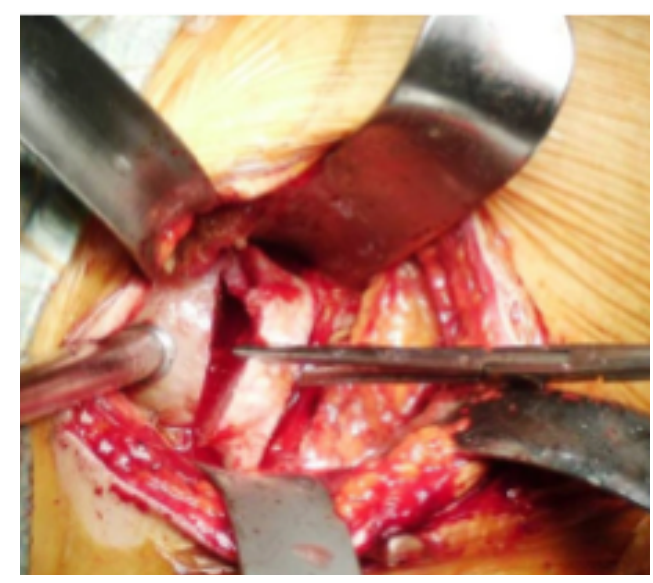

Figure 8. Double osteotomy performed during direct anterior approach.

After the osteotomy, the procedure continues like any other hip replacement. The canal of the femur is broached to an appropriate size, a stem is implanted (generally without cement for this approach ${ }^{2}$ ), the acetabulum is reamed, a metal acetabular cup is installed, then a polymer liner, and finally a femoral ball is inserted and the joint is relocated (see Figure 9 below).

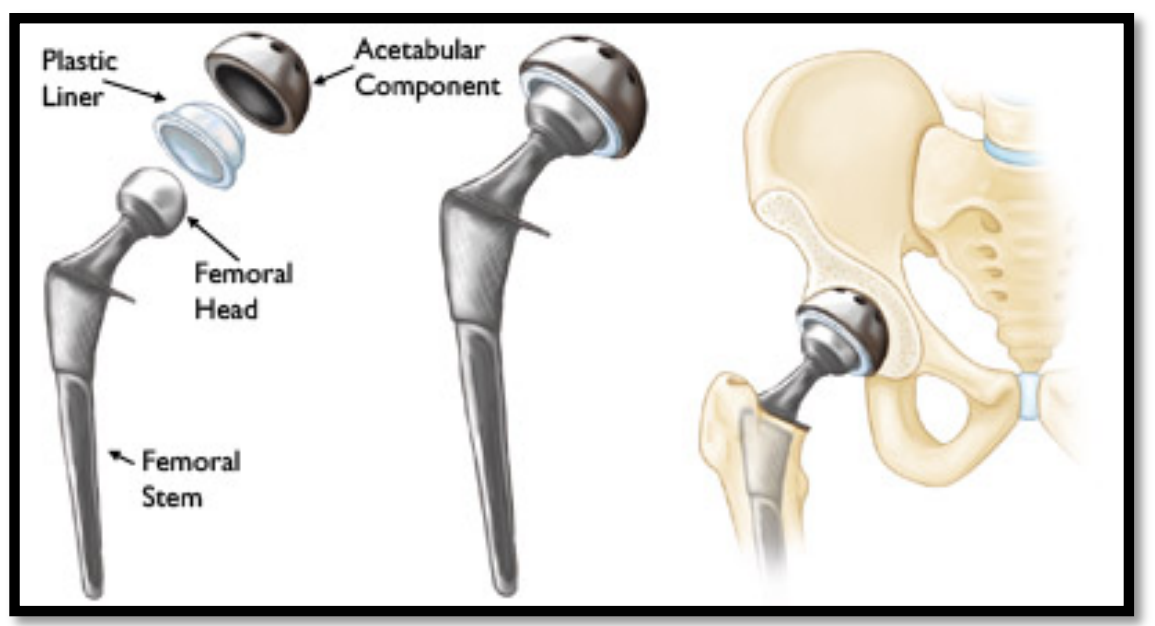

Figure 9. Total hip arthroplasty components and placement ${ }^{10}$.

Some companies have developed offset handles to make the approach easier, but essentially the case proceeds like any other modern Charnley based hip replacement. 
By utilizing a joint replacement procedure that allows for such impressive postsurgical joint stability, patients are able to go home faster and start rehabilitating sooner. From 2006-2009, Dr. Vincenzo Alecci and his team performed 419 total hip replacements on a randomly distributed group of patients; half received a standard lateral approach, while the other half received a direct anterior approach ${ }^{8}$. All other treatment was the same. Alecci found that direct anterior patients left the hospital significantly faster ( 7 days vs. 10 days on average $p<.0005$ ), required less blood transfusions ( $40 \%$ needed a transfusion with the lateral approach, only $19 \%$ with the direct anterior approach $\mathrm{p}<.0005$ ), and consistently were released more often to their homes instead of to assisted living facilities (88\% lateral approach went to assisted living, 58\% direct anterior approach did $\mathrm{p}<.0005)$.

\section{History of the Direct Anterior Approach}

The direct anterior approach was originally described in 1923 by Dr. Marius Nygaard Smith-Petersen, who had developed a "mould arthroplasty" that is what we consider now to be the acetabular component of a THA ${ }^{6}$. The hip was dislocated and the acetabular cup was screwed into place to provide a new wear surface for the femoral head (see Figures 10 and 11). Smith-Petersen used a variety of materials including glass and different metal alloys. 


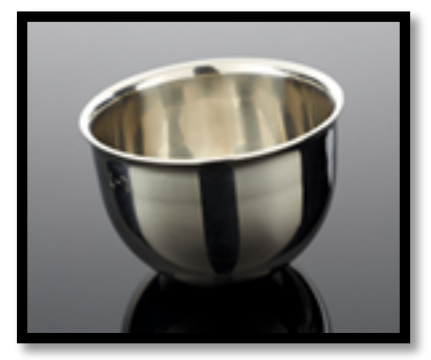

Figure 10. Smith-Petersen mold arthroplasty made of cobalt chrome ${ }^{12}$.

Through this approach, Dr. Smith-Petersen was able to access the hip socket without causing the trauma associated with more invasive approaches (see description of the approach in the previous section).

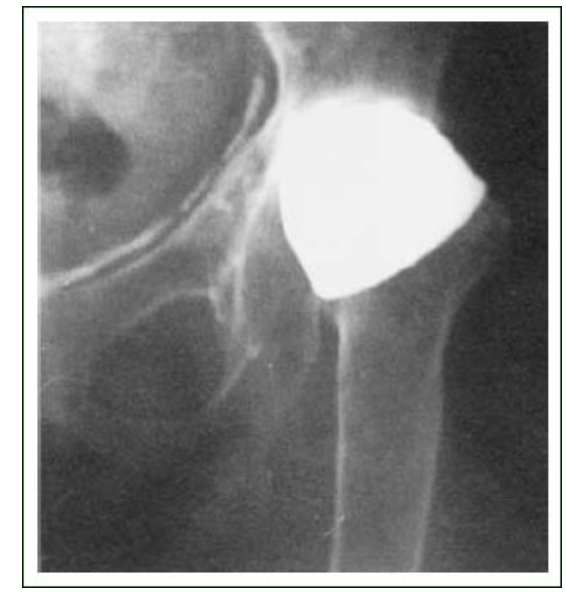

Figure 11. Smith-Peterson mold arthroplasty X-ray image from $1949^{13}$.

The Smith-Petersen mold arthroplasty was the standard method of hip replacement until Dr. Charnley invented the total hip replacement in the early 1960 's. In order to accommodate the new femoral stem that Charnley had developed, he used a more invasive lateral approach ${ }^{7}$. This approach caused severe injury to the surrounding musculature, but did allow placement of the femoral stem. 
Patients of the Charnley hip replacement were placed on bed immobilization for 4-6 days after the procedure, then crutches for 6 weeks, and then used a cane for 1-2 months if not indefinitely ${ }^{7}$. A slightly modified version of this original approach is still used today ${ }^{7}$. As the total hip replacement grew and matured from both a procedural and component standpoint, different approaches were attempted to minimize the damage done to the area.

The less trauma to the joint, the less concern there would be about post-operative dislocation, and the faster patients would be able to rehabilitate and return to normal activities. The direct anterior approach, which causes less damage to the joint than any other approach, has been revitalized in the last decade by the efforts of a handful of surgeons including Joel Matta, MD. Dr. Matta practices in Southern California and has trained many surgeons to perform the direct anterior approach to THA. While this approach does produce excellent clinical results, it requires very specific patient positioning to access the joint.

\section{Mizuhosi PROfx Surgical Table}

Dr. Matta identified this patient positioning issue quickly and developed a table with Mizuhosi based off of an existing pelvic fracture table. Figure 12 below shows the result of this collaboration - the PROfx table. 


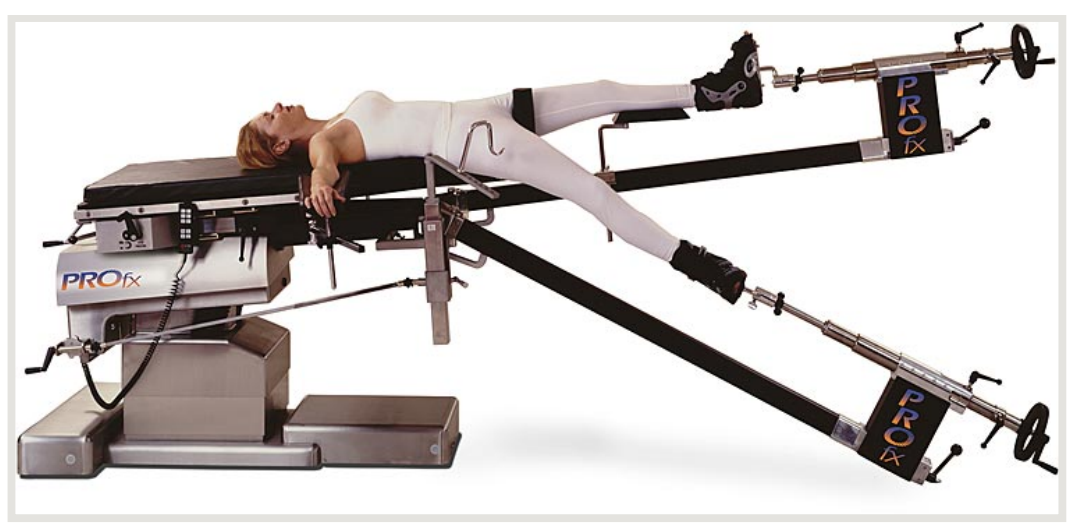

Figure 12. Mizuhosi PROfx table with orthopedic attachments ${ }^{11}$.

While this table provides excellent positioning and table flexibility there are some distinct disadvantages. The primary concern for most surgeons is the mechanical advantage provided by the traction and elevation mechanisms. The table does an excellent job of allowing extreme patient positioning and traction with almost no physical effort required by the surgeon. However, that convenience comes at the price of feedback. The hand-cranked traction and elevation components provide such advantage that the surgeon must gauge force visually based on tissue movement and deformation. This visual approach is inadequate at best, dangerous at worst. There have been fractures of the femur caused by excess force applied to the femoral elevating hook seen in Figure $12^{2}$. Likely, these would have been avoided if the surgeon could feel the amount of force being applied. Surgeons are trained to operate and position patients based on feel. The PROfx table takes some of that ability away from surgeons and places patients at risk for injury. 
Another disadvantage of the PROfx table is price. At over $\$ 100,000$ it represents a large investment for a surgical practice or hospital that currently uses a standard table with adequate results. This cost limits the acceptance of the direct anterior approach as surgeons are being trained to believe they need this specialized table to perform the approach appropriately. Therefore, the adoption of the procedure is happening more

slowly than one would expect based on the clinical results ${ }^{8}$, as surgeons and hospital administrators are hesitant to make the investment.

\section{Need}

There is a clear need for a simple, inexpensive, and hand powered surgical table attachment package that allows the anterior approach to THA to be performed in any surgical venue. This package will allow more surgeons to adopt the direct anterior approach to hip replacement.

\section{Project Goals}

This main goal of this project is to create a functional design and prototype that will be able to be used effectively for the direct anterior approach to a total hip arthroplasty. This should be a simple, robust design that inspires confidence in the hands of the surgeon who uses the product. Ideally the prototype will be used in a cadaver lab first, then an actual surgical environment to verify functionality. 
This project is privately funded and will potentially be used to garner interest in developing the product further with the help of a company interested in the approach and the tooling. If possible, protection of the intellectual property associated with this project will be secured before further development. 


\section{CHAPTER 2}

\section{Design \\ Overview}

This design was developed to make the anterior THA available to surgeons that would otherwise be unable to attempt the procedure due to the prohibitive cost of the PROfx table. Developed along with two orthopedic surgeons currently using an extra surgical assistant to perform anterior THA, this design is intended to be simple and reliable. The following requirements were developed:

- Package must be able to attach to a standard Skytron surgical table.

- No mechanical advantage may be utilized for leg/femur traction.

- Any force applied must be surgeon generated.

- Cost must not exceed $\$ 2,500 /$ assembly for a quantity of 1000 units.

- Patient contact components must be able to be autoclaved.

- $\quad$ Entire package weight must not exceed $25 \mathrm{lbs}$.

In order to satisfy the requirements listed above the philosophy of design for this project centered on simplicity. Components were designed to be easily manufacturable where possible, lightweight (through the use of aluminum in most parts), and reliable due to simple mechanisms. The attachments are shown on a representative table below in Figure 13. 


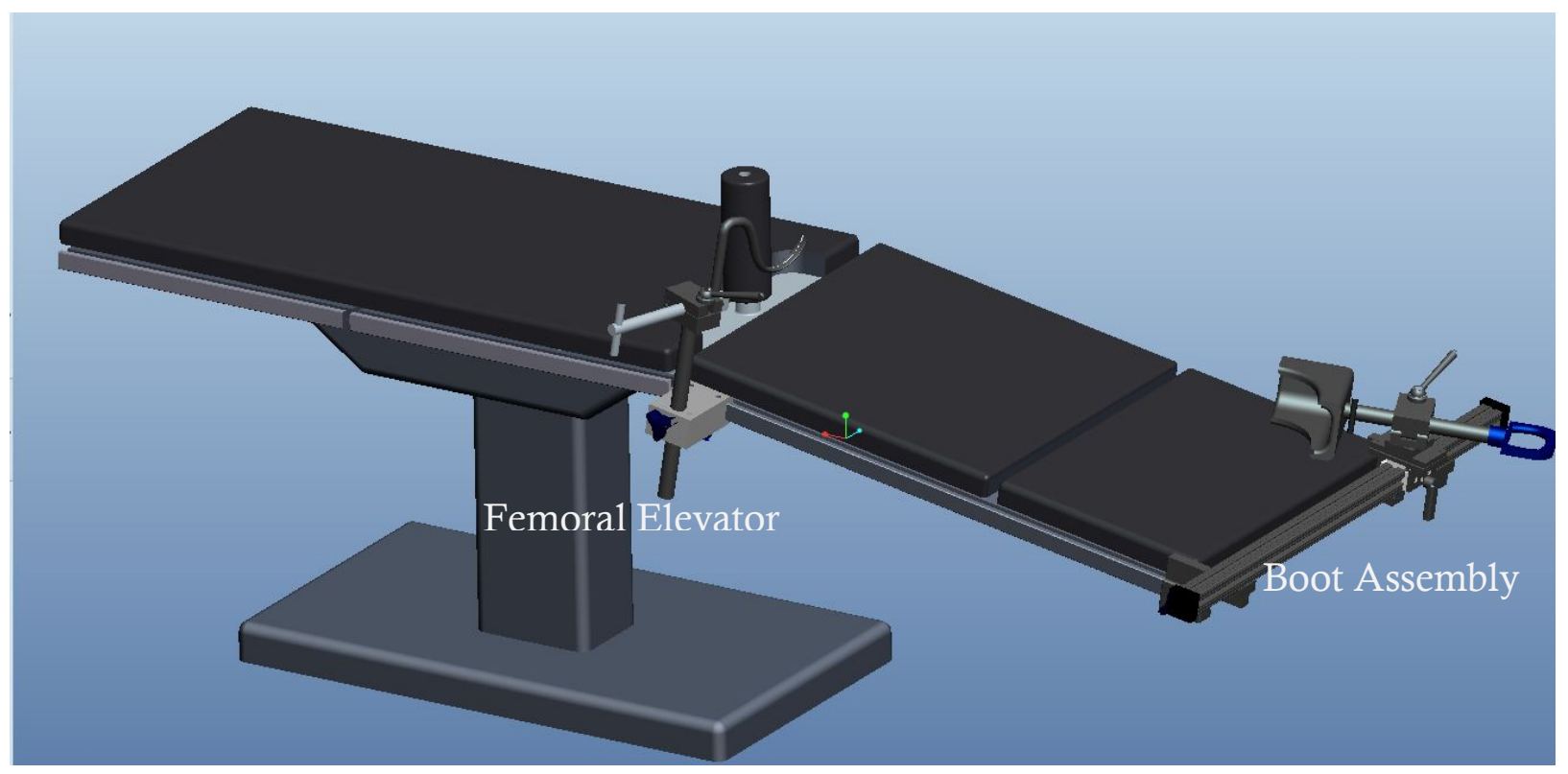

Figure 13. Full surgical attachment package shown on a representative table.

The two main assemblies identified in Figure 13 are the femoral elevator and the boot assembly. Functionally, these are the two assemblies that are manipulated during surgery. The femoral elevator is used for applying upward and lateral force on the femur, while the boot assembly is used for applying traction and rotational torque on the leg.

Figure 14 shows the essential position of the patient during the procedure. The femoral elevator is meant to replace the surgical assistant seen levering up the femur. Not shown is a second assistant that applies traction to the leg in order to give proper access to the joint. This other assistant will pull on the leg to apply strong traction while externally rotating the foot to open up the joint. 


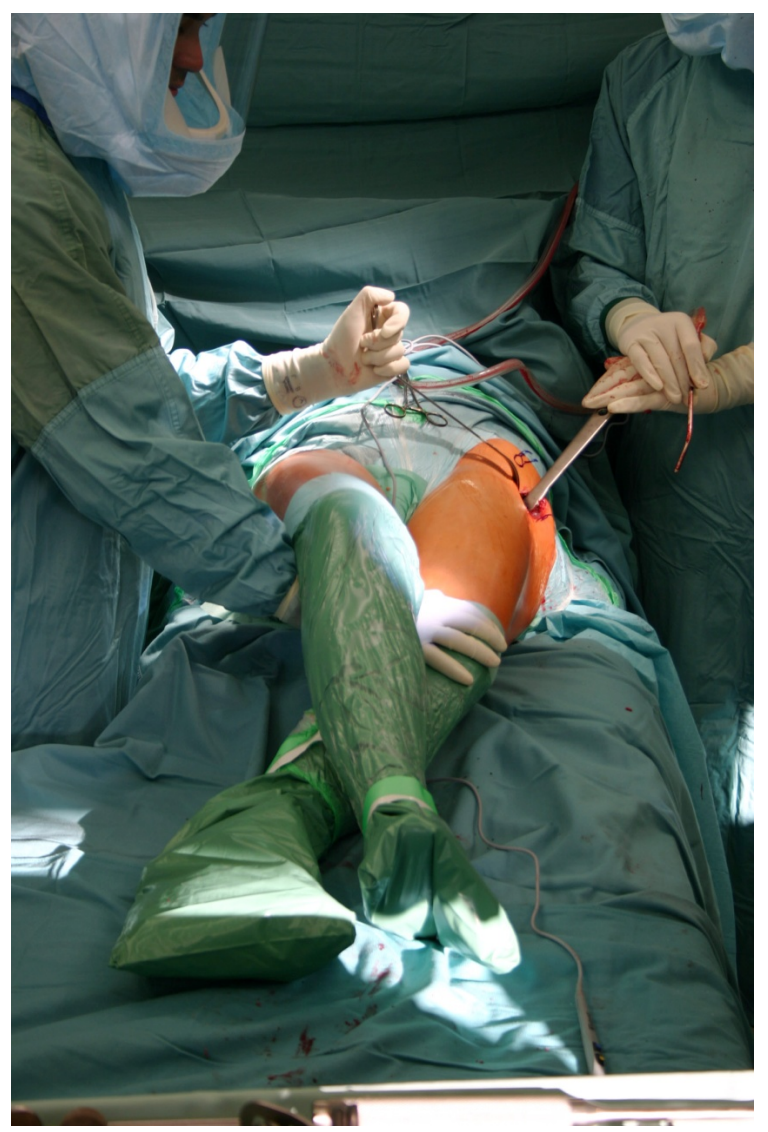

Figure 14. Surgical view of anterior THA. Note the external rotation of the leg undergoing procedure. Figure courtesy of Dr. Phil Merritt. 


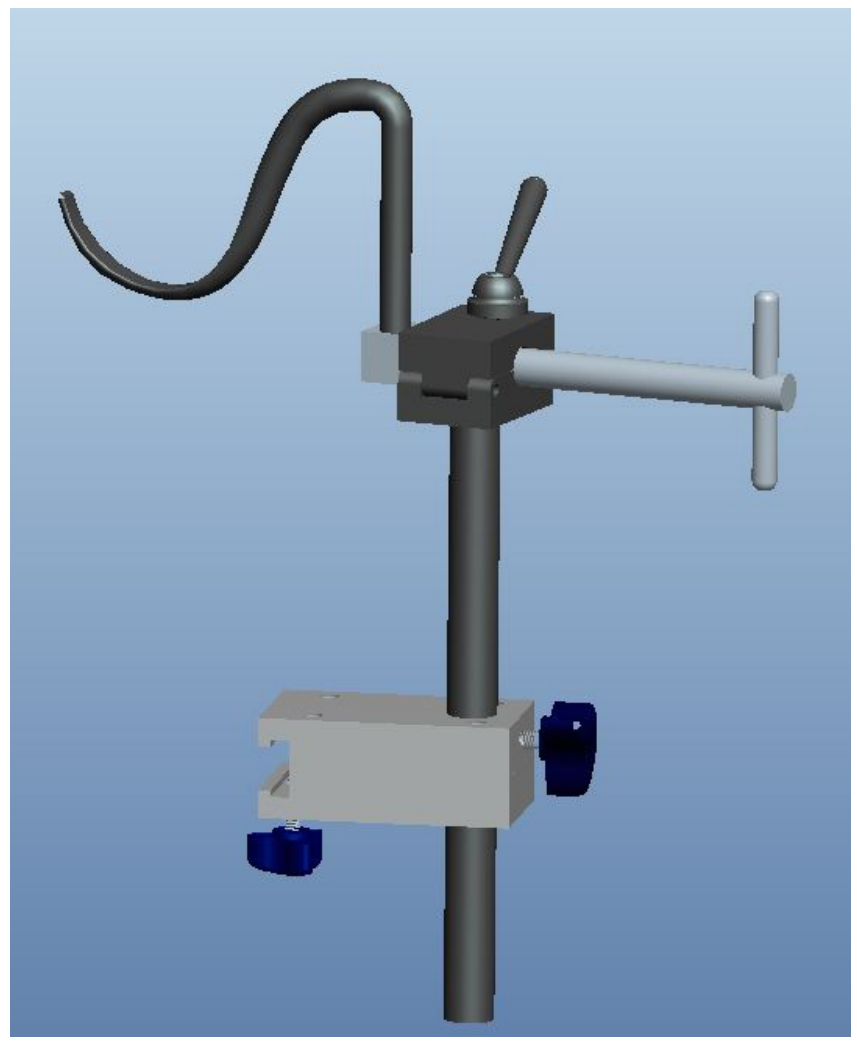

Figure 15. Femoral elevator assembly.

The femoral elevator assembly (Figure 15) is intended to be very simple to operate. The hook is removed from the pull rod by pulling back a spring-loaded retaining pin. The hook is then slid under the femur and reattached to the pull rod by sliding it back into the receiver (see Figure 16 for an exploded view of the assembly). In order to elevate the femur the surgeon loosens the handle (oriented horizontally in figure 15) and pulls up on the vertical tube until satisfied with the amount of force, then retightens the handle. The pull rod and hook assembly is then free to rotate about the vertical axis established by the vertical tube and to move in and out radially relative to the vertical tube. 
Both of those motions are locked with the screw-down lever located on top of the rotating bracket mounted on the vertical tube. The locking mechanisms are very simple in order to ensure reliable performance over time and minimal manufacturing complexity. See Figures 16, 17 and 18 for exploded views of the individual assemblies found in the femoral elevator.

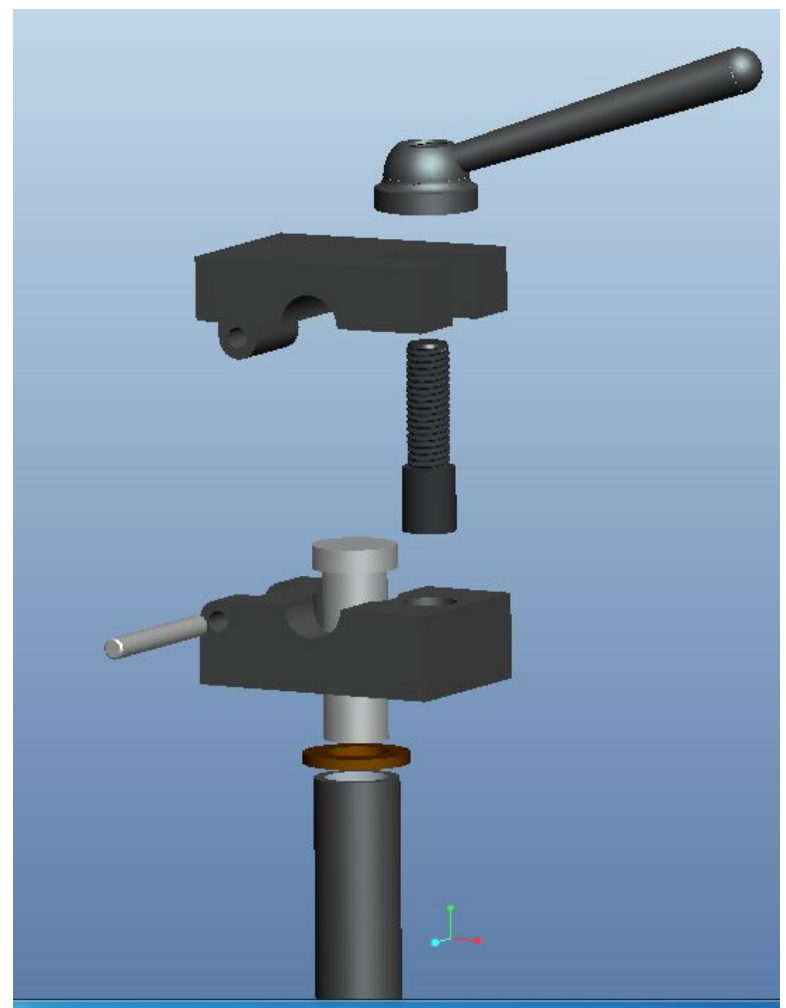

Figure 16. Exploded view of femoral elevator clamp. 


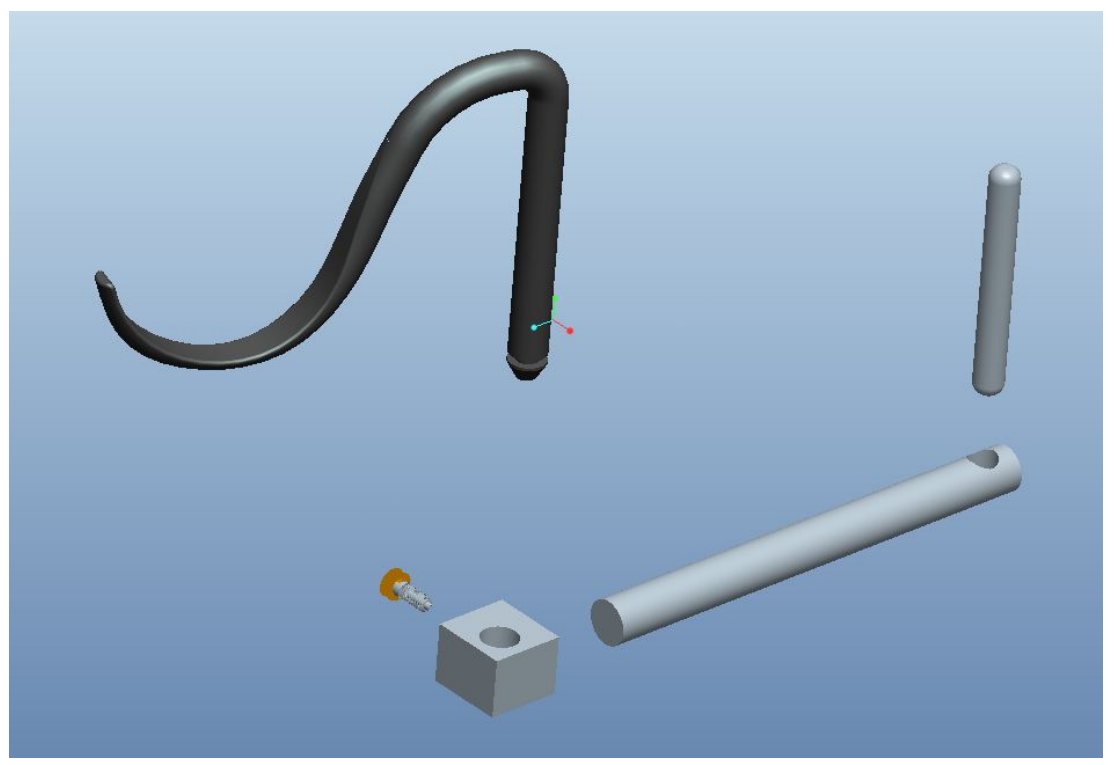

Figure 17. Exploded view of hook and pull rod assembly.

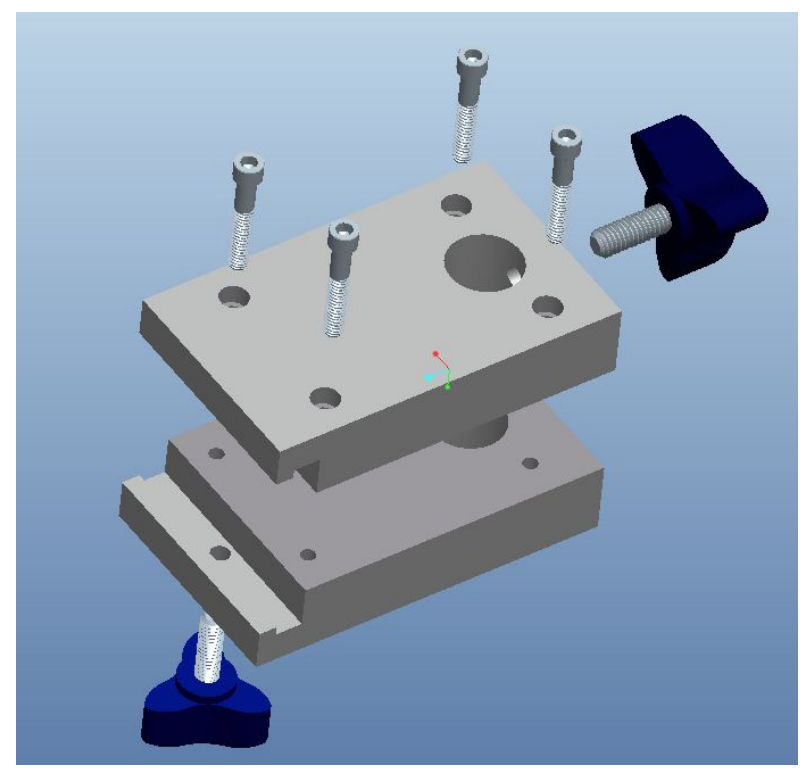

Figure 18. Exploded view of femoral elevator rail clamp, designed to fit standard Skytron surgical tables. 
All of the component parts in the femoral elevator assemblies except for the hook and the hinge pin are made of 6061 aluminum in order to save weight, and due to the good machinability of the material. Both the hook and the hinge pin are made of 316 stainless steel due to the higher strength requirements as seen in the design analysis section starting on page 34 . The hook was designed to accommodate a femur of diameter $3.5 "+/-.5 "$, which should fit more than $95 \%$ of the population ${ }^{2}$. See appendix A for detailed drawings and dimensions for each component part. The total cost of production for this assembly is estimated to be $\$ 634.40$ (see appendix B for analysis) at a quantity of 1000 units. All connections not screwed together are press fit with an interference of $0.0005-0.0015 "$ in order to assure a permanent connection without extra fasteners or a welding operation. The only patient contact component is the stainless steel hook, which can be repeatedly autoclaved with no concern for functional degradation. 


\section{Boot Assembly}

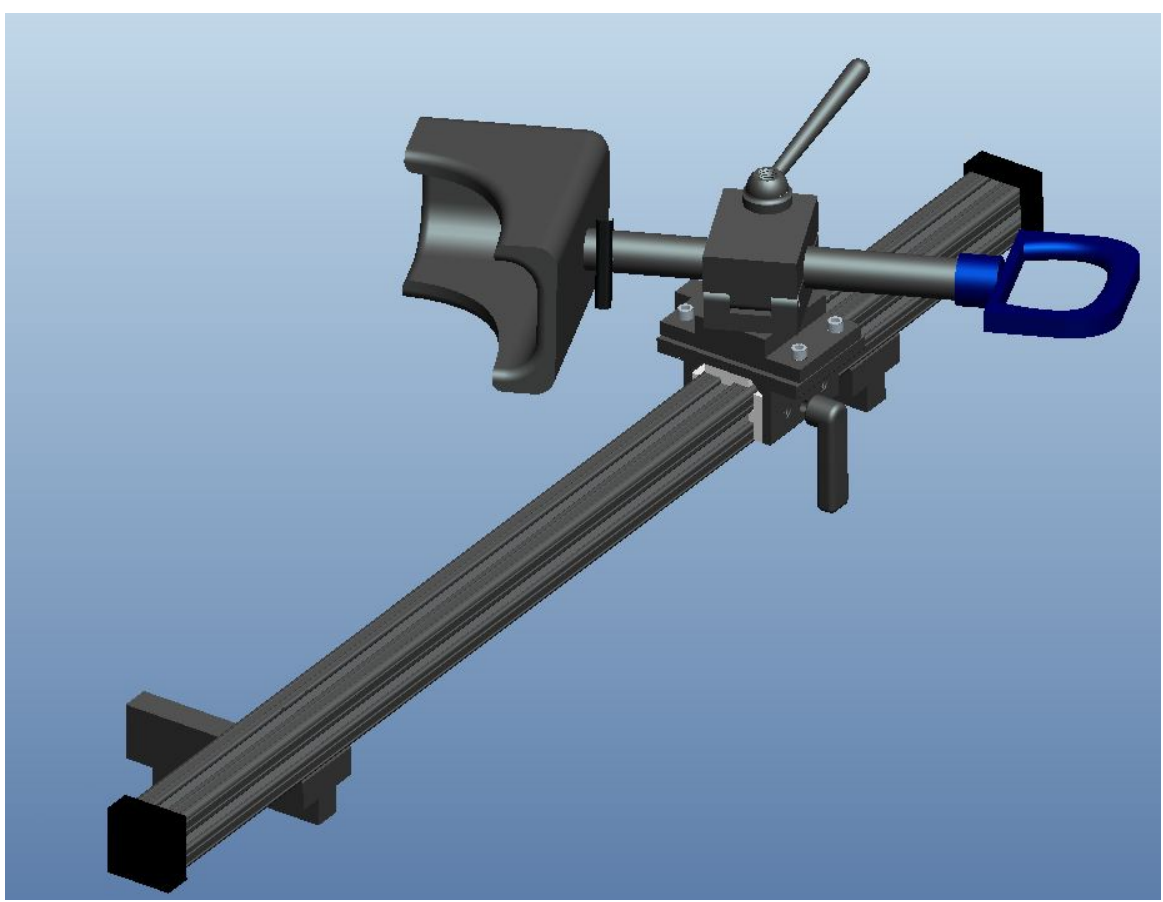

Figure 19. Boot assembly.

The boot assembly (Figure 19) is used to provide traction and rotational torque to the leg. The assembly is seated onto the table rail using the simple rail clamp (see Figure 22) and secured prior to surgery. Next, the patient's foot is wrapped into the boot with a sterile surgical wrap. The slider assembly is free to slide until locked with the threaded brake lever seen in Figure 23. This allows either leg to be accommodated without changing the assembly conformation. The clamp holding the boot/traction rod is also able to rotate freely about a vertical axis, utilizing the same mechanism seen in the femoral elevator assembly. This motion enables the movement of the leg while strapped into the boot, and allows the surgeon to position the foot with the desired amount of traction and external rotation (seen in Figure 30). 
As in the femoral elevator, rotation and traction are both locked with the top mounted screw-down lever. This simplifies the final setting of the leg location by locking multiple motions simultaneously. See Figures 20, 21, 22, and 23 for exploded views of the assemblies contained in the Boot assembly.

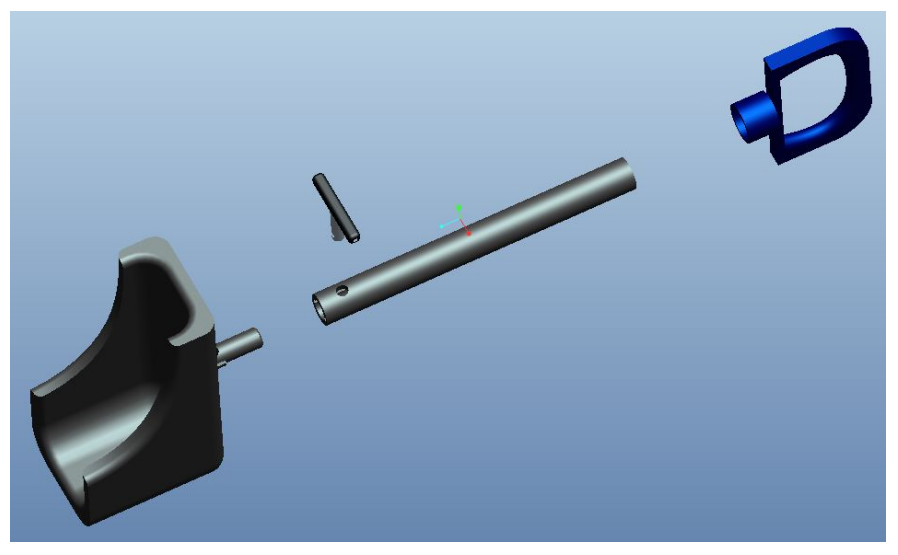

Figure 20. Exploded view of boot and traction rod.

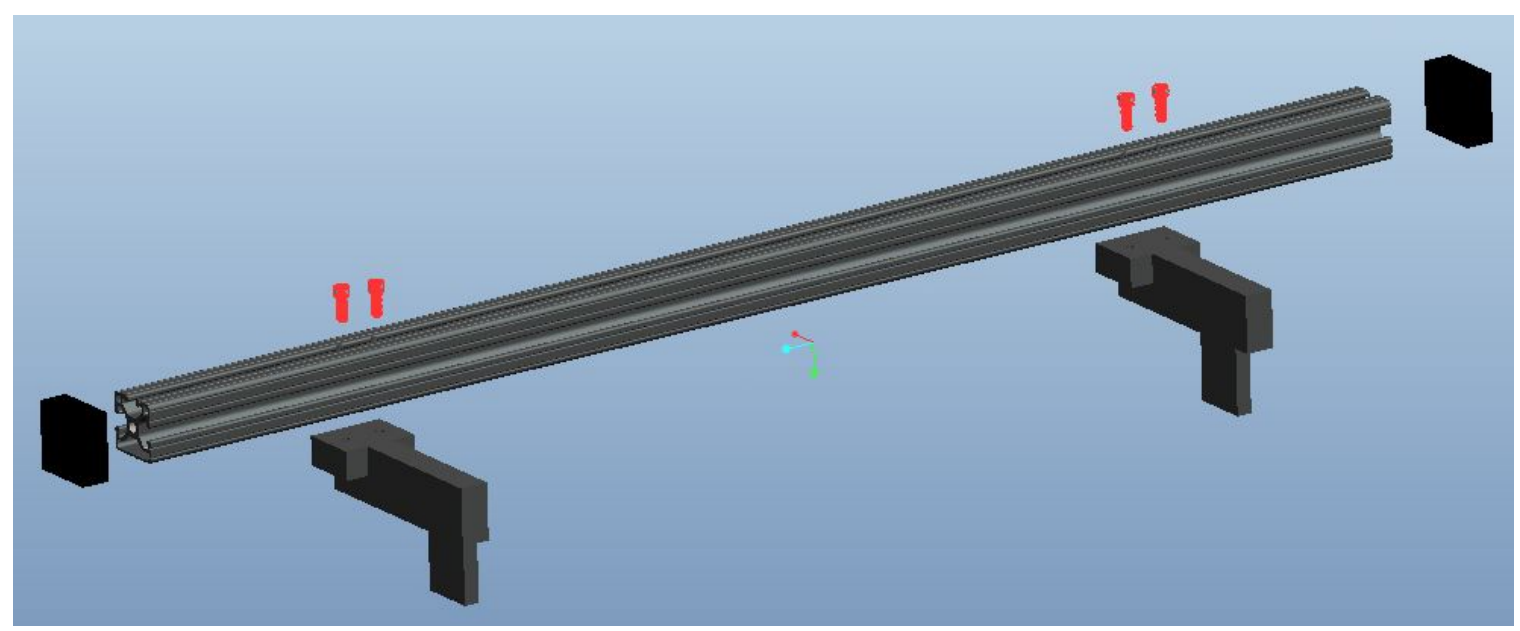

Figure 21. Exploded view of rail assembly. 


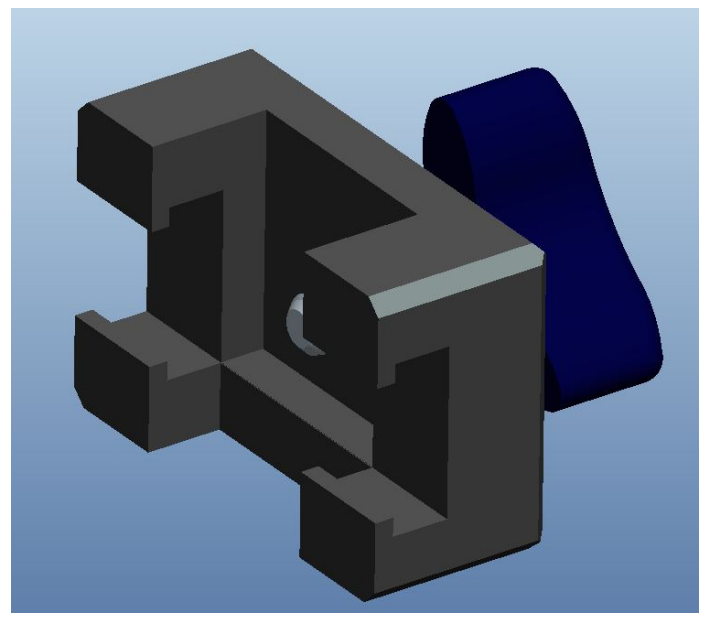

Figure 22. Simple rail clamp used to secure boot assembly to surgical table, designed to fit standard Skytron surgical tables.

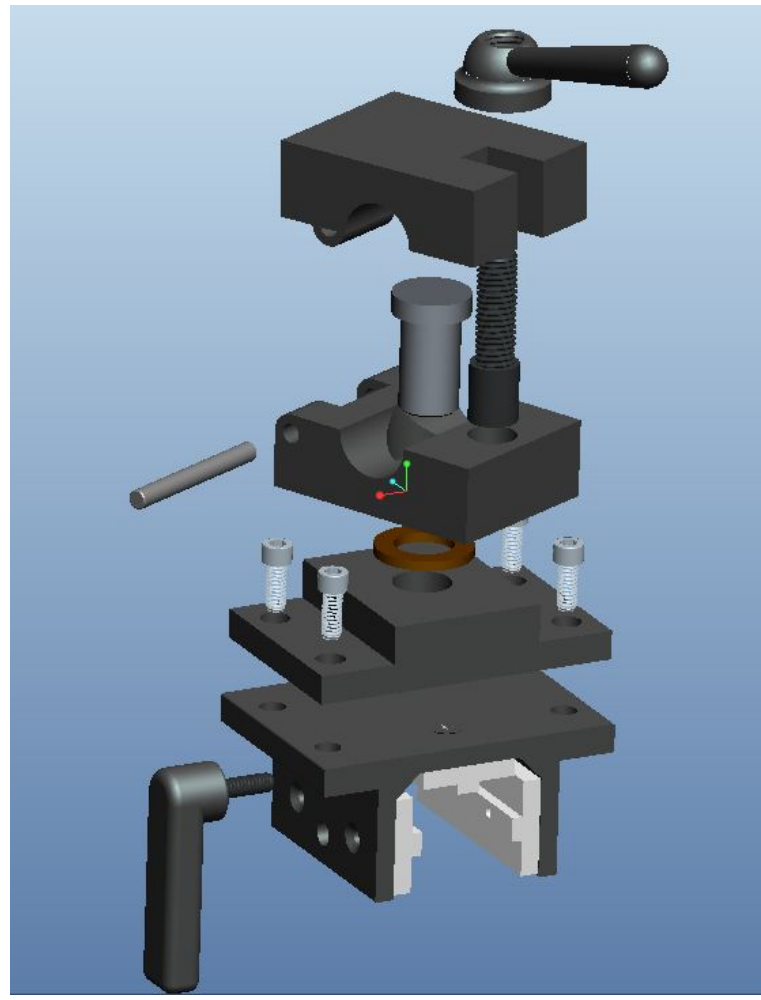

Figure 23. Track slider assembly. 
Like the femoral elevator, all of the parts except the hinge pin are made from 6061 aluminum for its lightweight and desirable machining characteristics. The rail and slider can be purchased directly from the $80 / 20$ Corporation (Columbia City, IN, USA). The $80 / 20$ slider uses Teflon inserts as the sliding surface. This ensures smooth sliding operation without the need for grease or oil, a definite advantage when attempting to maintain a sterile environment. The only patient contact piece is the boot, which can be removed and autoclaved without concern for degradation of the aluminum. The total cost of this assembly at a 1000 assembly quantity is estimated to be $\$ 673.26$. See appendix A for detailed design drawings and dimensions, and appendix B for estimated manufacturing cost estimates.

\section{Analysis}

In order to ensure the assembly would be able to withstand the loads expected in surgery, strength analysis was performed. The femoral elevator assembly was used as the analysis model, but the boot components were sized with the same assumptions and analysis. Due to the simple design of the components in the assemblies, all of the analysis was possible through hand calculations without the need for more sophisticated methods.

General assumptions: The main force on the femoral elevator components is limited by the strength of the surgeon who applies the upward force and traction. This is assumed to be $50 \mathrm{lbs}$ in vertical force and $50 \mathrm{lbs}$ of lateral traction. This will be represented as a force couple at the center of the hook as shown in Figure 24 below. 
The hook traction rod is also assumed to be fully extended (shown in Figure 24 below in fully retracted position) in order to represent a worst-case scenario for the moment applied on the assemblies. This case would represent a patient that had anatomically impossibly narrow hips, but still was performed as a conservative analysis as surgeons can be unpredictable in their utilization of tooling.

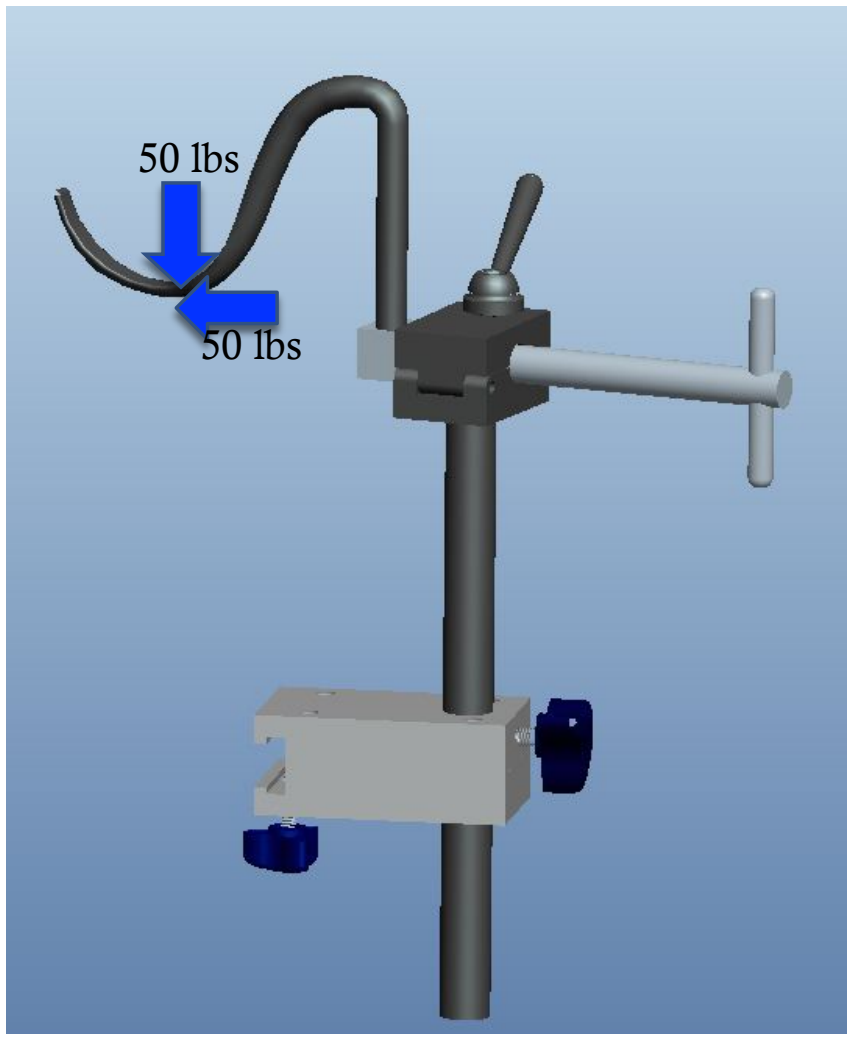

Figure 24. Femoral elevator with assumed forces.

The first step was to determine the amount of flex that would be seen in the aluminum traction rod in which the hook connects. This flexion is functionally very important, as the surgeons require a stable base while operating, and would find a rod that flexed unacceptable. 
Traction rod resistance to forces applied:

Diameter of $\operatorname{rod}=0.75^{\prime \prime}$

Modulus of elasticity for $6061 \mathrm{Al}=10,000 \mathrm{ksi}$

Distance from support to force application (worst-case assumption) $=11.87$ "

Total deflection of rod in vertical direction $\delta=\frac{P L^{3}}{3 E I}$

For a cantilevered $\operatorname{rod}, \mathrm{I}=p i * r^{4} / 4$ and $\mathrm{r}=.375^{\prime \prime}$

$\mathrm{I}=0.0155 \mathrm{in}^{4}$

$$
\delta=\frac{50 l b s \times 11.87^{\prime 3}}{3 \times 0.015 \sin ^{4} \times 1 E 7 p s i}=0.179 "
$$

This calculated amount of deflection ( 0.179 ") is still a relatively small amount and would still be deemed acceptable by the surgeon.

The next step in the analysis of the elevator assembly was to find the maximum overall load the traction rod could handle before permanently deforming. The axial loading component along the shaft of the traction rod was neglected as it adds a minimal amount of stress to the surface in bending.

Maximum vertical load:

Yield strength of 6061-T6 Al $=40,000 \mathrm{psi}$

$$
\begin{gathered}
\sigma=\frac{M y}{I} \\
I=\frac{\pi r^{4}}{4}
\end{gathered}
$$




$$
\text { Maximum moment }=\frac{40000 \text { si } \times \pi \times .375 \mathrm{in}^{4}}{4 \times .375 \mathrm{in}}=1657 \mathrm{in} * \mathrm{lbs}
$$

Maximum load $=\frac{1657 \mathrm{in} * \mathrm{lbs}}{11.43 \mathrm{in}}=145 \mathrm{lbs}$

$$
\text { Factor of safety }=145 \mathrm{lbs} / 50 \mathrm{lbs}=2.9
$$

This factor of safety (2.9) is deemed to be acceptable considering it is a worst-case scenario involving unlikely traction rod positioning (assumes rod is fully extended which places the hook center past the center of the table).

After completing the calculations for loading on the traction rod itself, it was necessary to check the vertical support tube. As with the traction rod, the deformation to the design loads was done first, then the overall maximum load acceptable before permanent deformation.

Vertical support tube resistance to forces applied:

Assume tube extended 11" up from rail mount

Outer diameter of tube $=1.00 "$

Inner diameter of tube $=.50 "$

Modulus of elasticity for $6061 \mathrm{Al}=10,000 \mathrm{ksi}$

Distance from support to force application (horizontally) $=11.87$ "

Total deflection of rod in horizontal direction $\delta=\frac{P L^{3}}{3 E I}+\frac{M L^{2}}{3 E I}$ 
For a cantilevered rod, $I=\frac{\pi\left(r o^{4-} r i^{4}\right)}{4}$ where $\mathrm{r}=0.5 "$ $\mathrm{I}=0.046 \mathrm{in}^{4}$

$$
\delta=\frac{50 \text { lbs } x 11^{\prime \prime}}{3 \times 0.046 \text { in }^{4} \times 1 E 7 p s i}+\frac{50 \operatorname{lbs} \times 11.87^{\prime \prime} \times 11^{2}}{3 \times 0.046 \text { in }^{4} \times 1 E 7 p s i}=0.095^{\prime \prime}
$$

Again, like the traction rod, the calculated deformation is quite small and would be acceptable to the surgeon The last step was to calculate the maximum load prior to permanent deformation on the vertical support tube.

Loading safety - load required to cause permanent deformation

Yield strength of $6061 \mathrm{Al}=40,000 \mathrm{psi}$

$$
\begin{gathered}
\sigma=\frac{M y}{I} \\
I=\frac{\pi\left(r o^{4-} r i^{4}\right)}{4} \\
\text { Maximum moment }=\frac{40000 \text { psi } \times \pi \times\left(.50 \mathrm{in}^{4}-.25 \mathrm{in}^{4}\right)}{4 \times .5 \mathrm{in}^{2}}=3682 \mathrm{in} * \mathrm{bs}
\end{gathered}
$$

Maximum load (assuming equal forces laterally and vertically) $=\left(\frac{3682 \mathrm{in} * \mathrm{lbs}}{11.43 \mathrm{in}}\right) / 2$

$$
=161 \mathrm{lbs}
$$

Factor of safety $=161 \mathrm{lbs} / 50 \mathrm{lbs}=3.2$

Again, this factor of safety is acceptable as this is a worst-case scenario with full vertical tube extension. 
After verifying these components, it was necessary to verify the sizing of the hinge pins used in both the elevator and boot assemblies. Stainless steel was chosen for these pins to ensure that no noticeable deformation would occur. Seen below is the analysis verifying the strength of the pin in shear:

Pin Strength:

Assumptions - Clamping force maximum of $100 \mathrm{lbs}$

Yield strength of 316 sst $-60,000$ psi

Pin Diameter - .250"

The force the pin can resist prior to deformation can be calculated using the cross sectional area of the pin and the yield stress of the steel.

$$
\begin{gathered}
F=\left(\left(p i * r^{2}\right) * \text { yield strength }\right) * 2(\text { double shear scenario }) \\
\mathrm{F}=3.14 * .125^{\prime \prime 2} * 60,000 p s i * 2 \\
\mathrm{~F}=5,887 \mathrm{lbs}
\end{gathered}
$$

This force is much greater than any force these pins will experience during operation.

The final analysis performed was to verify the strength of the 316 sst hook used for elevating the femur. Stainless steel was chosen for this piece for its ability to hold up well to repeated auto-clave cycles, and resistance to damage by other surgical tools that may nick it in operation.

The only portion of the hook that feasibly could be compromised by surgical use is the thinned portion at the bottom of the hook identified in figure 25 below. 


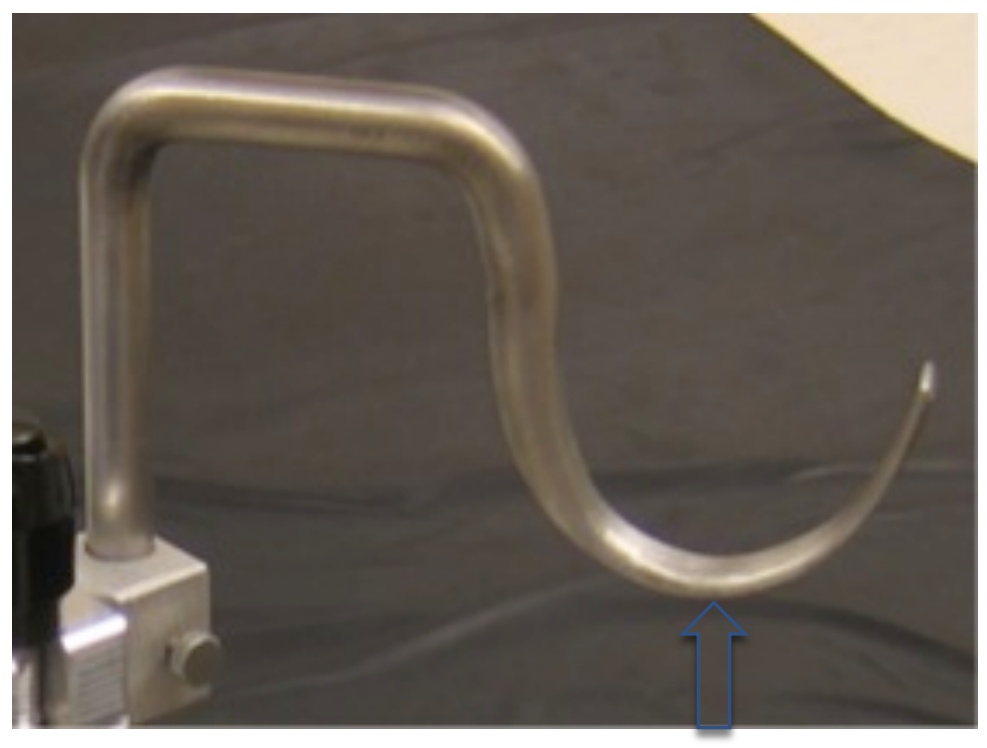

Figure 25. Blue arrow shows analysis point of interest of hook.

Assumptions:

Rectangular dimensions of hook at point of interest - .25 ” .625 ”

Constant radius bend of $1.75 "$

Loading at tip of hook of $50 \mathrm{lbs}$ as used in previous analysis, horizontal and away from hook base.

Yield strength of $316 \mathrm{sst}-60,000 \mathrm{psi}$

The moment at the point of interest:

$$
\begin{gathered}
M=50 l b s * 1.75 " \\
M=87.5 \mathrm{in} * l b s
\end{gathered}
$$

This moment is considered the worst-case load. The stress on the inner hook surface caused by this load will be found, as this is the surface that will yield in tension based on the loading condition. 
For curved beam analysis it is important to consider the shift the neutral axis makes away from the centroid of the shape. However, in this analysis the beam in question (the hook) has a very small thickness compared to the radius of the bend itself.

Therefore, while there is a shift in the neutral axis, it can reasonably be neglected to simplify the analysis. For this case, the stress on the inner surface can be found with:

$$
\begin{gathered}
\sigma=\frac{M c}{I} \\
\sigma=\frac{87.5 \mathrm{in} * l b s * .125^{\prime \prime}}{\left(\frac{1}{12}\right) * .625^{\prime \prime} * 25^{\prime 3}} \\
\sigma=13,440 \mathrm{psi} \\
\text { Factor of safety }=60,000 \mathrm{psi} / 13,440 \mathrm{psi} \\
\text { Factor of safety }=4.5
\end{gathered}
$$

This is a conservative factor of safety that assumes maximum loading conditions. 


\section{CHAPTER 3}

\section{Manufacturing and Testing}

\section{Overview}

The intent of this design is to produce a simple, effective set of table attachments that will allow surgeons to safely perform the anterior approach to total hip arthroplasty. The overall cost of this project at a 1000 unit quantity is estimated to be $\$ 1,307.66 /$ unit, well below the design requirement of $\$ 2,500 /$ unit. All components directly in contact with patients can be autoclaved, and the surgeon supplies any force applied to the patient with no mechanical advantage. The components can be attached to any Skytron surgical table, and at an estimated weight of 11.3 pounds, company representatives can easily transport the entire package.

\section{Manufacturing}

Overall, the prototype manufacturing went as expected. The detailed design drawings included in the appendix were used during the mostly manual machining process. Total shop time from start to finish was approximately 100 hours. However, there were a few changes/challenges that are worth mentioning. It was extremely difficult to find a block of aluminum large enough to create a boot as designed, and the Cal Poly shop said it would be impossible to machine the boot out of a block due to tool stick-out limitations. Instead, multiple sheets of polycarbonate were used at 1/2" thickness as a replacement for the aluminum. These were cut out on a CNC mill and laminated together with high-heat epoxy in order to create the block. 
Bolt holes were drilled through each sheet in order to allow precise clamping of the sheets together during the final lamination. In order to make sure the sheets did not delaminate, the $\mathrm{CNC}$ program was adjusted to increase the thickness of the walls of the boot by $.100 "$ as a safety measure for the prototype. In a production environment it would be advantageous to make the sizeable investment on a mold for this large and difficult to machine boot.

It was expected that the stainless steel hook would be able to be precisely $\mathrm{CNC}$ machined to the CAD part file. However, due to the difficult geometry involved Cal Poly was unable to develop a tool approach that could accurately make the part. Therefore, it was necessary to form the hook manually. This was accomplished by taking a long piece of 316 sst bar stock and turning the end down on a lathe to create the end features shown in Figure 26.

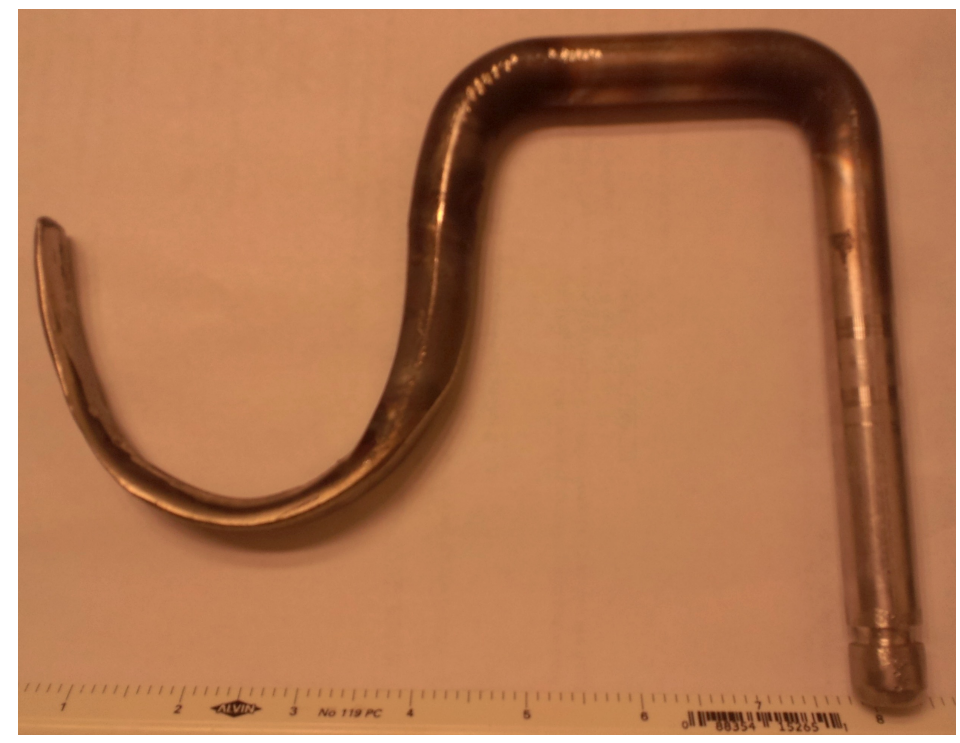

Figure 26. Femoral hook after initial forming and grinding. 
After turning, the bends in the hook were created by using an oxy/acetylene torch, a vise, and a cheater bar. The geometry was visually checked and referenced with a scale printout of the CAD hook. After bending, the end of the hook was thinned using an angle grinder and a pneumatic burr grinder. The femoral hook was finished by smoothing out imperfections on a wire wheel, and polishing with progressively finer sand paper. The finished result is shown in Figure 27 below.

The $80 / 20$ Corp. rail had to be ordered at a length of 48 " instead of the initially designed 36". The surgeons decided that it would be best to leave the rail longer for the prototype to see if it would be useful during a case. 


\section{Completed Prototype}

Seen below in Figures 27 and 28 is the completed prototype mounted on a Skytron 3600 surgical table.

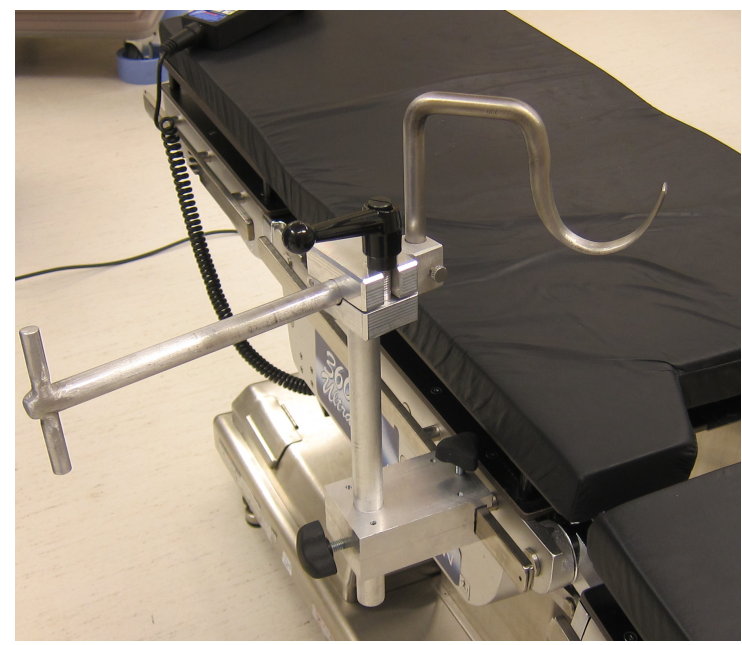

Figure 27. Prototype femoral elevator assembly.

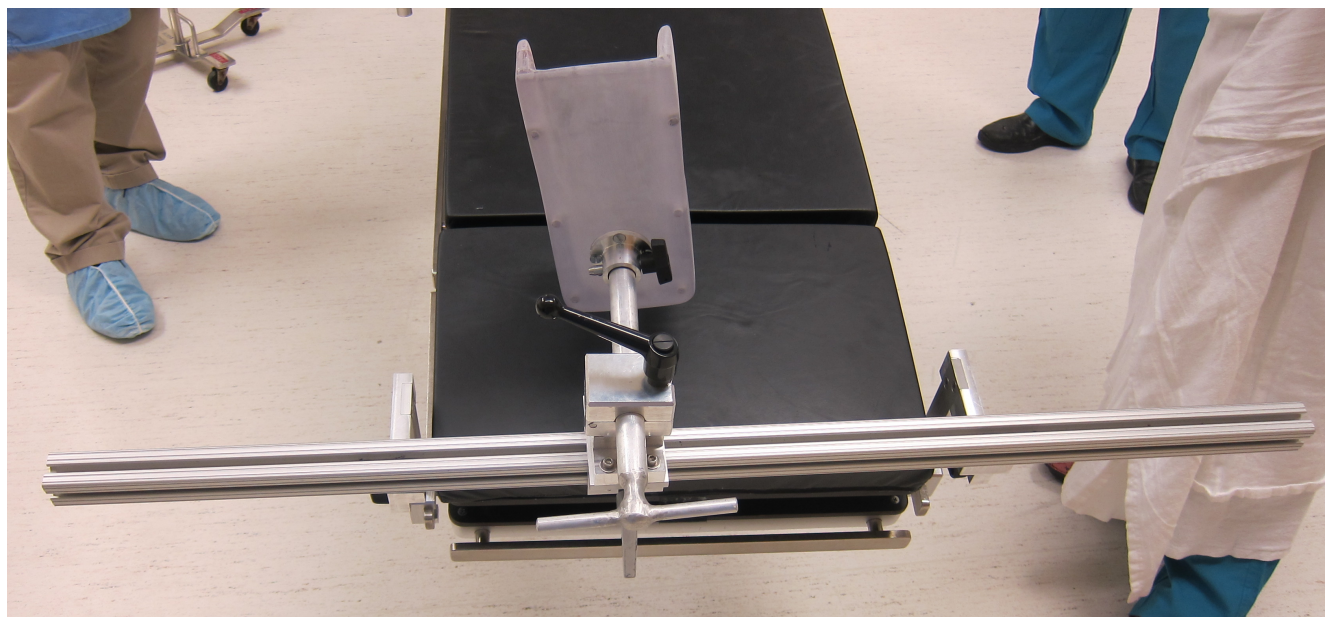

Figure 28. Prototype boot assembly.

The completed prototype met the desired specifications for this product. The overall weight of the total assembly was $18.8 \mathrm{lbs}$ (heavier than the expected $11.3 \mathrm{lbs}$, but still significantly less than the requirement of $25 \mathrm{lbs}$ ). 
The increase in weight is due to the weight of all the fasteners and screw down handles, which were not accounted for in the initial estimate, the thicker boot, and the rail being 12" longer than originally designed. The total cost was $\$ 1999.96$, but this doesn't include machining labor for about $2 / 3$ of the parts. The increased cost over the estimated \$1307 seen in Appendix B is due to the higher cost of individual component parts rather than bulk, as well as the additional material cost when only a small portion was needed. This cost bodes well for a larger production level and should easily stay under the $\$ 2500$ target. 


\section{Prototype Testing}

The first test was the fit of the components together and the locking mechanisms for both the femoral elevator and the boot assembly. If prototype tolerances were off these parts would not interact correctly. The rods slid well through the surfaces for both assemblies, and locked appropriately when the clamps were screwed down. In both assemblies the lock of rotation and lateral in/out movement were stronger than any force I could produce manually.

The next test was the interface with the surgical table. The manufacturer had sent rail dimensions and tolerances, but unfortunately these tolerances did not account for the abuse that the rails undergo during use. The surgical table used has significant dings, dents, and nicks from years of use. The rail clamps would not fit on the first attempt. The inner surface of the rail clamps was modified to add .010 " of extra clearance on every surface that interfaced with the rail. Upon a second trial the clamps slid well, locked solidly, and unlocked easily. 
The next test involved the use of a simulated patient to verify the surgical package appropriately moved into position with a patient. Figures 29 and 30 show that the boot was able to turn and meet the position requirements for the patient, as well as adjust for the height of the patient who was 6' tall. Figure 29 shows the femoral elevator in an appropriate position with lots of adjustment as needed to meet the specific surgical needs.

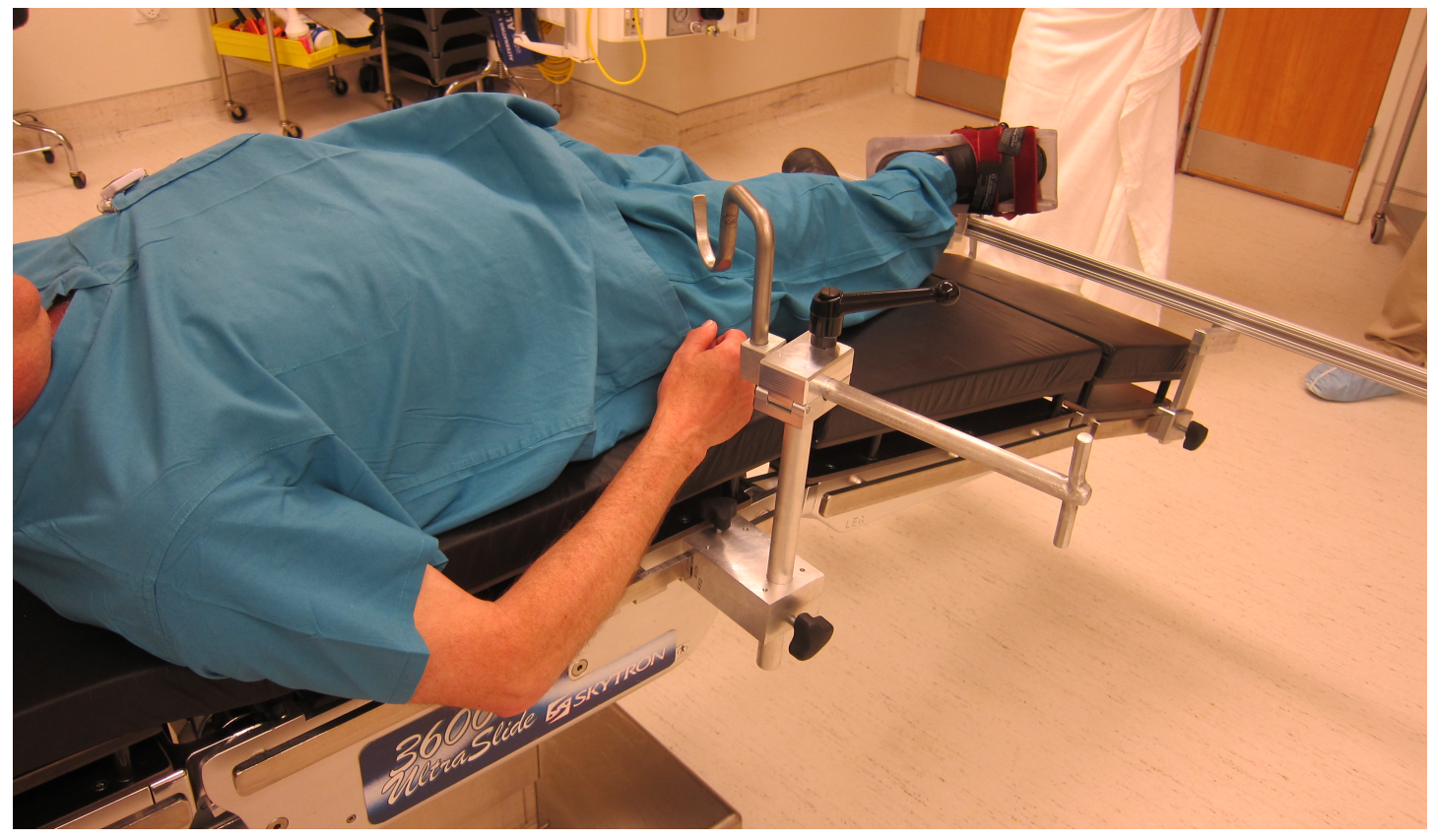

Figure 29. Patient on table with entire surgical package in place. 


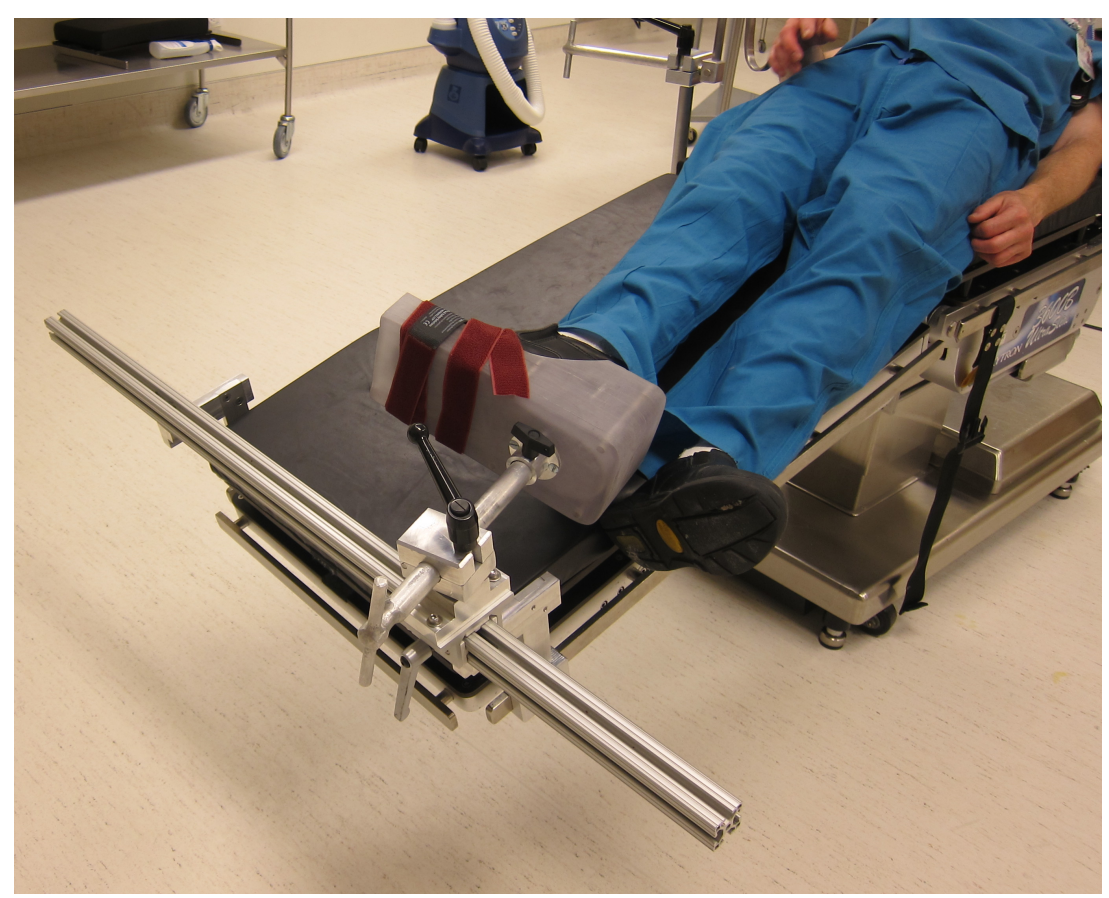

Figure 30. Boot assembly strapped onto patient and rotated.

The overall strength of the elevator assembly was not tested to failure as this prototype is intended for future surgical use. However, with the femoral hook in the extreme position of sticking out into the middle of the table, there was still excellent rigidity when a manual force of approximately $50 \mathrm{lbs}$ was applied. Similarly, the boot assembly was solid with strong manual forces applied. 


\section{CHAPTER 4}

\section{Limitations, Improvements, Future Work, and Conclusions}

\section{Limitations}

There are some specific limitations to this design and project that must be acknowledged. Hand-powered assemblies are useful for many aspects of this surgery, but they also rely on the surgeons and assistants to be very physical, which can be taxing during long cases. A design that is able to safely provide mechanical advantage would be ideal. That could possibly be provided through force gauges that allow the surgeon to see the force applied. The hook design is difficult to manufacture on a larger scale without the development of a casting process and set of molds. CNC manufacturing may be possible, but utilizing Cal Poly resources it was not possible. Draping of this design is an issue. It's difficult to drape the rail and allow sliding motion, to drape the tube in the traction assemblies to enable motion, and to secure the boot in a sterile manner. A set of customized drapes will be required to get this tooling into a surgical suite.

\section{Improvements}

While the prototype does function as designed, there are some improvements that would make it more user friendly, efficient, and robust. The first overall improvement is to design for and incorporate hard anodizing on all of the aluminum components. 6061 Aluminum is a great alloy for machining and development of prototypes, but it is quite soft and scratches very easily. If the device is expected to hold up through thousands of surgeries it will need to be hard anodized. 
The sliding mechanism for the rods on both the femoral elevator and the boot assembly involves simply a rod sliding in the machined block that holds it. While this is very simple and eliminates grease and facilitates the locking mechanism that is used, it also allows for some sticking of the rod when it is under vertical load. For example, when using the simulated patient to test the boot assembly we found the boot itself had to be pulled up in order to apply traction and extend the leg. A similar problem exists with the femoral hook mildly binding under load. In both cases the binding can be overcome, but it would be much nicer to have a linear bearing that allowed these rods to slide easily during loading. The linear bearing would still have to allow locking with the current clamp mechanism, which may be more difficult than it seems.

The polycarbonate boot seemed like a good way to keep weight down, maintain a rigid structure, and solve the issue of sourcing the aluminum block. However, input from the surgeons indicates that the boot is far too heavy and that a slightly flexible boot may actually have some advantages. Therefore, a lighter, flexible, aluminum or stainless steel boot would likely be a better product. They would also prefer a faster quick-connect lock between the boot and the boot traction rod to be able to feel leg motion and length during the procedure. 


\section{Future Work}

This project is to be used in a surgery towards the end of the summer of 2013. Dr. Merritt and Dr. Meckel feel confident that it will perform up to the standards they expect, and understand that a device failure represents a very minimal risk to the success of the surgery. Before that surgical case, minor improvements are to be made to the fit and function of the device. Private sponsorship of the device will also be sought in hopes of developing a production model and receiving compensation for our work.

\section{Conclusions}

The intent of this project was to design and manufacture a functional prototype to facilitate the direct anterior approach to hip replacement, without the need for a specialized table. Through analysis and computer aided design a final set of drawings was created and a prototype was manufactured that met the design specifications. The prototype functioned as intended and passed all applicable non-destructive testing that was possible. Surgeon input on the prototype was very positive and the tooling should be used soon for an actual surgical procedure. 


\section{BIBLIOGRAPHY}

1. Centers for Disease Control and Prevention, Inpatient Surgery, December 1, 2012, http://www.cdc.gov/nchs/fastats/insurg.htm.

2. Christopher Meckel, MD, Orthopedic Surgeon.

3. Kurtz S, Ong K, Lau E, Mowat F, Halpern M, Projections of primary and revision hip and knee arthroplasty in the United States from 2005 to 2030, J Bone Joint Surg Am. 2007 Apr;89(4):780-5.

4. American Academy of Orthopedic Surgeons, Total Hip Replacement, December 1, 2012, http://orthoinfo.aaos.org/topic.cfm?topic=a00377

5. Kelmanovich, D, Parks, M.L, Sinha, R, Macaulay, W, Surgical Approaches to Total Hip Arthroplasty, Journal of the Southern Orthopaedic Association. 12(2):90-94, 2003.

6. Mahalingham, K, Reidy, D, Smith-Petersen Vitalium Mould Arthroplasty: A 45-Year Follow-up, British Society of Bone and Joint Surgery, 1996;78B:496-8

7. Callaghan, J, Albright, JC, Goetz, DD, Olejniczak, BA, Johnston, RC, Charnley Total Hip Arhtroplasty with Cement: Minimum twenty-five year follow-up,J. of Bone and Joint Surgery, 2000:82-A;4

8. Alecci, V, Valente, M, Crucil, M, Minerva, M, Pellegrino, C, Sabbadini, D, Comparison of primary total hip replacements performed with a direct anterior approach versus the standard lateral approach: perioperative findings, J Orthop Traumatol. 2011 September; 12(3): 123-129. 
9. NIH Conference, Osteoarthritis: New Insights, Ann. Internal Med. 2000;133:635-646.

10. AAOS, Total Hip Replacement, http://orthoinfo.aaos.org/topic.cfm?topic=a00377, 2013.

11. Mizuhosi, Orthopedic Fracture/Trauma, http://www.mizuhosi.com/products/orthopedic-fracture-trauma/profx/, 2013

12. ACCIS Ceramic Engineering, The early designs, http://www.accis.nl/pg resurfacing hip.html 2013.

13. BoneSmart, Hip Arthroplasty Follow-up at 62 years, http://bonesmart.org/forum/threads/hip-arthroplasty-follow-up-at-62years.11836/2013.

14. Castandea, S, Roman-Blas, J, Largo, R, Herrero-Beaumont, G, Subchondral bone as a key target for osteoarthritis treatment, Biochem Pharm, 2012;83 $315-323$

15. International Society of Arthroscopy, A short basic sciences review of articular cartilage, http://www.isakos.com/innovations/luscombe.aspx 2013.

16. Mark A. Wolgin, MD, Osteoarthritis, http://www.drwolgin.com/Pages/Osteoarthritis.aspx 2013.

17. Blanco, F, Cuitian, R, Vazquez-Martul, E, de Toro, F, Galdo, F, Osteoarthritis chondrocytes die by apoptosis: A possible pathway for osteoarthritis pathology, Arthritis and Rheumatism, 1998;41 284-289. 
18. Rahme, E, Choquette, D, Bealieu, M, Bessette, L, Joseph, L, Toubouti, Y, LeLorier, J, Impact of a general practitioner educational interbention on osteoarthritis treatment in an elderly population, Amer. Journal of Med, $2005 ; 118$ 1262-1270.

19. NIH Conference, Osteoarthritis: New Insights. Part II: Treatment options, Ann. Internal Med. 2000;133:635-646.

20. Mayo Clinic, Knee osteotomy, http://www.mayoclinic.com/health/kneeosteotomy/MY00710 2013.

21. Noyes, F, Arthroscopic surgery, http://www.kneeguru.co.uk/KNEEnotes/courses/arthrofibrosis-12-part-coursefrank-noyes-md/arthroscopic-surgery-arthrofibrosis-part-7 2008.

22. Ortho Pediatrics, A Patient's Guide to Developmental Dysplasia of the Hip in Children, http://www.orthopediatrics.com/docs/Guides/dysplasia.html 2013.

23. Gomez, P, Morcuende, J, Early attempts at Hip Arthroplasty - 1700s to 1950s, The Iowa Orthopedic Journal, 2005;25 25-29.

24. Gomez, P, Morcuende, J, A Historical and Economic Perspective on Sir John Charnley, Chas F. Thackray Limited, and The Early Arthroplasty Industry, The Iowa Orthopedic Journal, 2005;25 30-37.

25. Delauney, F, The Charnley Total Hip Replacement, Matrise Orthopedics, http://www.maitriseorthop.com/corpusmaitri/orthopaedic/mo83 delaunay/delaunay us.shtml 2008. 
Appendix A - Detailed Drawings 


\section{BILL OF MATERIALS}

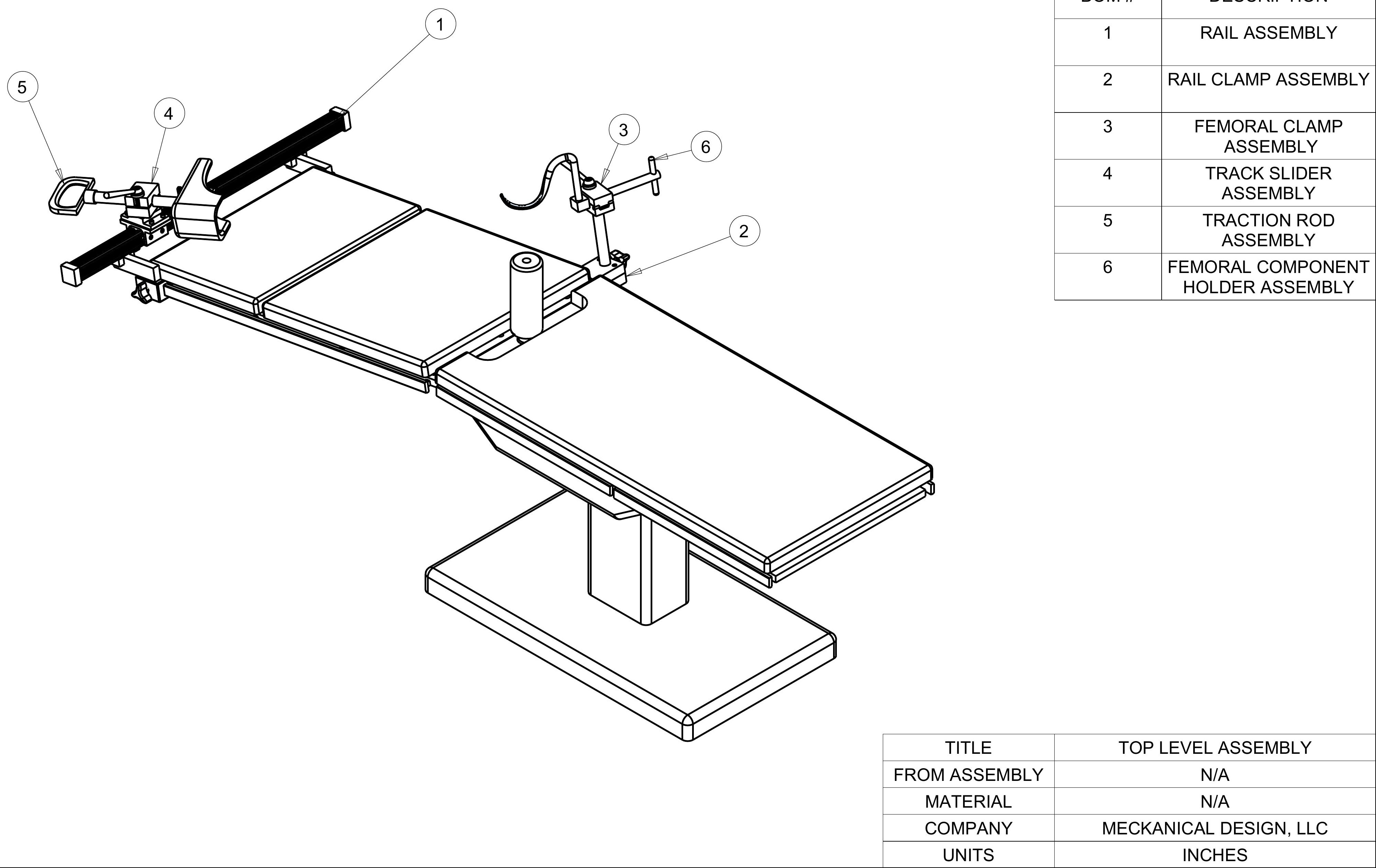



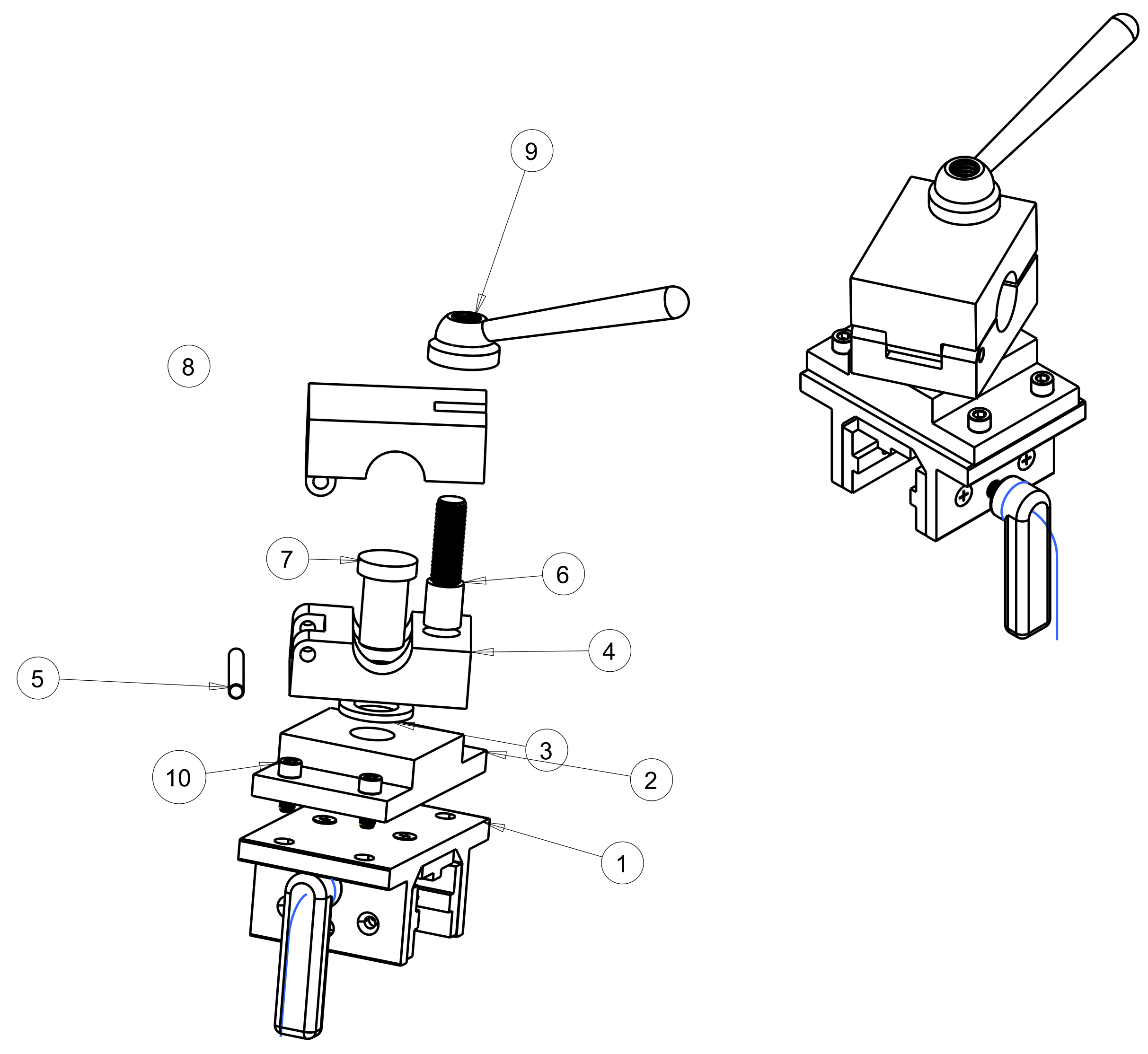

BILL OF MATERIALS

\begin{tabular}{|c|c|}
\hline \multicolumn{2}{|c|}{ BILL OF MATERIALS } \\
\hline BOM \# & DESCRIPTION \\
\hline 1 & $\begin{array}{c}80 / 20 \text { P/N 6825 } \\
\text { TRACK SLIDER }\end{array}$ \\
\hline 2 & CYLINDER SUPPORT \\
\hline 3 & BUSHING \\
\hline 4 & BOTTOM CLAMP \\
\hline 5 & HINGE PIN \\
\hline 6 & MCMASTER P/N \\
8420 K180
\end{tabular}



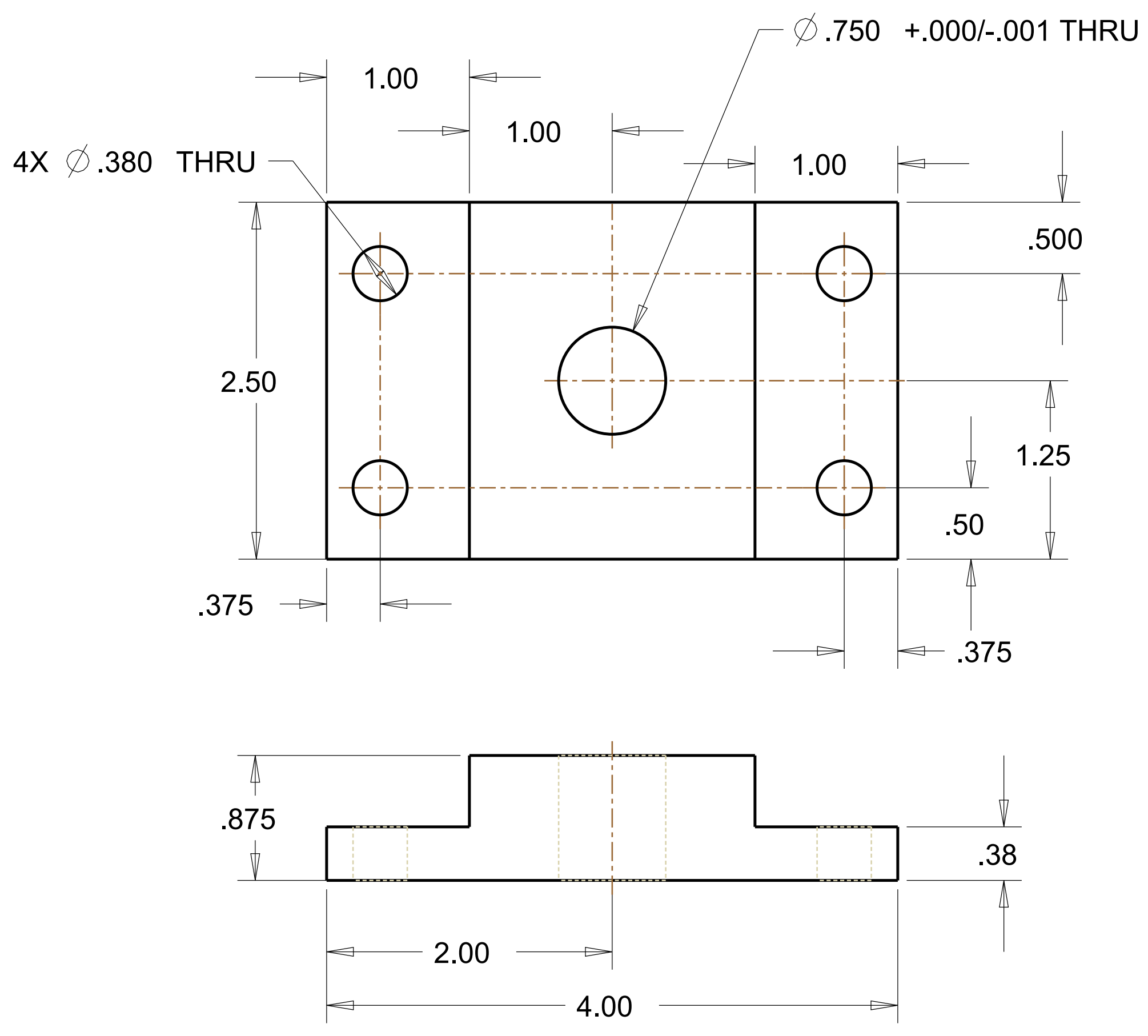

SCALE 1:1

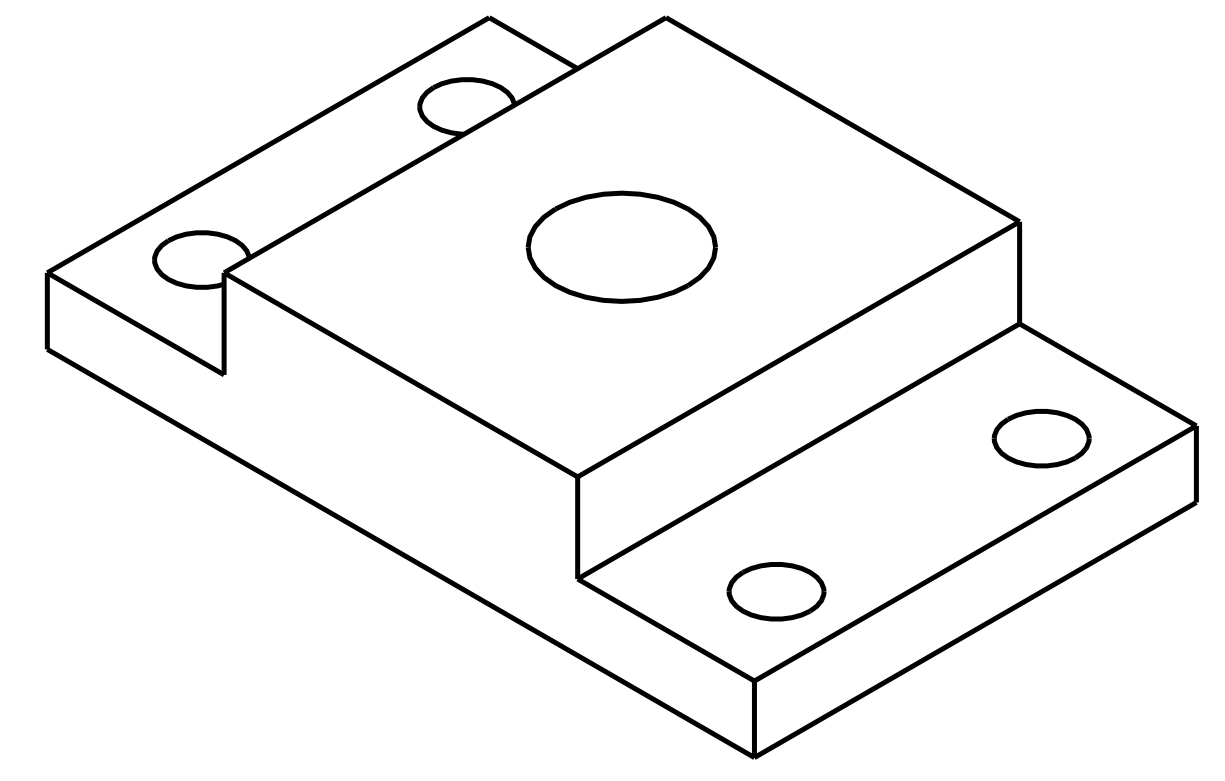

\begin{tabular}{|c|c|}
\hline TITLE & CYLINDER SUPPORT \\
\hline FROM ASSEMBLY & TRACK SLIDER \\
\hline MATERIAL & $6061 \mathrm{AL}$ \\
\hline COMPANY & MECKANICAL DESIGN, LLC \\
\hline UNITS & INCHES \\
\hline TOLERANCE & $0.01, . X X X= \pm \quad 0.005$ \\
\hline
\end{tabular}



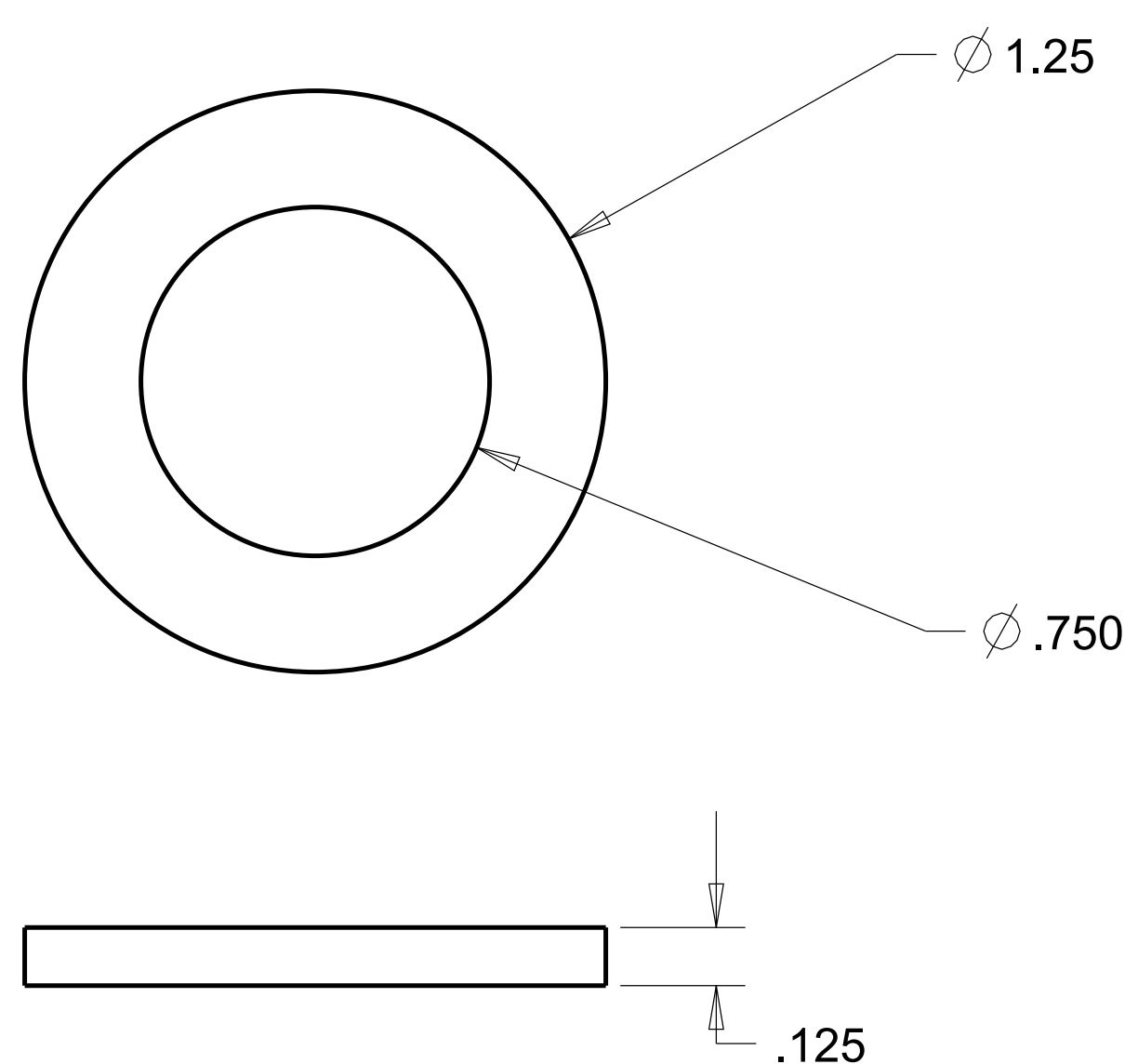

SCALE 2:1

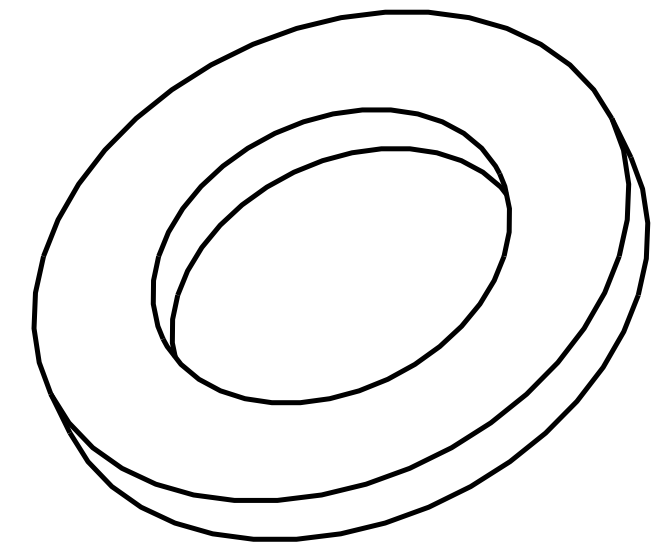

\begin{tabular}{|c|c|}
\hline TITLE & BUSHING \\
\hline FROM ASSEMBLY & TRACK SLIDER \\
\hline MATERIAL & BRONZE \\
\hline COMPANY & MECKANICAL DESIGN, LLC \\
\hline UNITS & INCHES \\
\hline TOLERANCE & $. X X= \pm \quad 0.01, . X X X= \pm \quad 0.005$ \\
\hline
\end{tabular}



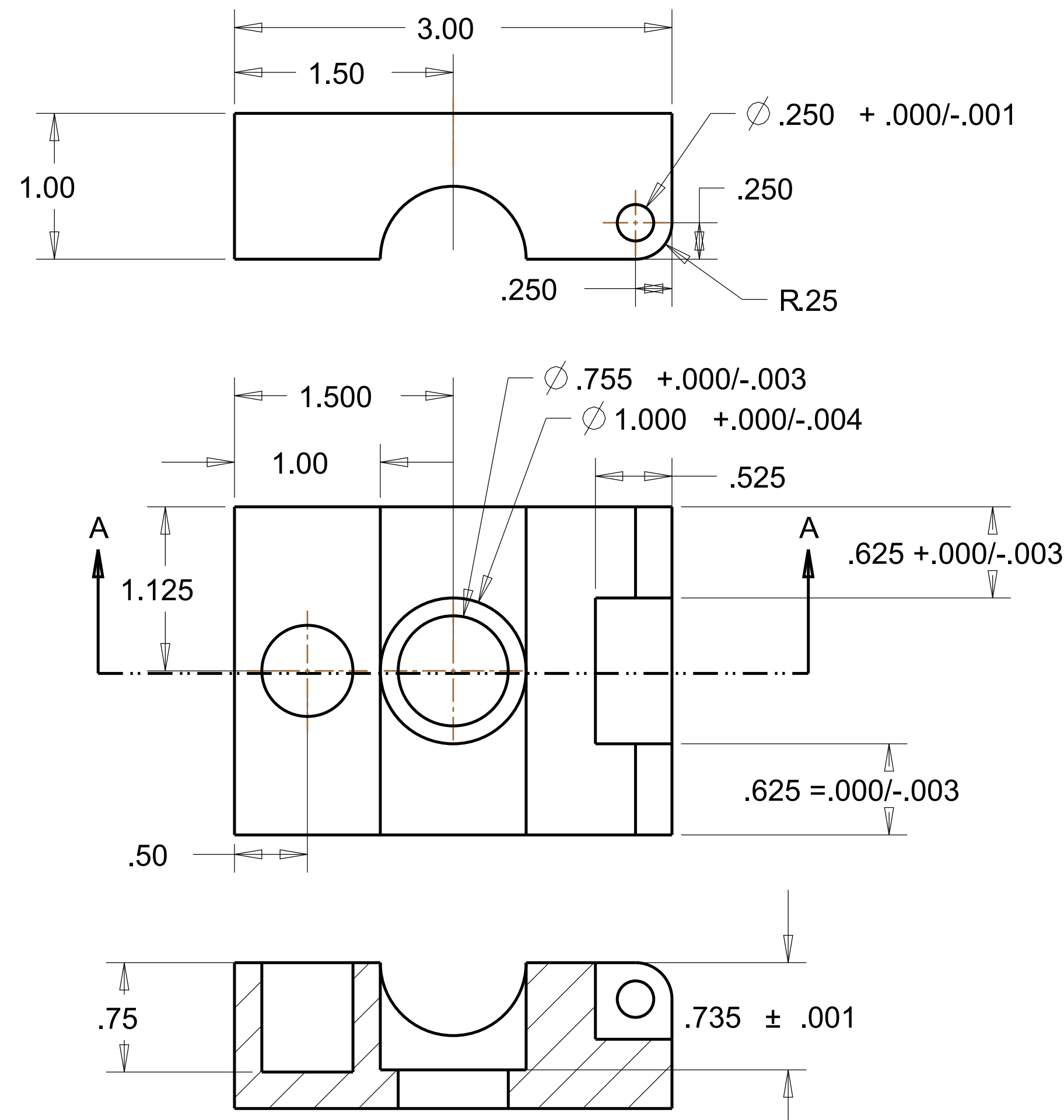

SECTION A-A

SCALE 1:1

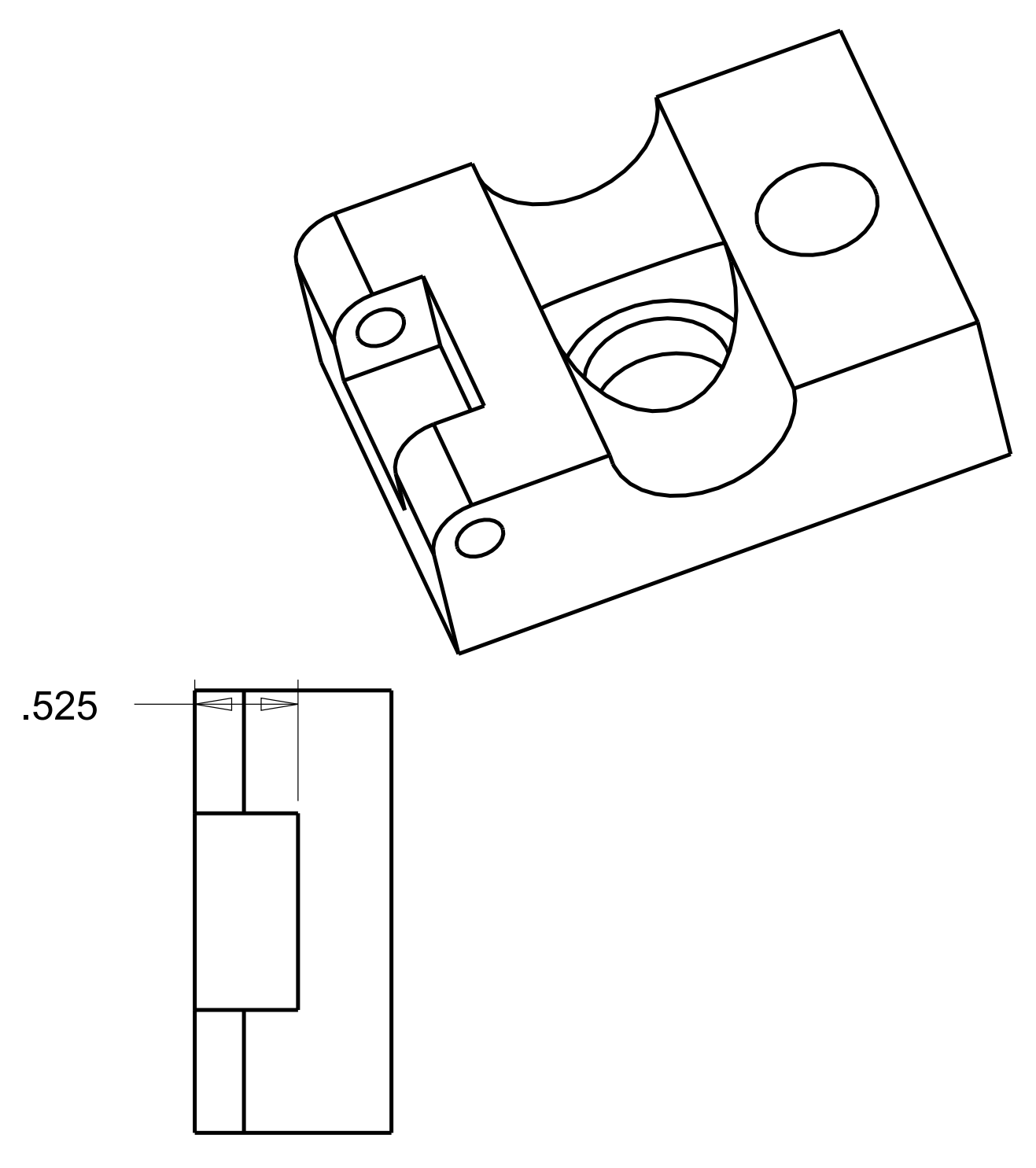

\begin{tabular}{|c|c|}
\hline TITLE & BOTTOM CLAMP \\
\hline FROM ASSEMBLY & TRACK SLIDER \\
\hline MATERIAL & $6061 \mathrm{AL}$ \\
\hline COMPANY & MECKANICAL DESIGN, LLC \\
\hline UNITS & INCHES \\
\hline TOLERANCE & $0.01, . X X X= \pm 0.005$ \\
\hline
\end{tabular}




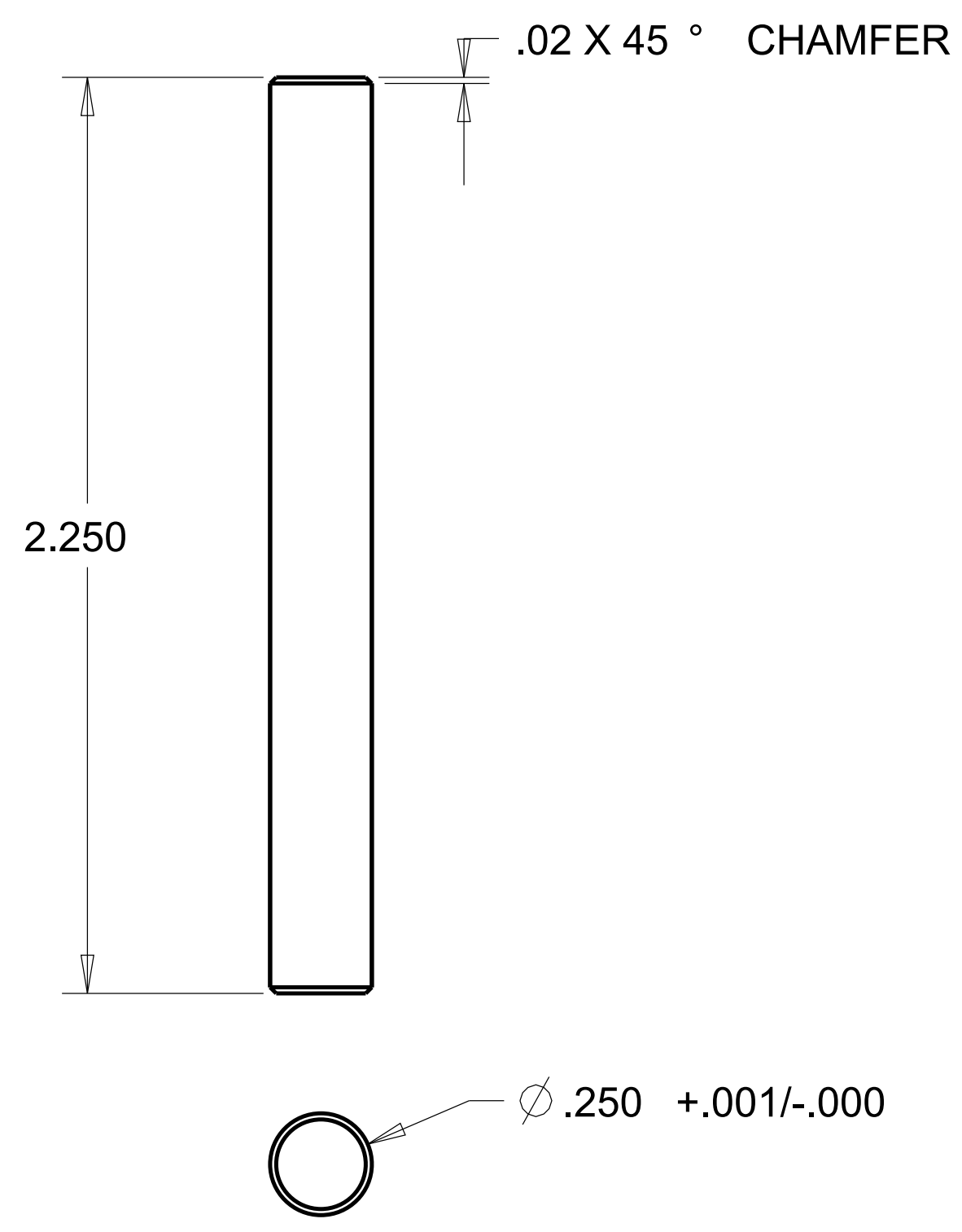

SCALE 2:1

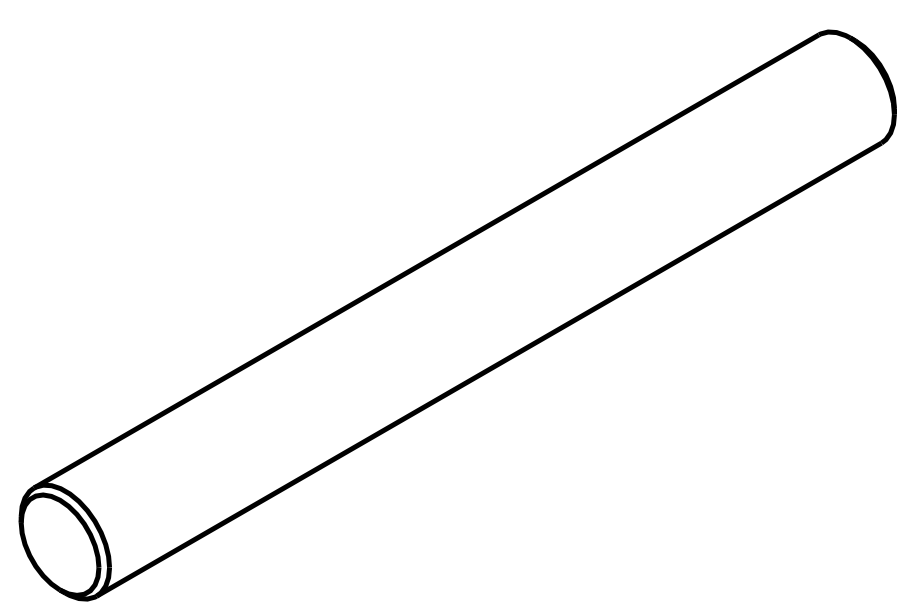

\begin{tabular}{|c|c|}
\hline TITLE & HINGE PIN \\
\hline FROM ASSEMBLY & TRACK SLIDER \\
\hline MATERIAL & STAINLESS STEEL \\
\hline COMPANY & MECKANICAL DESIGN, LLC \\
\hline UNITS & INCHES \\
\hline TOLERANCE & $. X X= \pm \quad 0.01, . X X X= \pm 0.005$
\end{tabular}



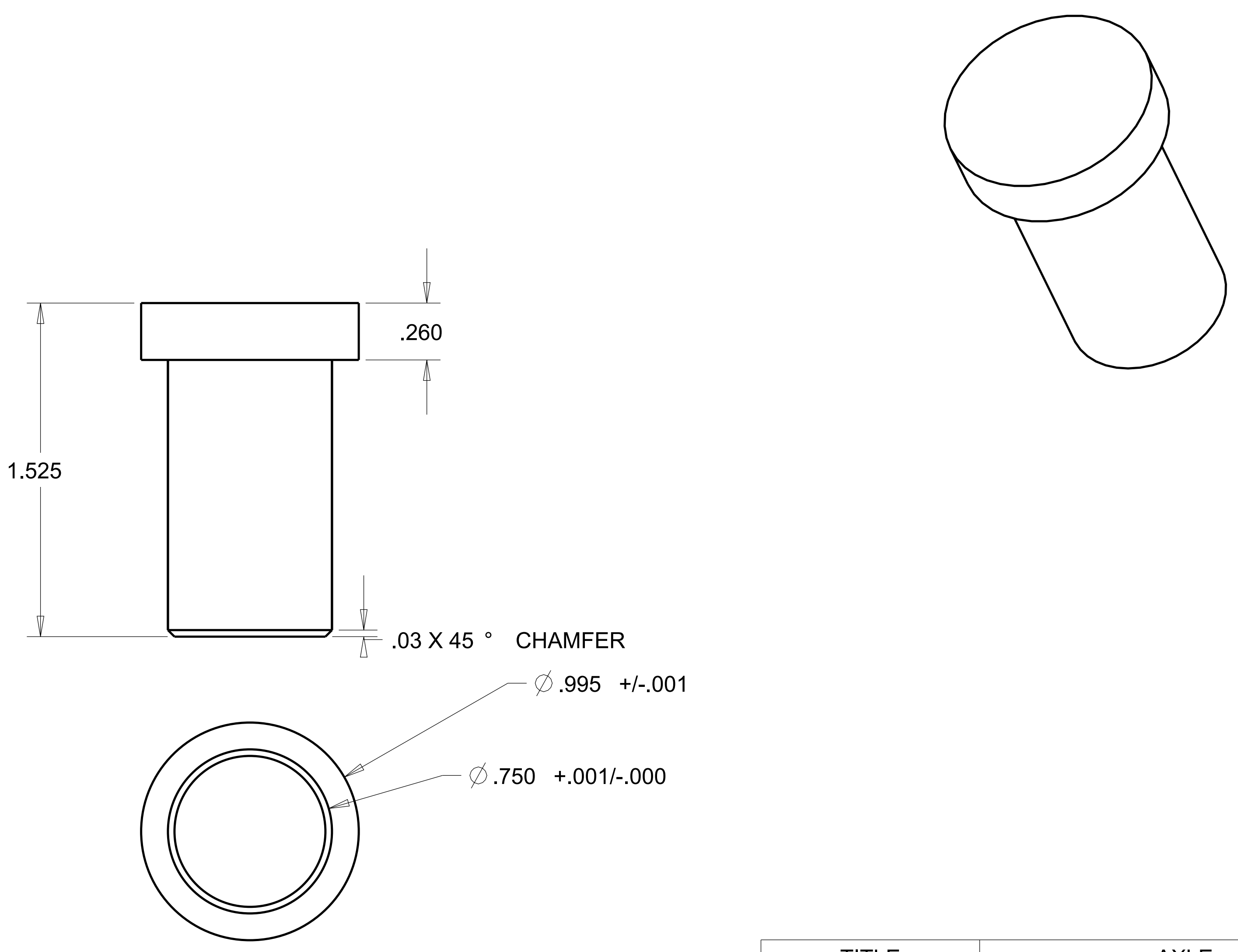

SCALE 2:1

\begin{tabular}{|c|c|}
\hline TITLE & AXLE \\
\hline FROM ASSEMBLY & TRACK SLIDER \\
\hline MATERIAL & $6061 \mathrm{AL}$ \\
\hline COMPANY & MECKANICAL DESIGN, LLC \\
\hline UNITS & INCHES \\
\hline TOLERANCE & $0.01, . X X X= \pm$ \\
\hline
\end{tabular}



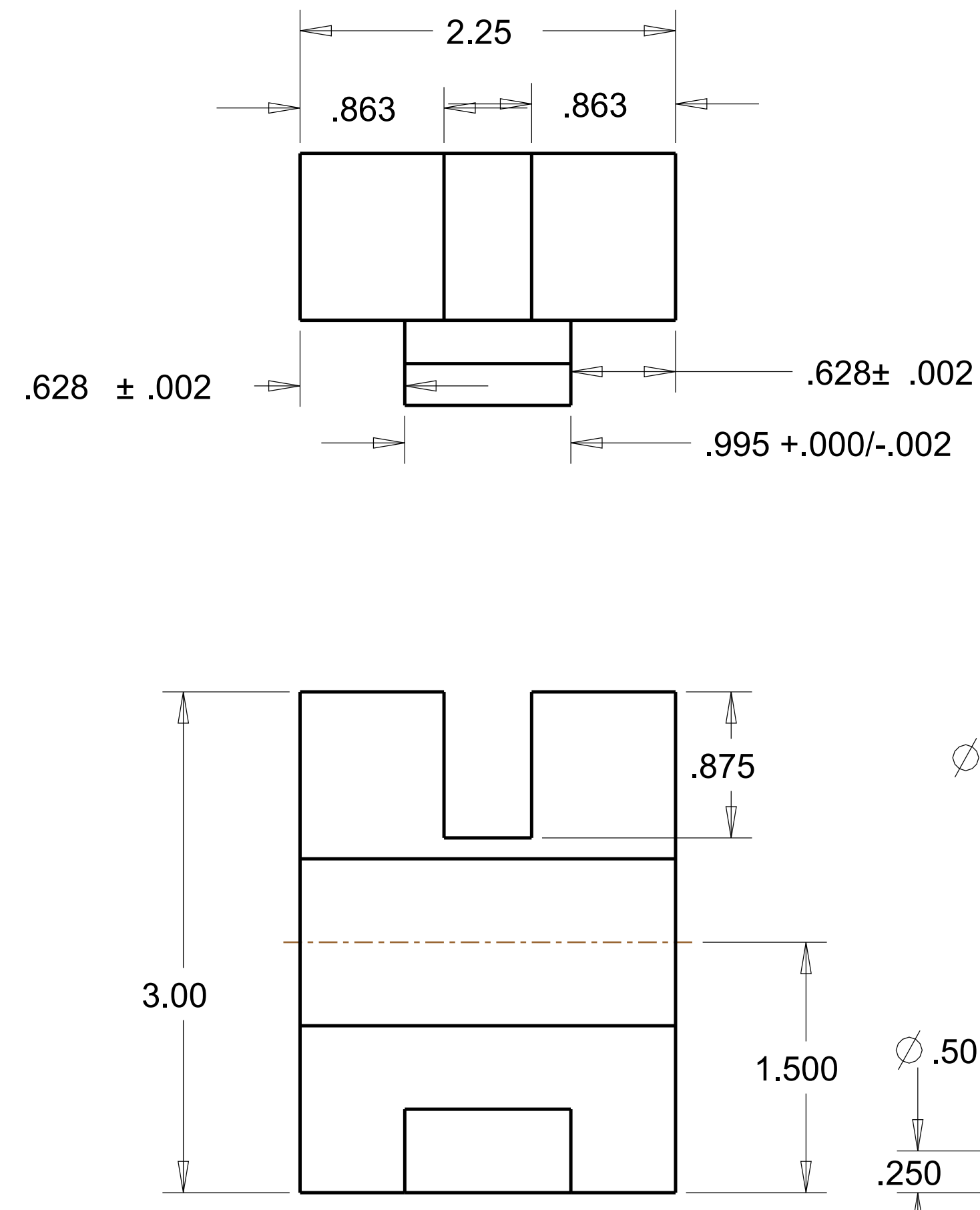

$\varnothing .250+.005 /-.000$

SCALE 1:1
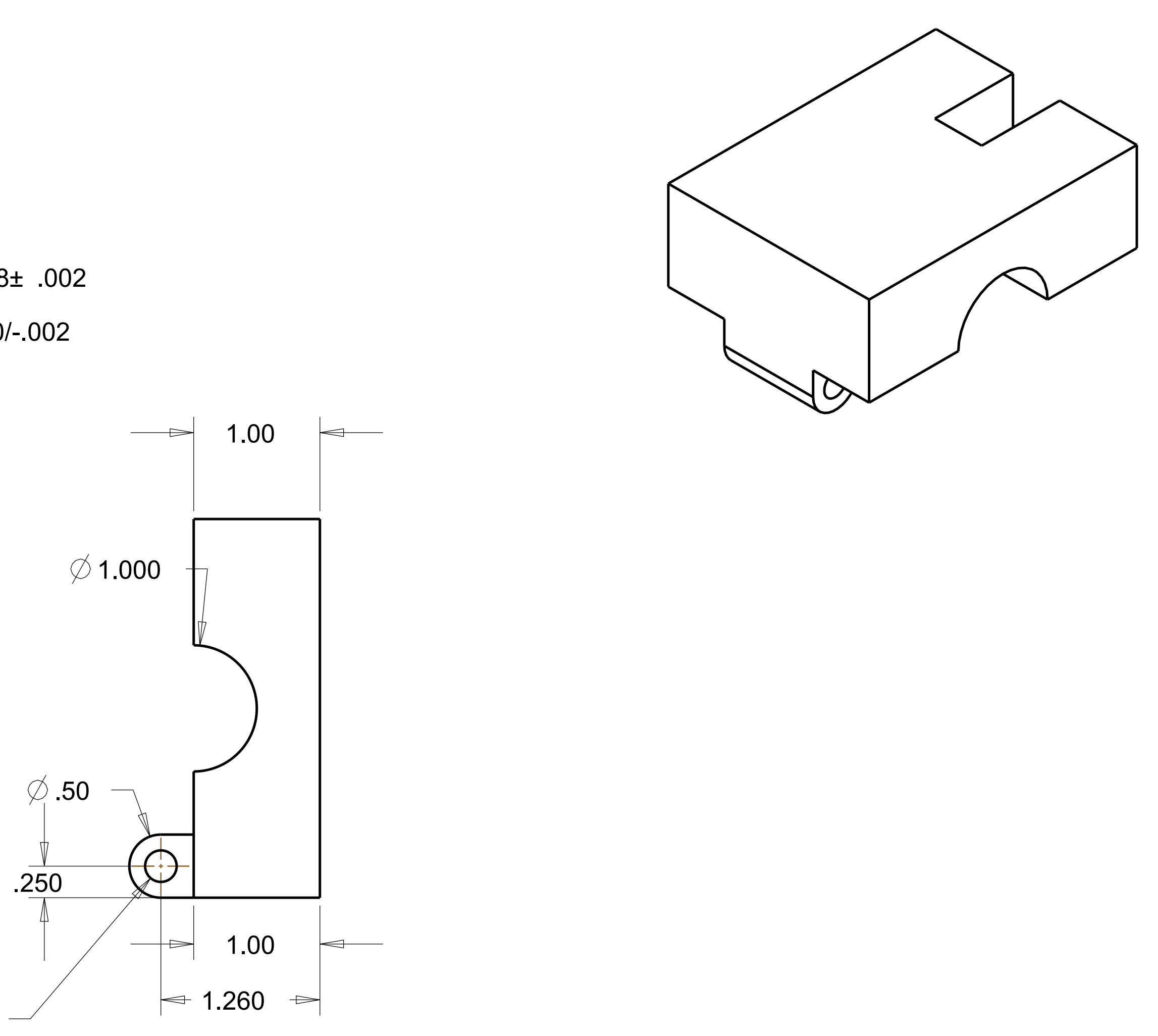

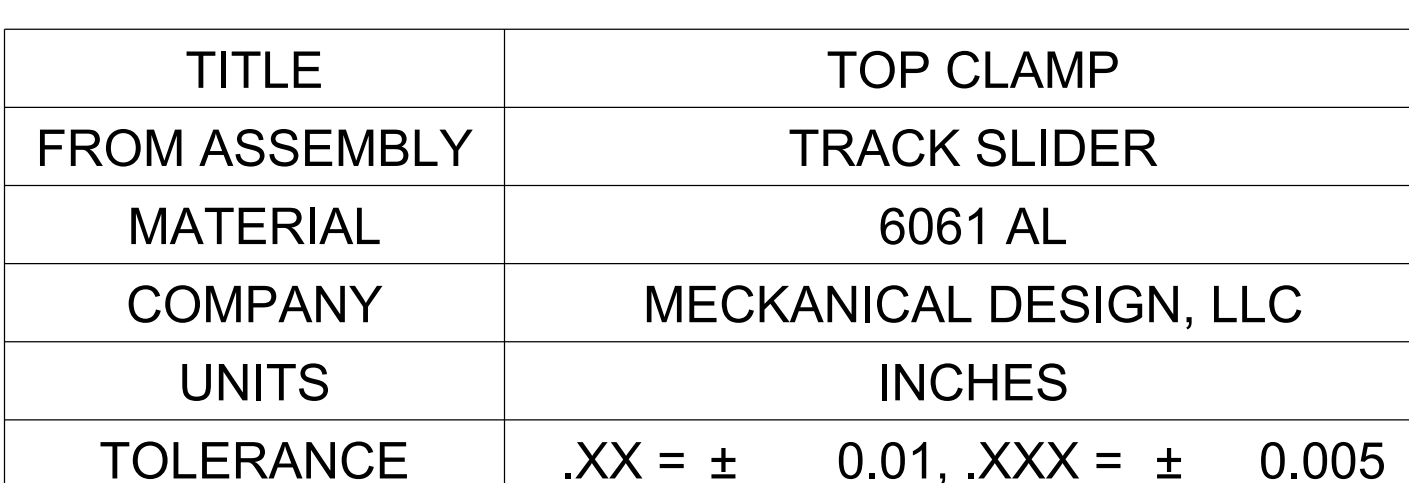


BILL OF MATERIALS
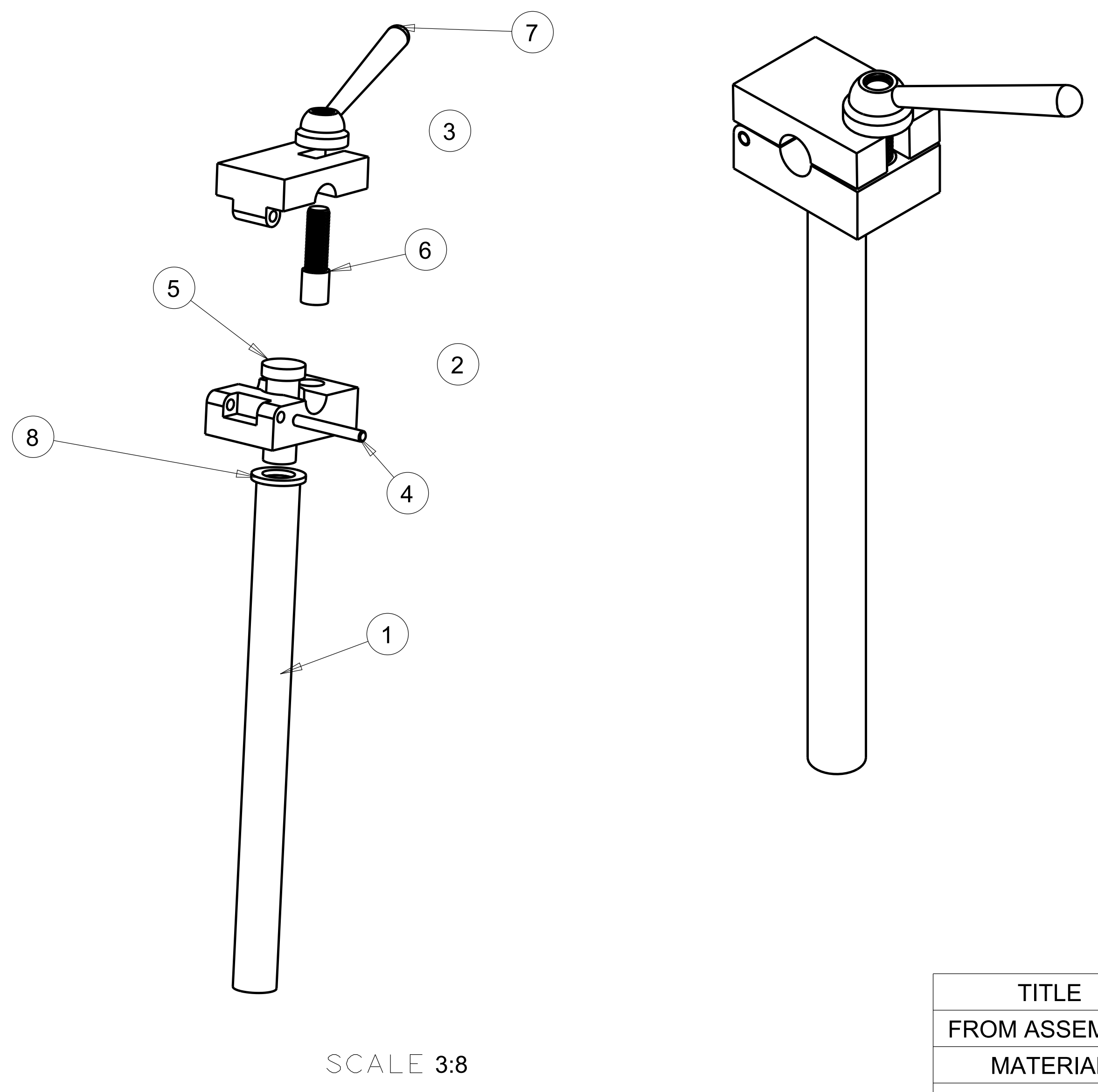

\begin{tabular}{|c|c|}
\hline BOM \# & DESCRIPTION \\
\hline 1 & VERTICAL TUBE \\
\hline 2 & FEMORAL CLAMP BASE \\
\hline 3 & FEMORAL CLAMP TOP \\
\hline 4 & SMALL PIN \\
\hline 5 & PRESS-FIT PIN \\
\hline 6 & $\begin{array}{c}\text { MCMASTER P/N } \\
8420 \text { K180 }\end{array}$ \\
\hline 7 & $\begin{array}{c}\text { MCMASTER P/N } \\
3577 \text { K900 } \\
\text { BUSHING } \\
\text { (SEACK SLIDER) }\end{array}$ \\
\hline 8 & \begin{tabular}{c} 
TRACK \\
\hline
\end{tabular}
\end{tabular}



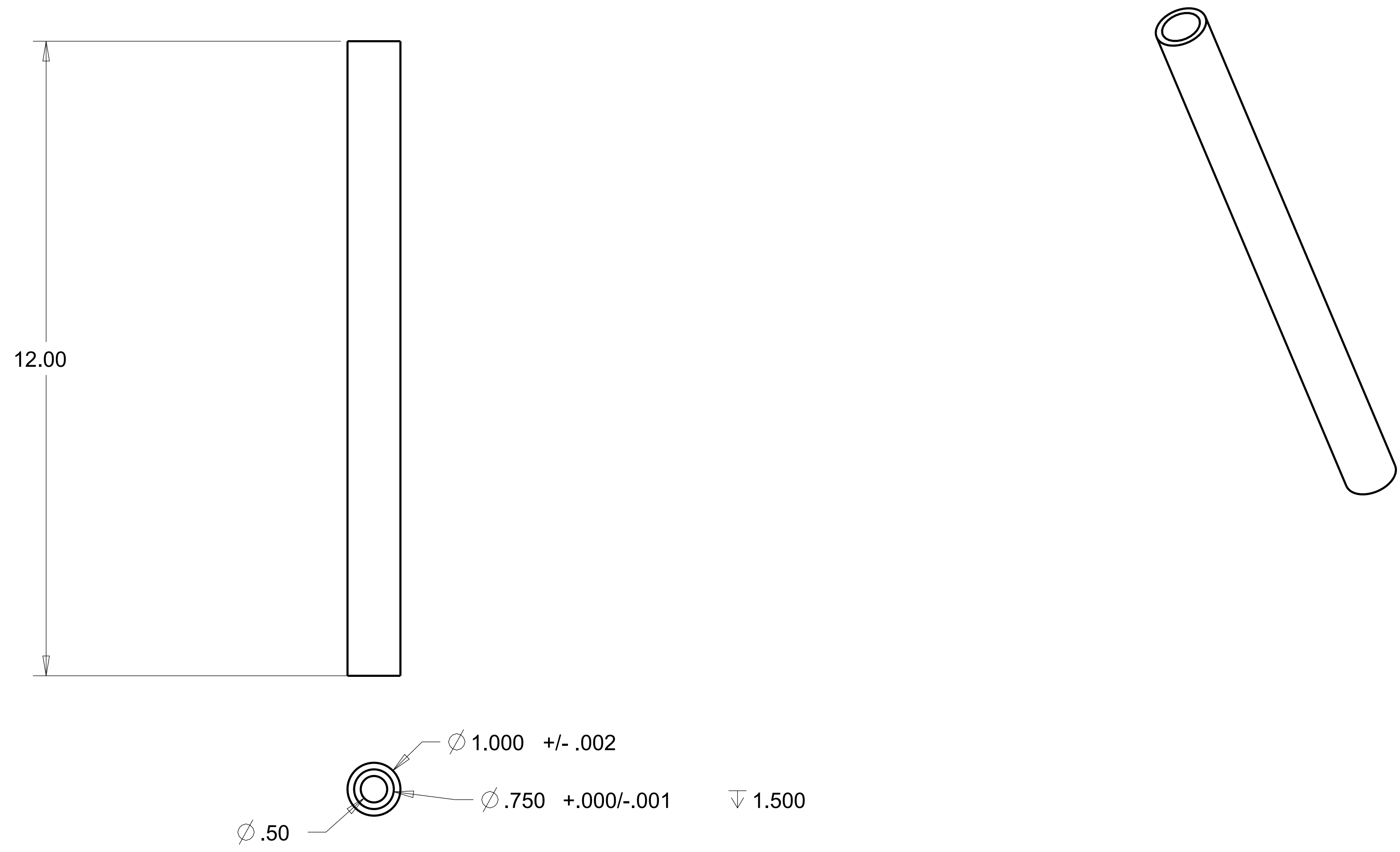

\begin{tabular}{|c|c|}
\hline TITLE & VERTICAL TUBE \\
\hline FROM ASSEMBLY & FEMORAL CLAMP \\
\hline MATERIAL & $6061 \mathrm{AL}$ \\
\hline COMPANY & MECKANICAL DESIGN, LLC \\
\hline UNITS & INCHES \\
\hline TOLERANCE & $0.01, . X X X= \pm$ \\
\hline
\end{tabular}



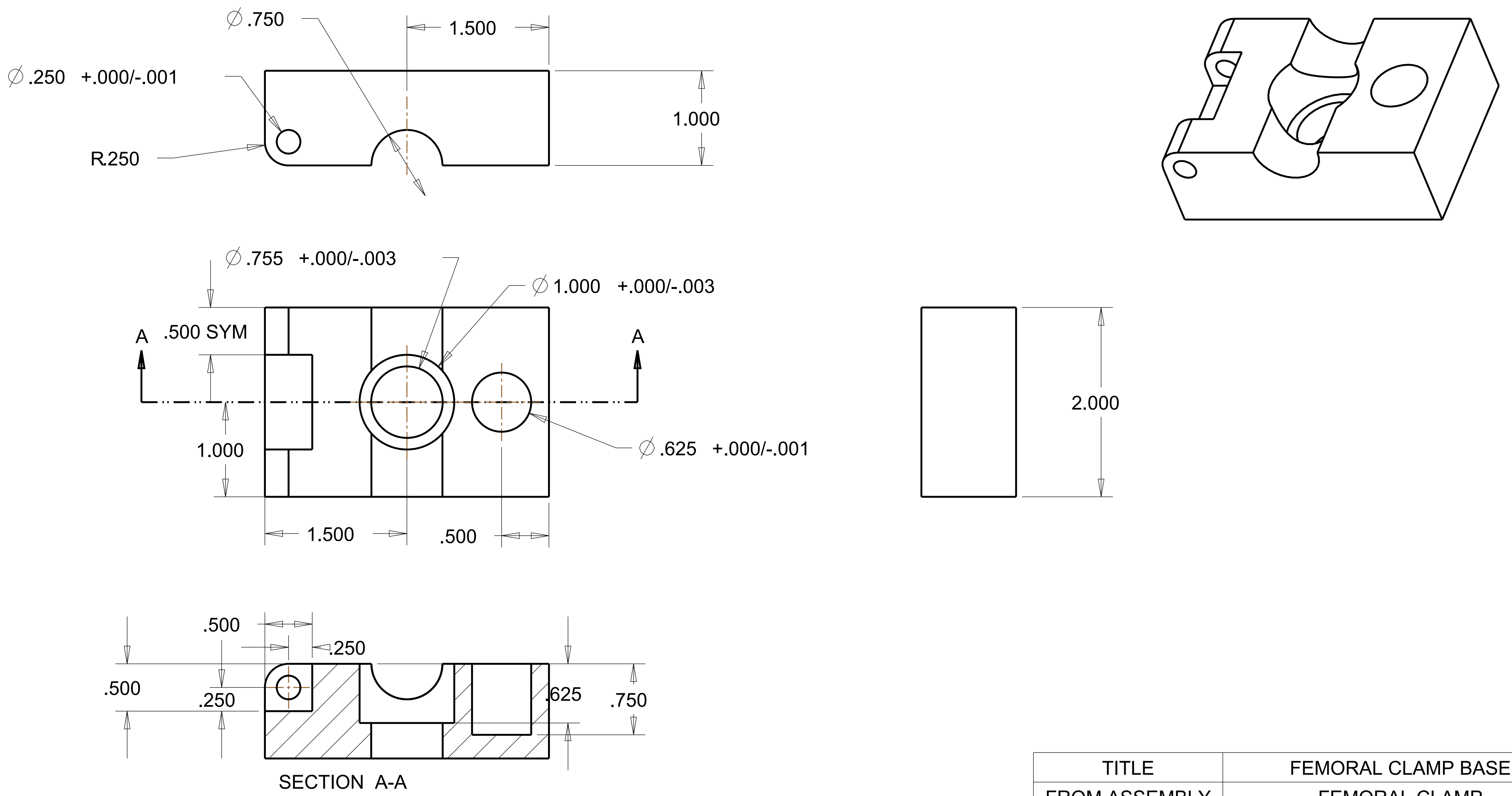

\begin{tabular}{|c|c|}
\hline TITLE & FEMORAL CLAMP BASE \\
\hline FROM ASSEMBLY & FEMORAL CLAMP \\
\hline MATERIAL & 6061 AL \\
\hline COMPANY & MECKANICAL DESIGN, LLC \\
\hline UNITS & INCHES \\
\hline TOLERANCE & $. X X= \pm \quad 0.01, . X X X= \pm 0.005$ \\
\hline
\end{tabular}




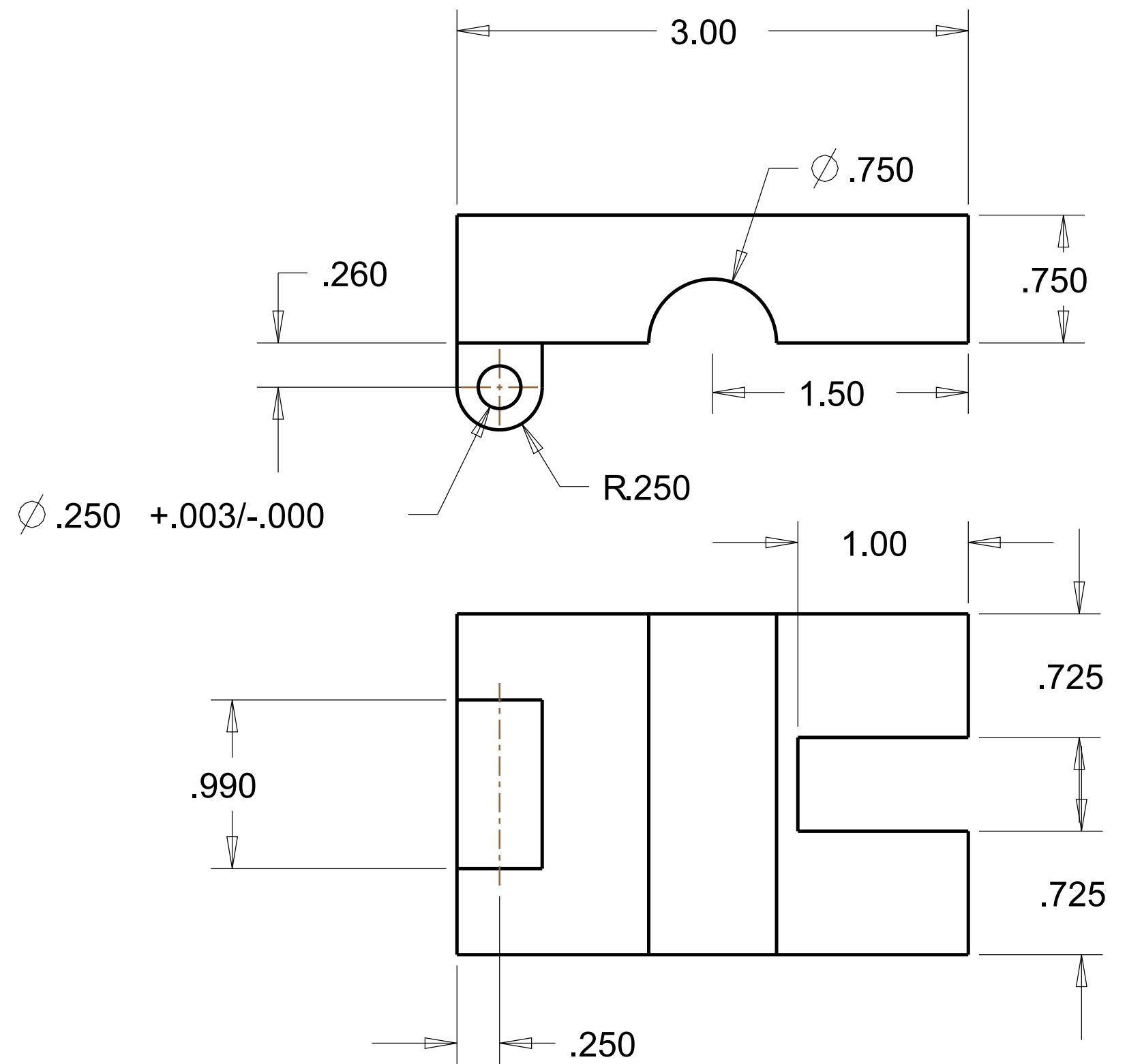

SCALE 1:1
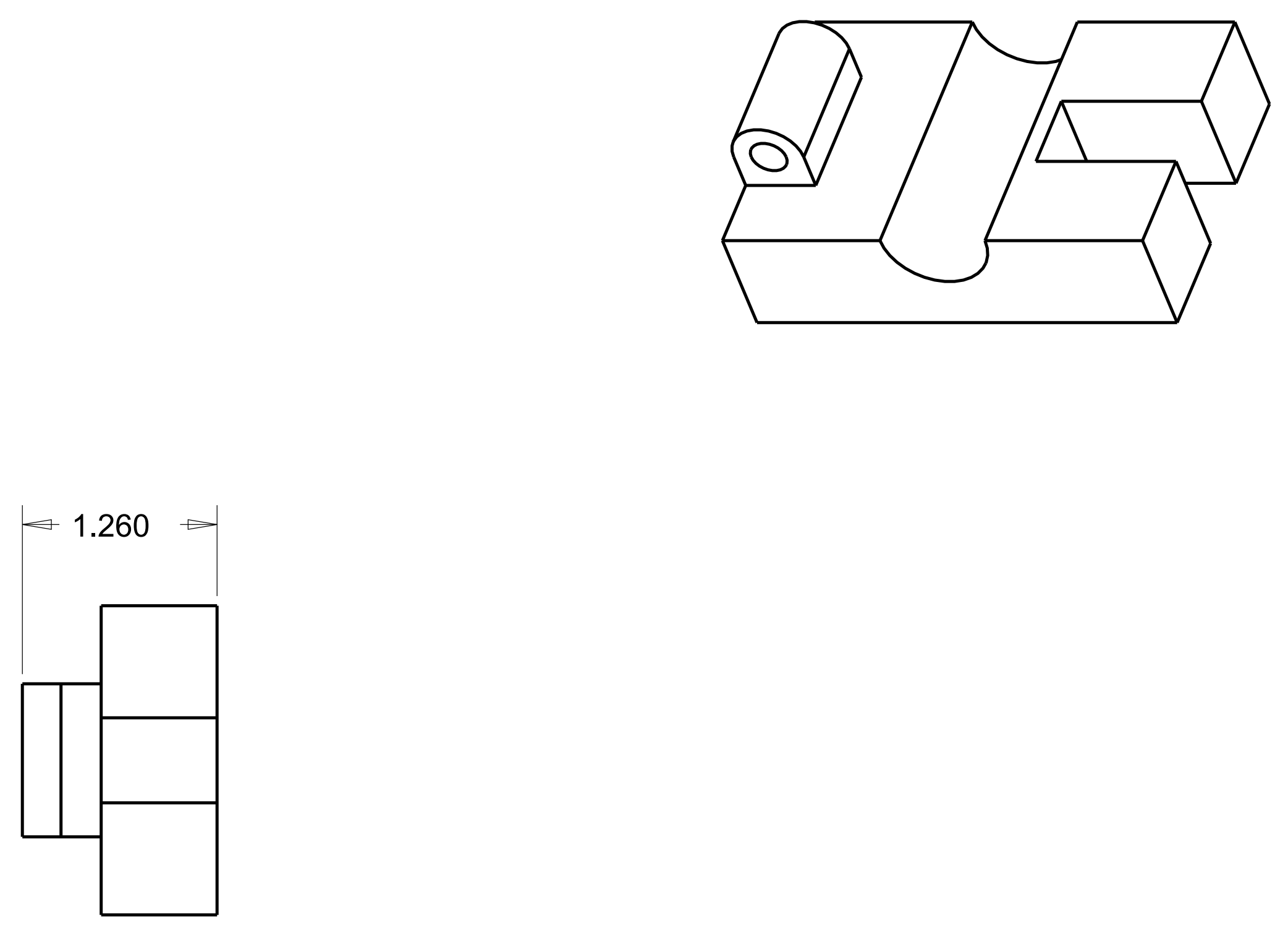

\begin{tabular}{|c|c|}
\hline FROM ASSEMBLY & FEMORAL CLAMP \\
\hline MATERIAL & $6061 \mathrm{AL}$ \\
\hline COMPANY & MECKANICAL DESIGN, LLC \\
\hline UNITS & INCHES \\
\hline TOLERANCE & $\mathrm{XX}= \pm \quad 0.01, . \mathrm{XXX}= \pm 0.005$ \\
\hline
\end{tabular}



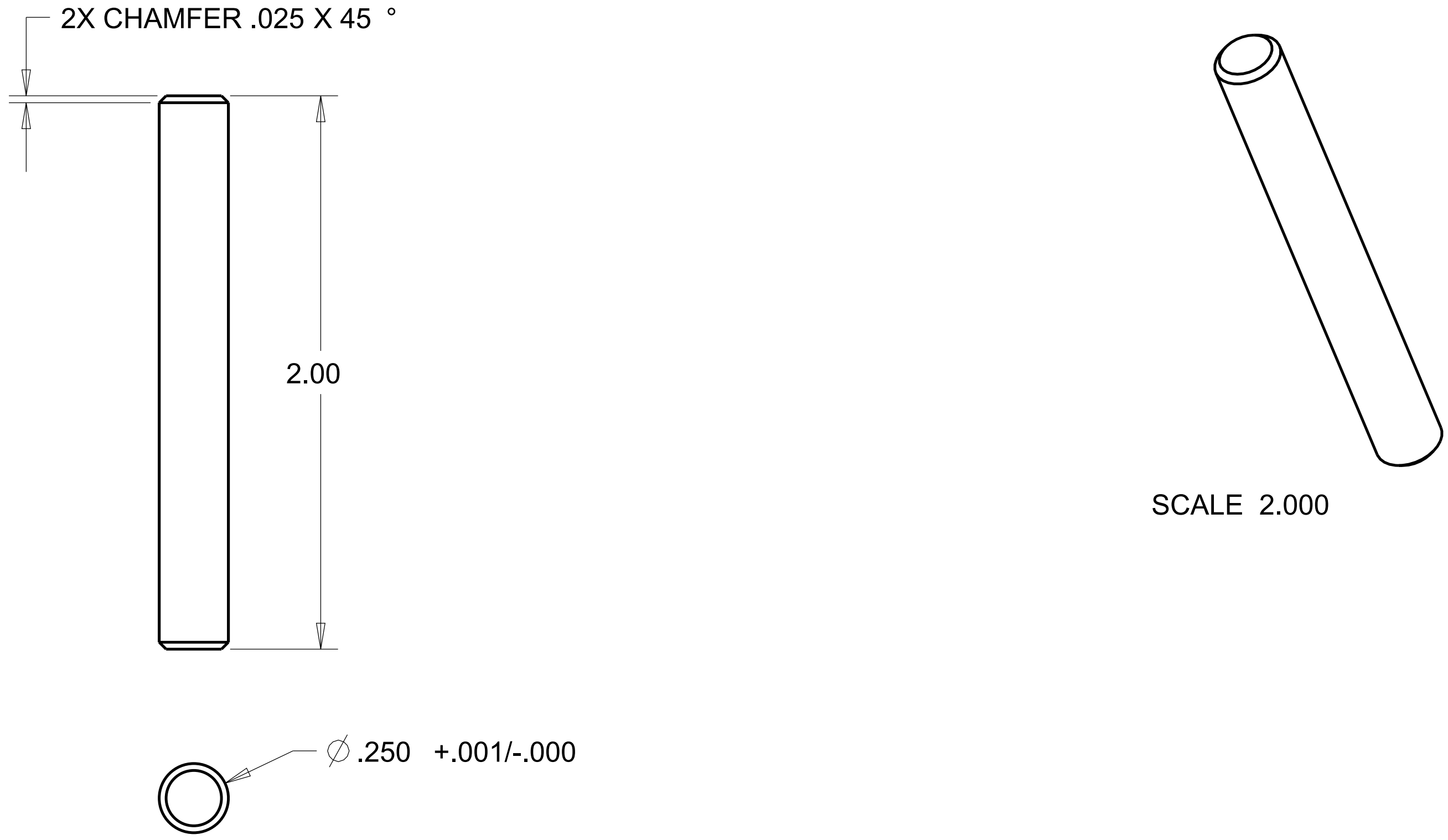

SCALE 2.000

SCALE 2:1

\begin{tabular}{|c|c|}
\hline TITLE & SMALL PIN \\
\hline FROM ASSEMBLY & FEMORAL CLAMP \\
\hline MATERIAL & STAINLESS STEEL \\
\hline COMPANY & MECKANICAL DESIGN, LLC \\
\hline UNITS & INCHES \\
\hline TOLERANCE & $0.01, . X X X= \pm$ \\
\hline
\end{tabular}



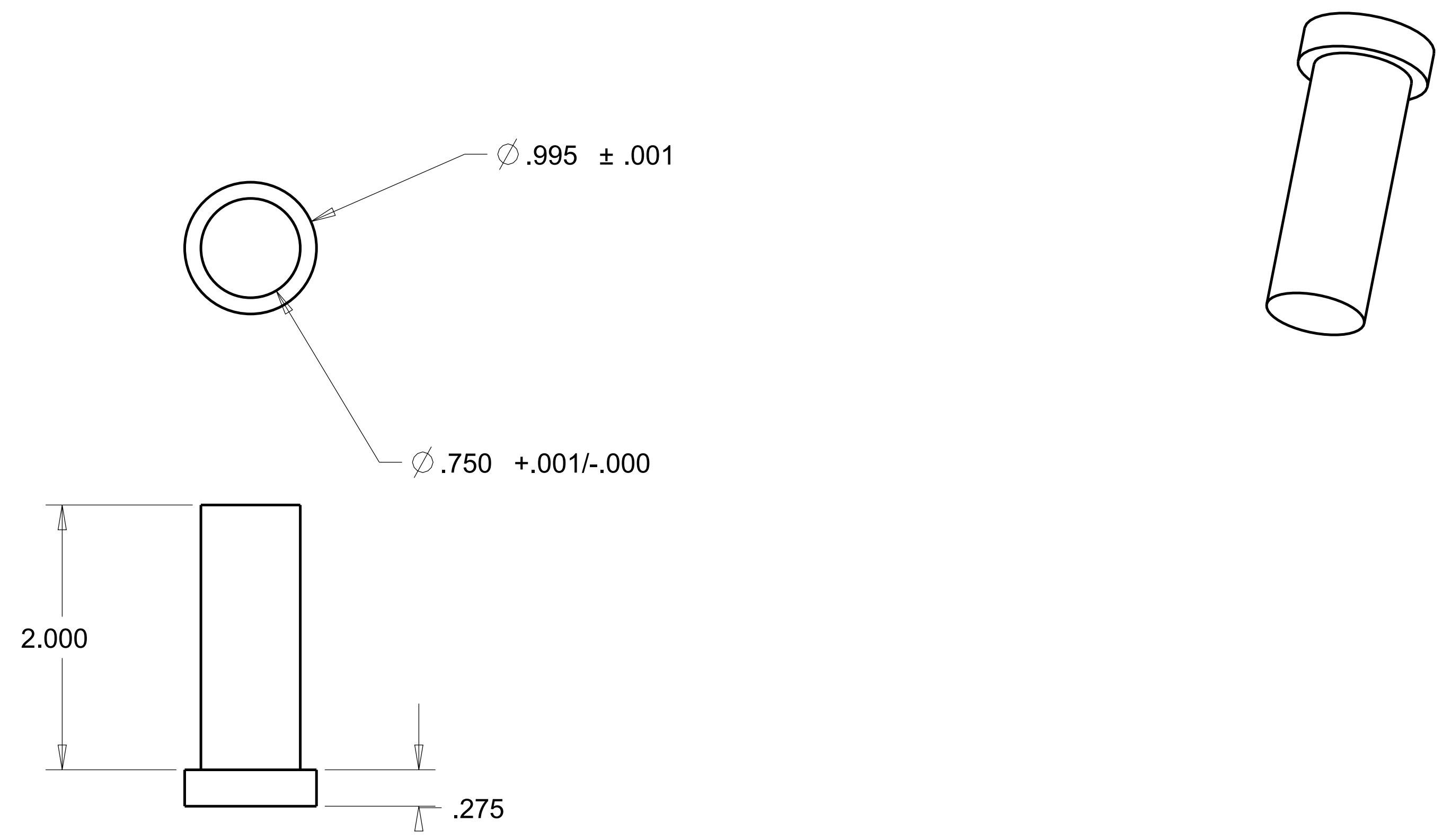

SCALE 1:1

\begin{tabular}{|c|c|}
\hline TITLE & PRESS-FIT PIN \\
\hline FROM ASSEMBLY & FEMORAL CLAMP \\
\hline MATERIAL & $6061 \mathrm{AL}$ \\
\hline COMPANY & MECKANICAL DESIGN, LLC \\
\hline UNITS & INCHES \\
\hline TOLERANCE & $. \mathrm{XX}= \pm \quad 0.01, . \mathrm{XXX}= \pm 0.005$ \\
\hline
\end{tabular}


BILL OF MATERIALS
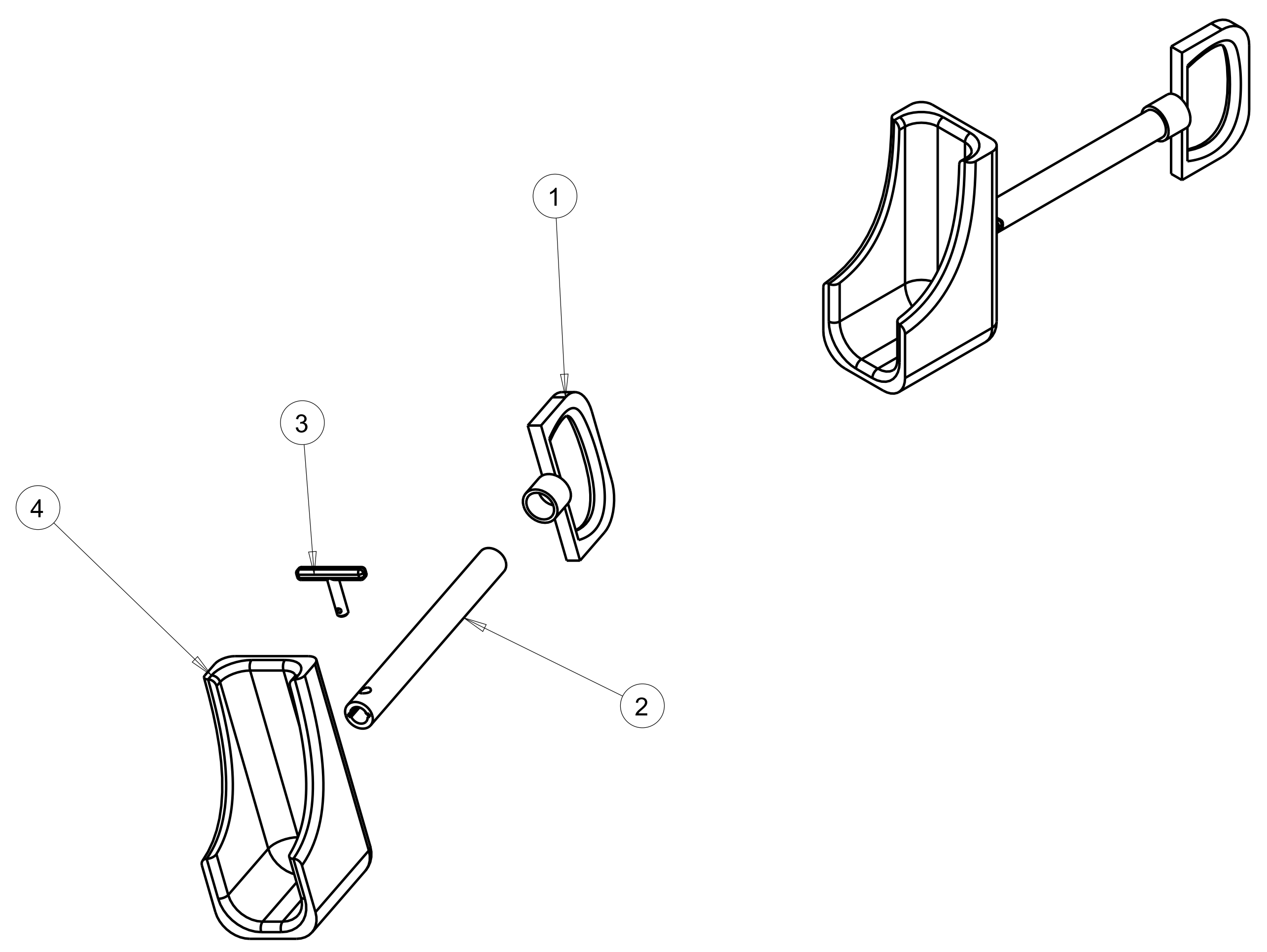

\begin{tabular}{|c|c|}
\hline BOM \# & DESCRIPTION \\
\hline 1 & $\begin{array}{c}\text { MCMASTER P/N } \\
97836 \text { A430 } \\
\end{array}$ \\
\hline 2 & PULL ROD \\
\hline 3 & $\begin{array}{c}\text { MCMASTER P/N } \\
92490 \text { A360 }\end{array}$ \\
\hline 4 & BOOT \\
\hline
\end{tabular}



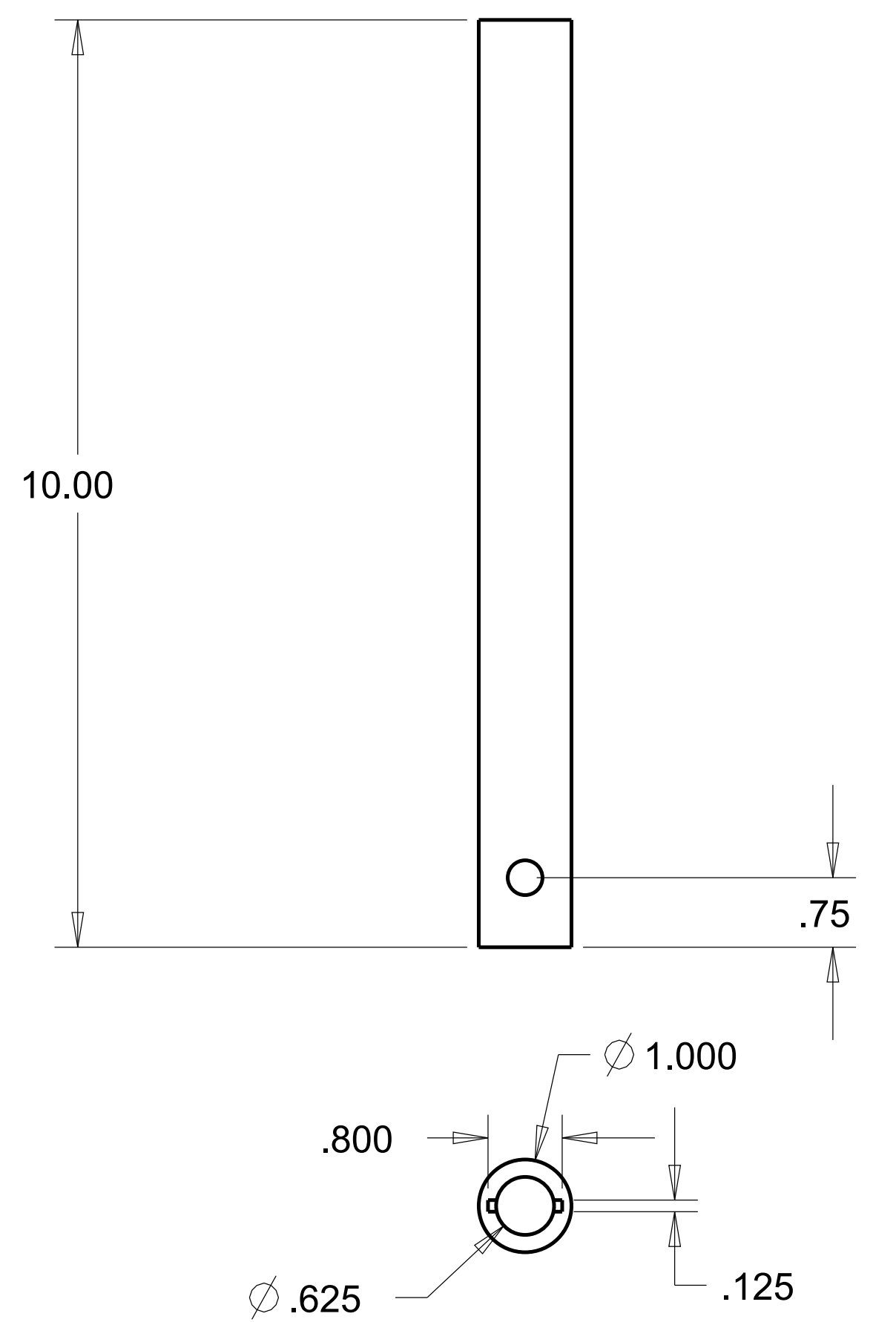

SCALE 1:2

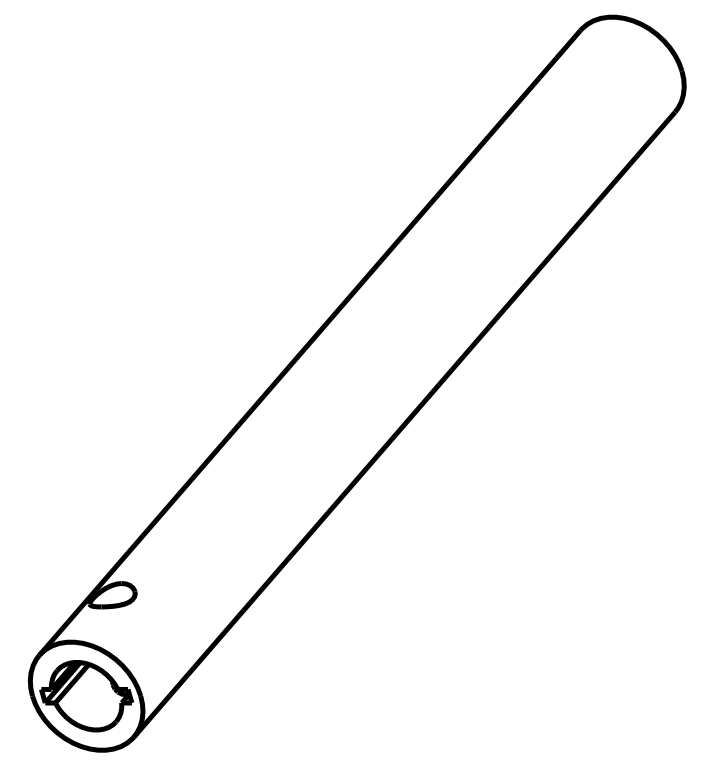

TITLE FROM ASSEMBLY MATERIAL COMPANY UNITS TOLERANCE
PULL ROD TRACTION ROD ASSEMBLY $6061 \mathrm{AL}$ MECKANICAL DESIGN, LLC INCHES

$0.01, X X X=$ 

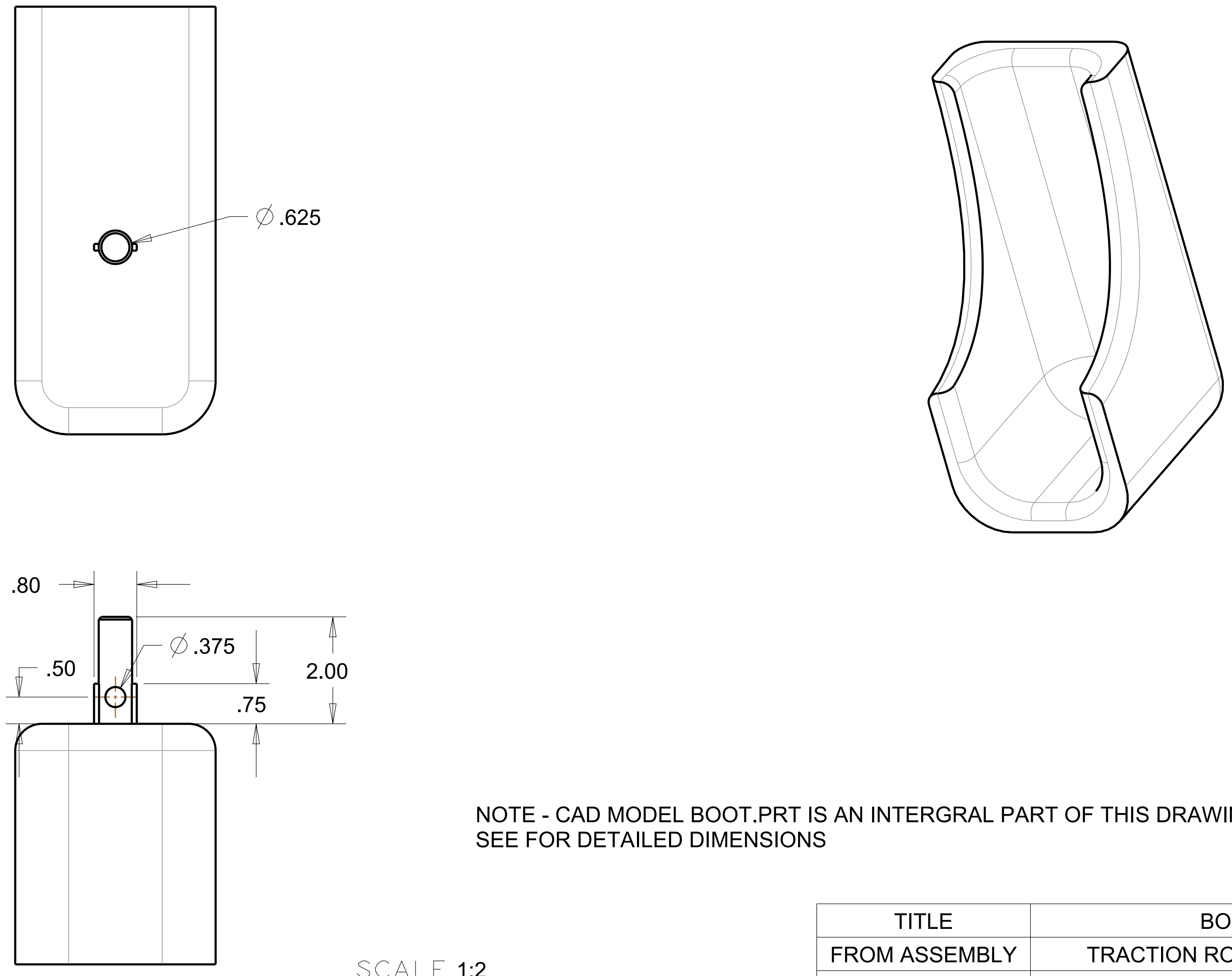

NOTE - CAD MODEL BOOT.PRT IS AN INTERGRAL PART OF THIS DRAWING SEE FOR DETAILED DIMENSIONS

\begin{tabular}{|c|c|}
\hline TITLE & BOOT \\
\hline FROM ASSEMBLY & TRACTION ROD ASSEMBLY \\
\hline MATERIAL & $6061 \mathrm{AL}$ \\
\hline COMPANY & MECKANICAL DESIGN, LLC \\
\hline UNITS & INCHES \\
\hline TOLERANCE & $. X X= \pm \quad 0.01, . X X X= \pm 0.005$ \\
\hline
\end{tabular}



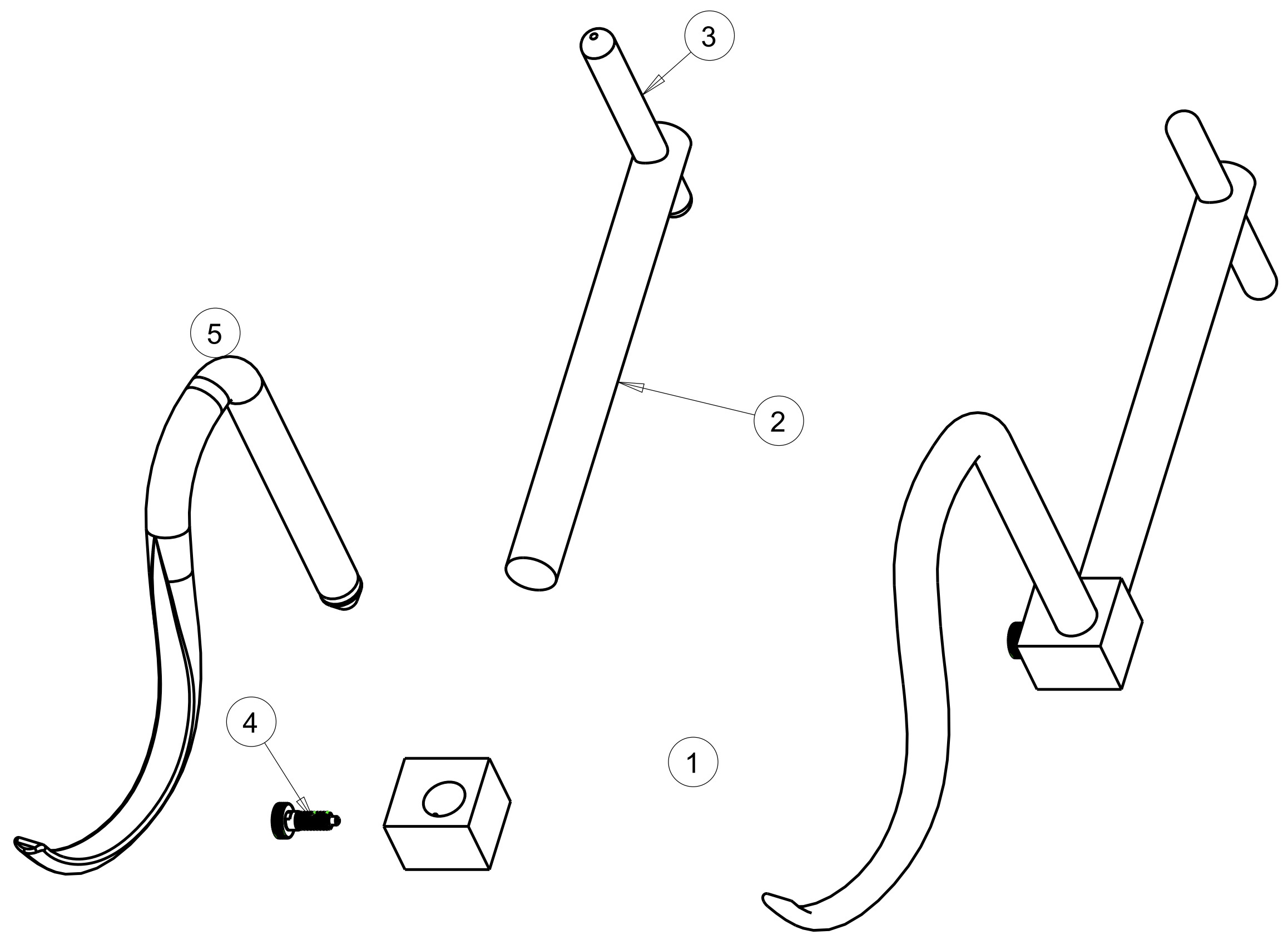

\begin{tabular}{|c|c|}
\hline BOM \# & DESCRIPTION \\
\hline 1 & RECEIVER BRACKET \\
\hline 2 & FEMORAL PULL ROD \\
\hline 3 & PULL HANDLE \\
\hline 4 & $\begin{array}{c}\text { MCMASTER P/N } \\
84935 \text { A140 }\end{array}$ \\
\hline 5 & HOOK \\
\hline
\end{tabular}

TITLE FROM ASSEMBLY MATERIAL COMPANY UNITS
FEMORALCOMPNENT HOLDER N/A

N/A

MECKANICAL DESIGN, LLC 
$\varnothing .750+.000 /-.001$

$\varpi .875$
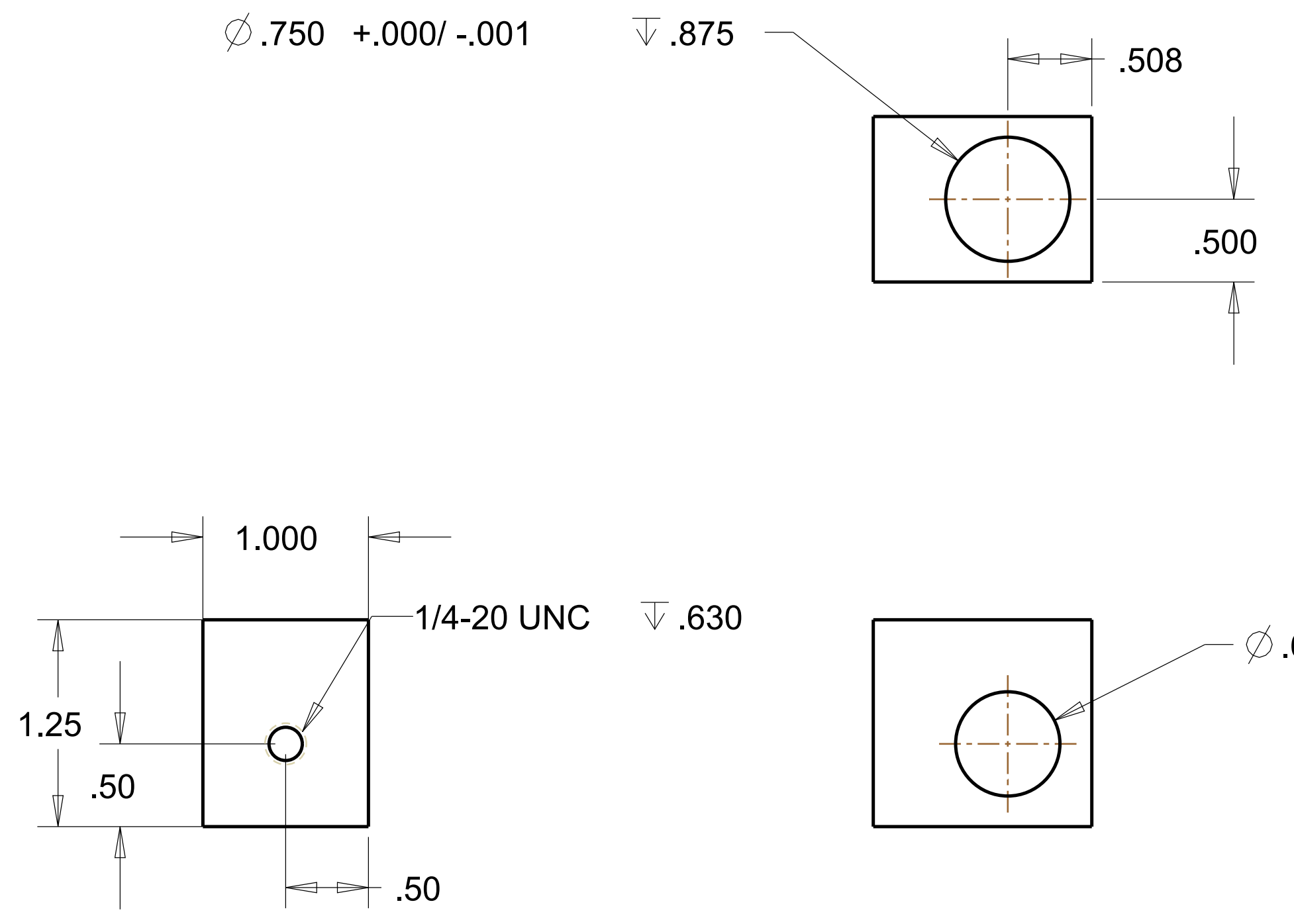
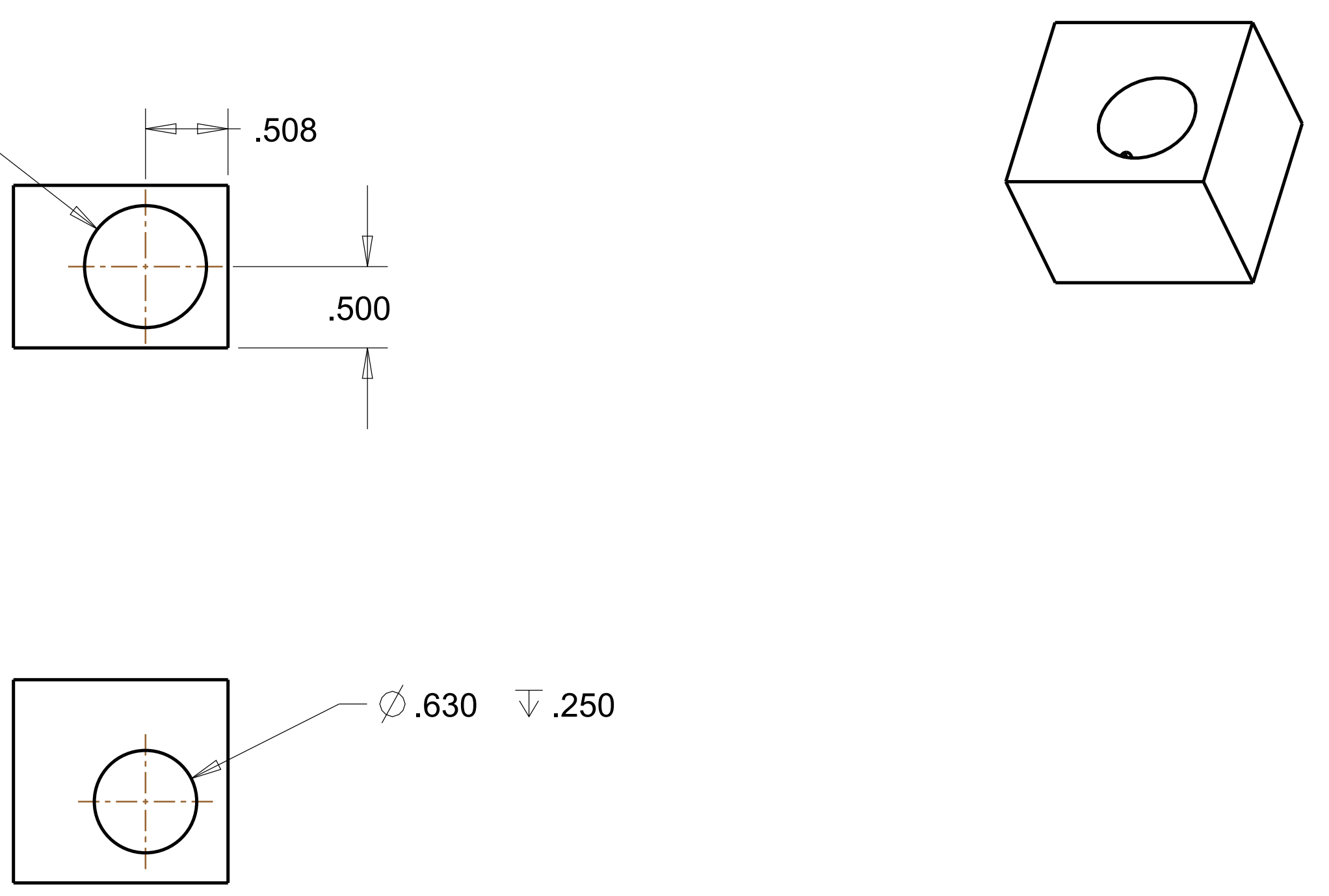

TITLE FROM ASSEMBLY MATERIAL COMPANY UNITS TOLERANCE
RECEIVER BRACKET FEMORAL COMPONENT HOLDER $6061 \mathrm{AL}$ MECKANICAL DESIGN, LLC INCHES $0.01, X X X=$ 

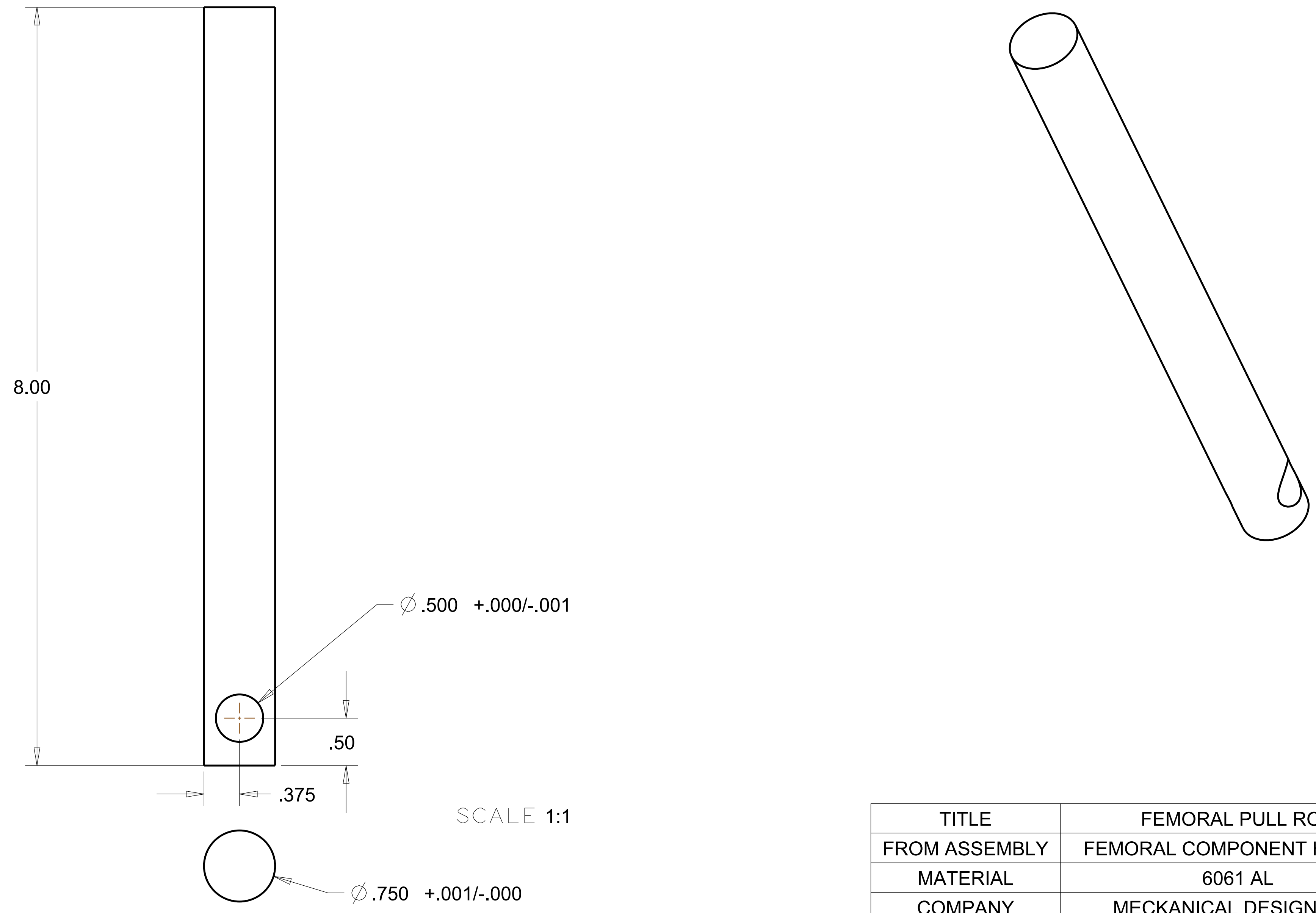

TITLE FROM ASSEMBLY MATERIAL COMPANY UNITS

TOLERANCE
FEMORAL COMPONENT HOLDER $6061 \mathrm{AL}$ MECKANICAL DESIGN, LLC INCHES

$0.01, X X X=$ 
R.20

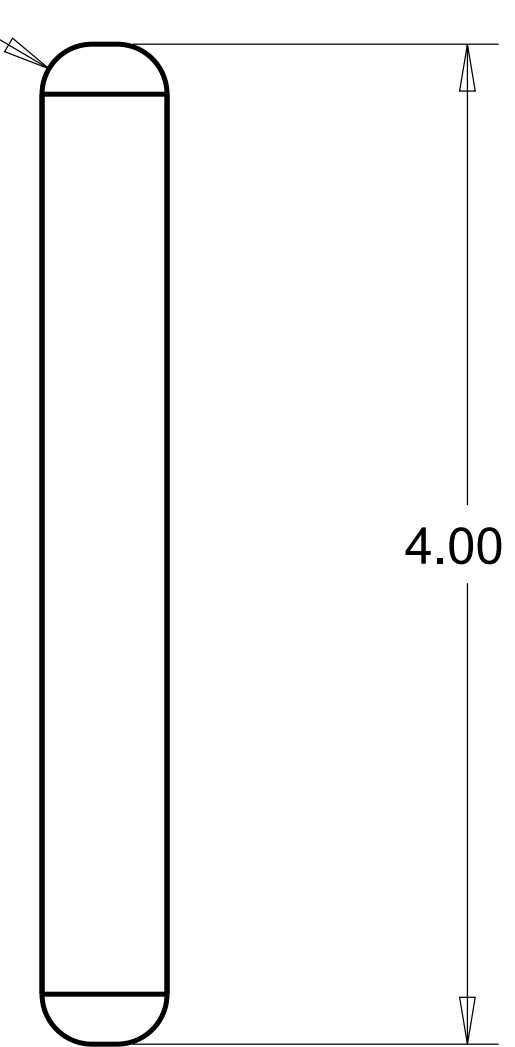

0

4.00

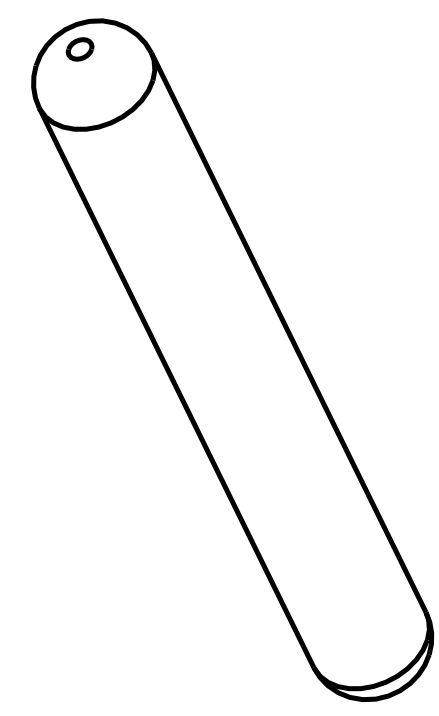

SCALE 1:1

TITLE FROM ASSEMBLY MATERIAL COMPANY UNITS TOLERANCE
PULL HANDLE

FEMORAL COMPONENT HOLDER $6061 \mathrm{AL}$ MECKANICAL DESIGN, LLC INCHES

01 XXX 


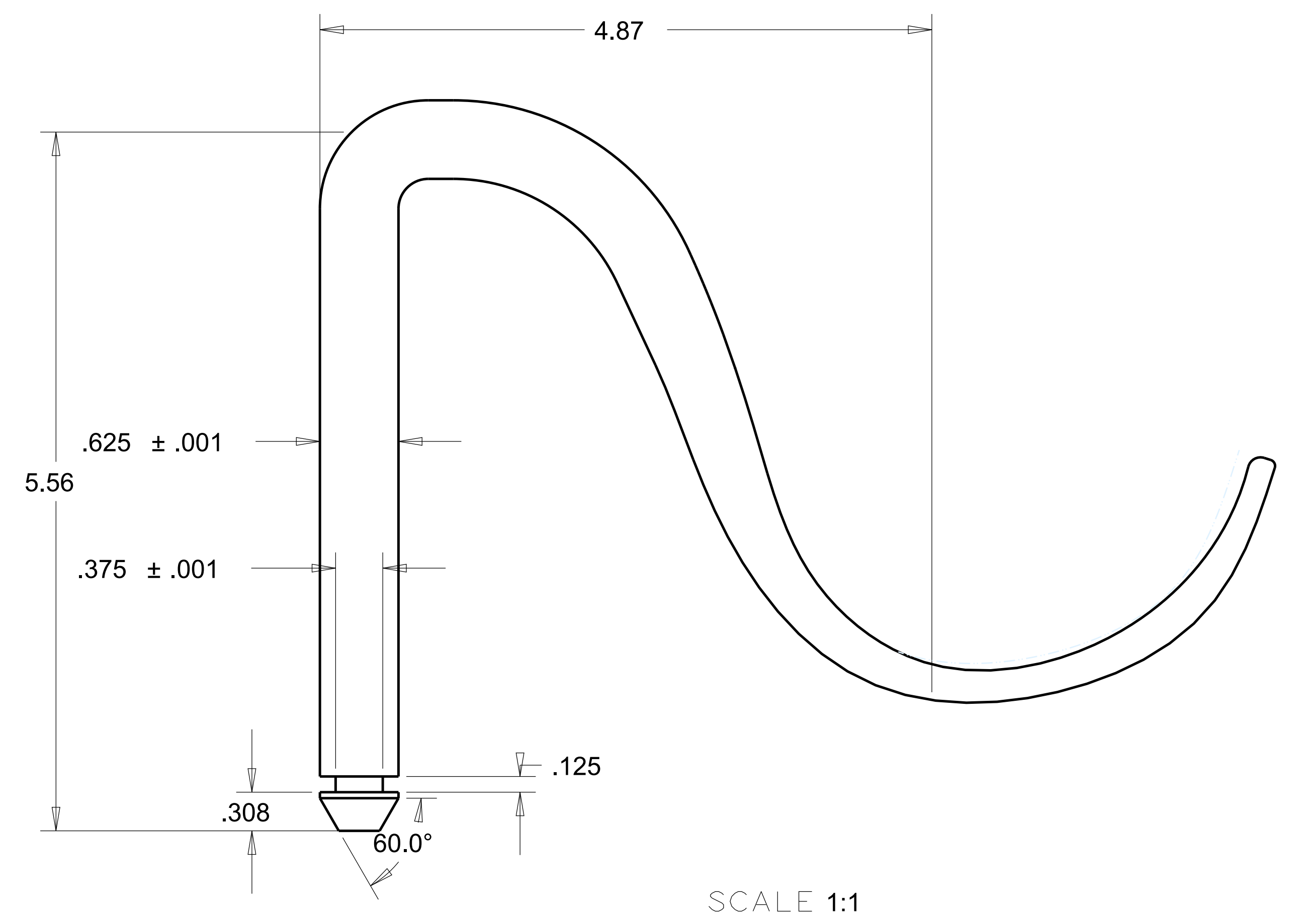

NOTE - CAD MODEL HOOK.PRT INTEGRAL PART OF DRAWING, SEE FOR DETAILED DIMENSIONS

\begin{tabular}{|c|c|}
\hline TITLE & HOOK \\
\hline FROM ASSEMBLY & FEMORAL COMPONENT HOLDER \\
\hline MATERIAL & STAINLESS STEEL \\
\hline COMPANY & MECKANICAL DESIGN, LLC \\
\hline UNITS & INCHES \\
\hline TOLERANCE & $. X X= \pm \quad 0.01, . X X X= \pm 0.005$ \\
\hline
\end{tabular}




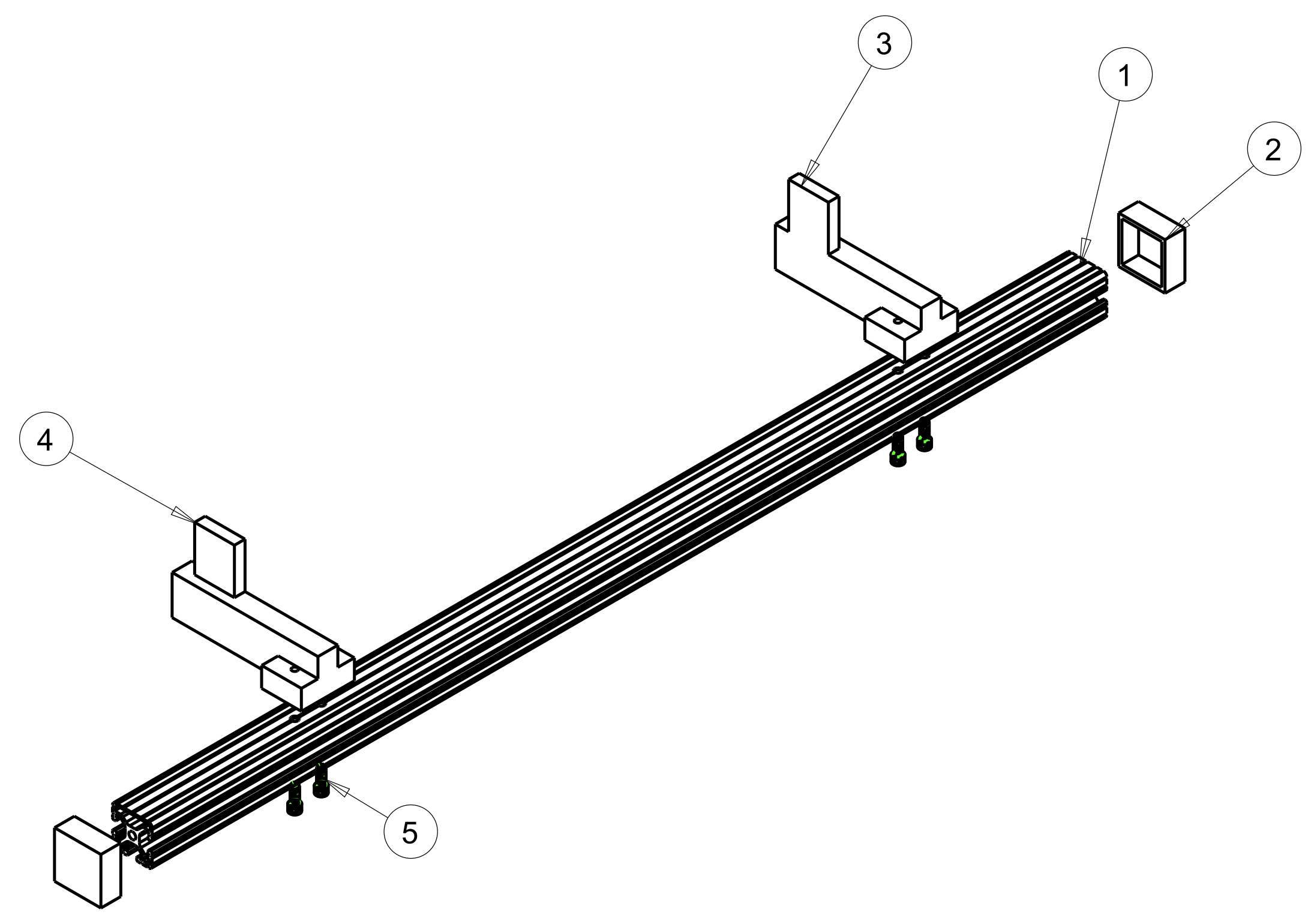




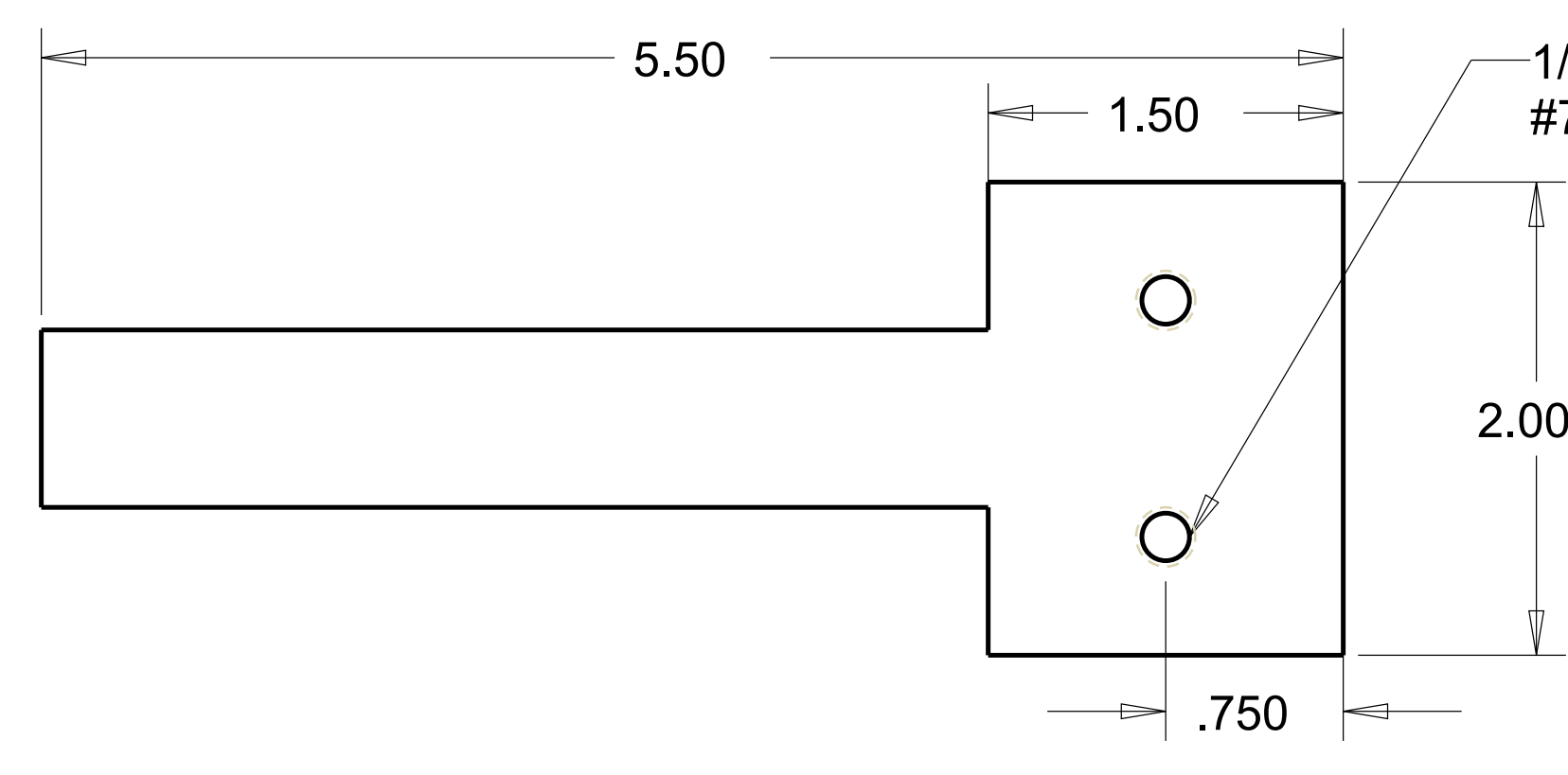

1/4-20 UNC- 2B TAP $\nabla 0.480$

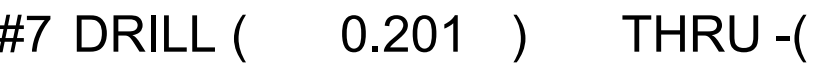

2 ) HOLE
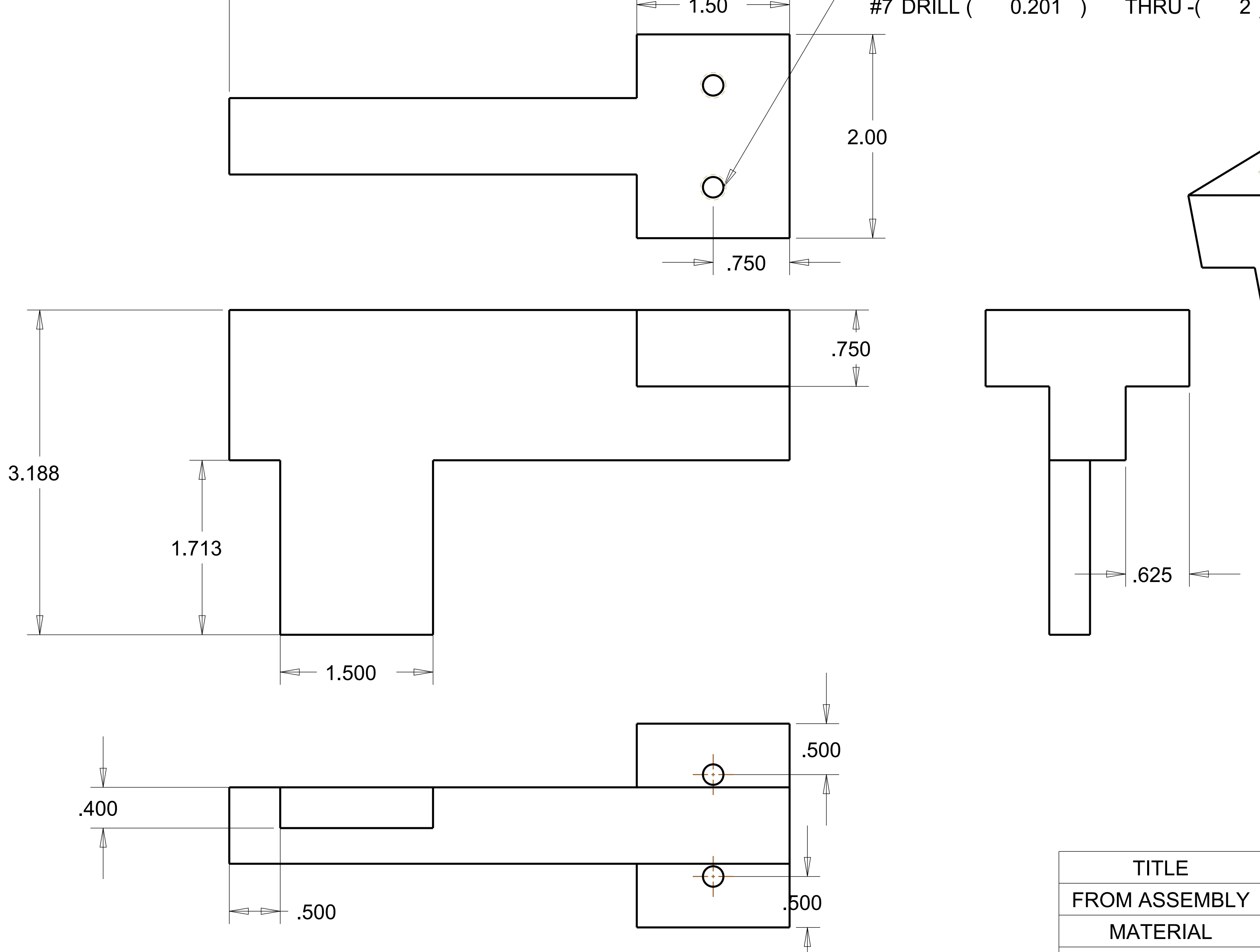

\begin{tabular}{|c|c|}
\hline TITLE & LEFT RAIL TAB \\
\hline FROM ASSEMBLY & RAIL SLIDER \\
\hline MATERIAL & $6061 \mathrm{AL}$ \\
\hline COMPANY & MECKANICAL DESIGN, LLC \\
\hline UNITS & INCHES \\
\hline TOLERANCE & $0.01, . X X X= \pm$ \\
\hline
\end{tabular}


- $=2-5$
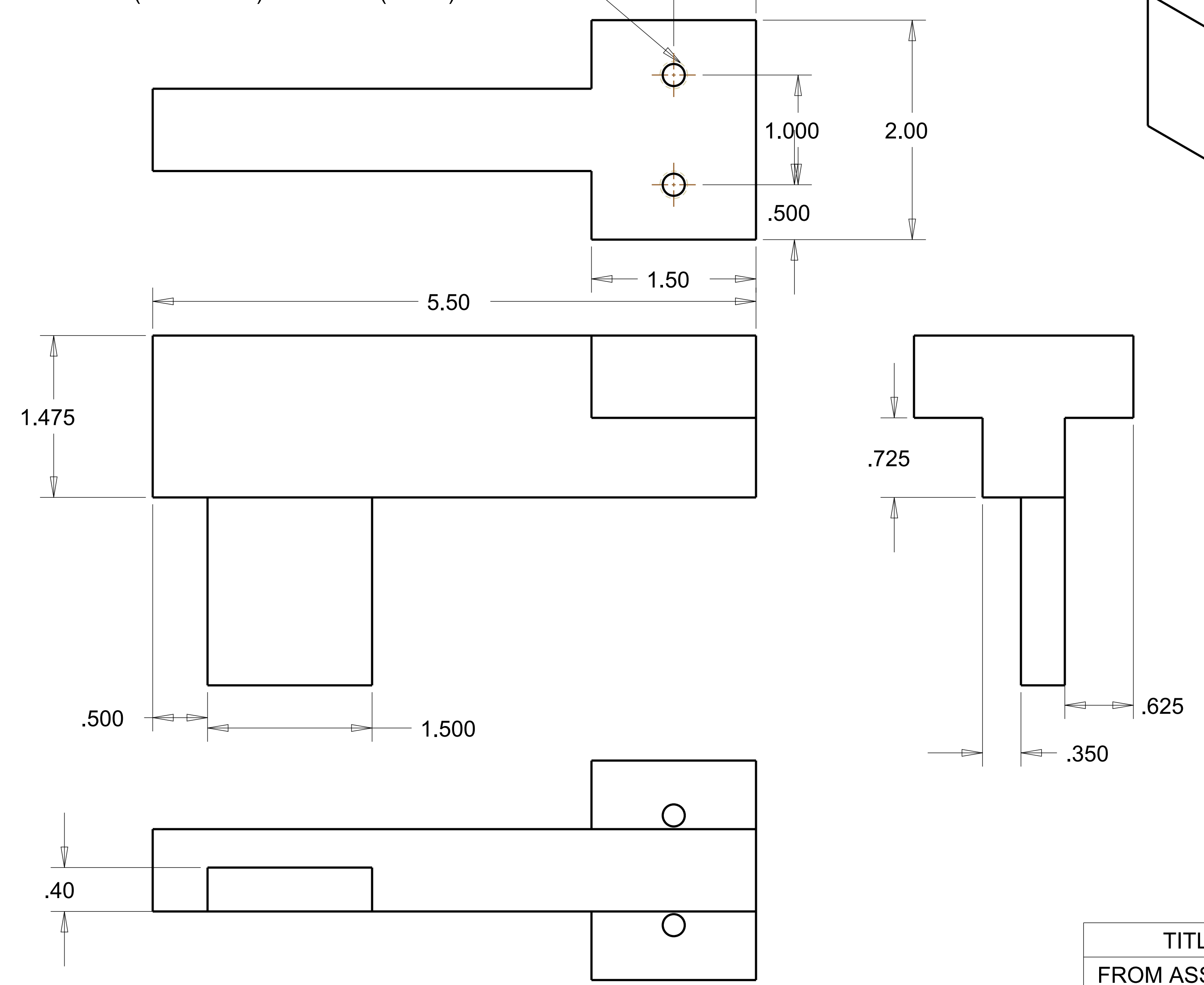

\begin{tabular}{|c|c|}
\hline TITLE & RIGHT RAIL TAB \\
\hline FROM ASSEMBLY & RAIL SLIDER \\
\hline MATERIAL & $6061 \mathrm{AL}$ \\
\hline COMPANY & MECKANICAL DESIGN, LLC \\
\hline UNITS & INCHES \\
\hline TOLERANCE & $0.01, . X X X= \pm$ \\
\hline
\end{tabular}




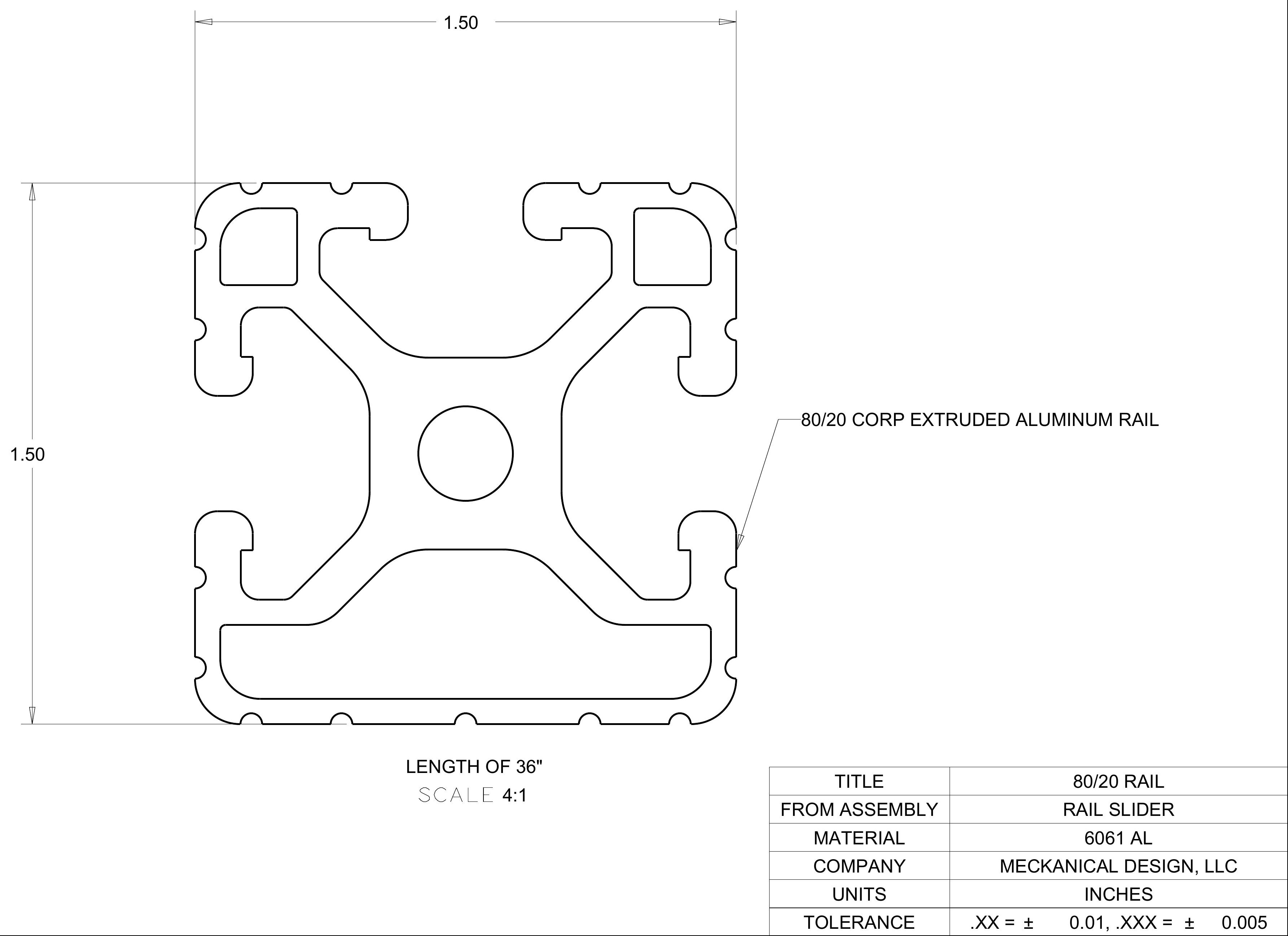



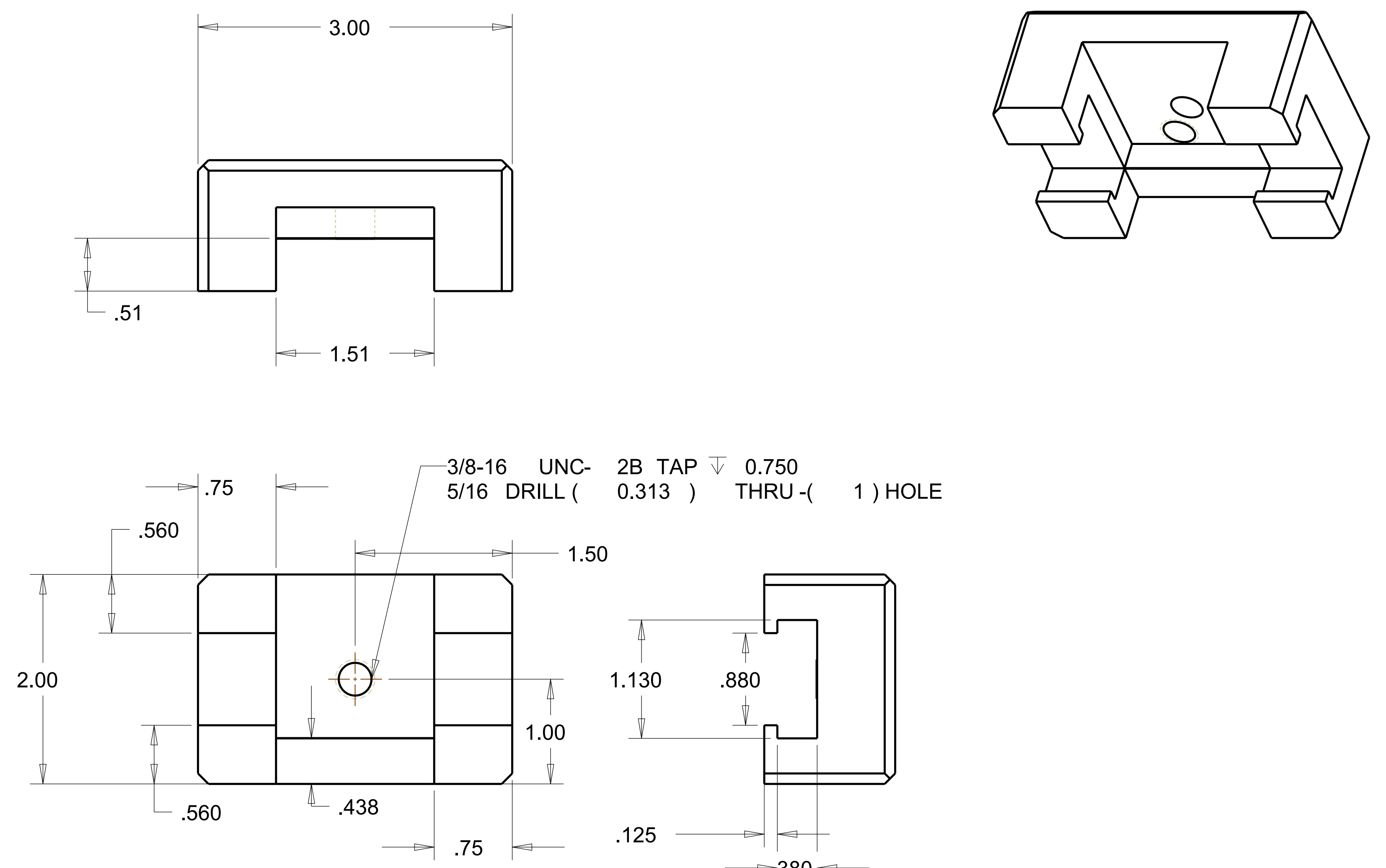

2B TAP $\nabla 0.750$

$0.313)$ THRU -( 1 ) HOLE

\subsection{0}

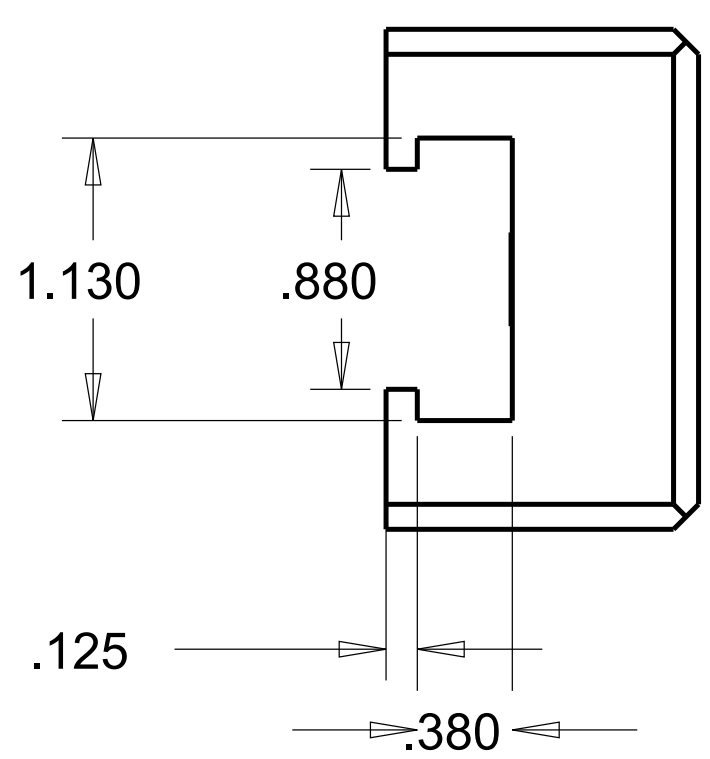

\begin{tabular}{|c|c|}
\hline TITLE & RAIL CLAMP \\
\hline FROM ASSEMBLY & N/A \\
\hline MATERIAL & $6061 \mathrm{AL}$ \\
\hline COMPANY & MECKANICAL DESIGN, LLC \\
\hline UNITS & INCHES \\
\hline
\end{tabular}


BILL OF MATERIALS
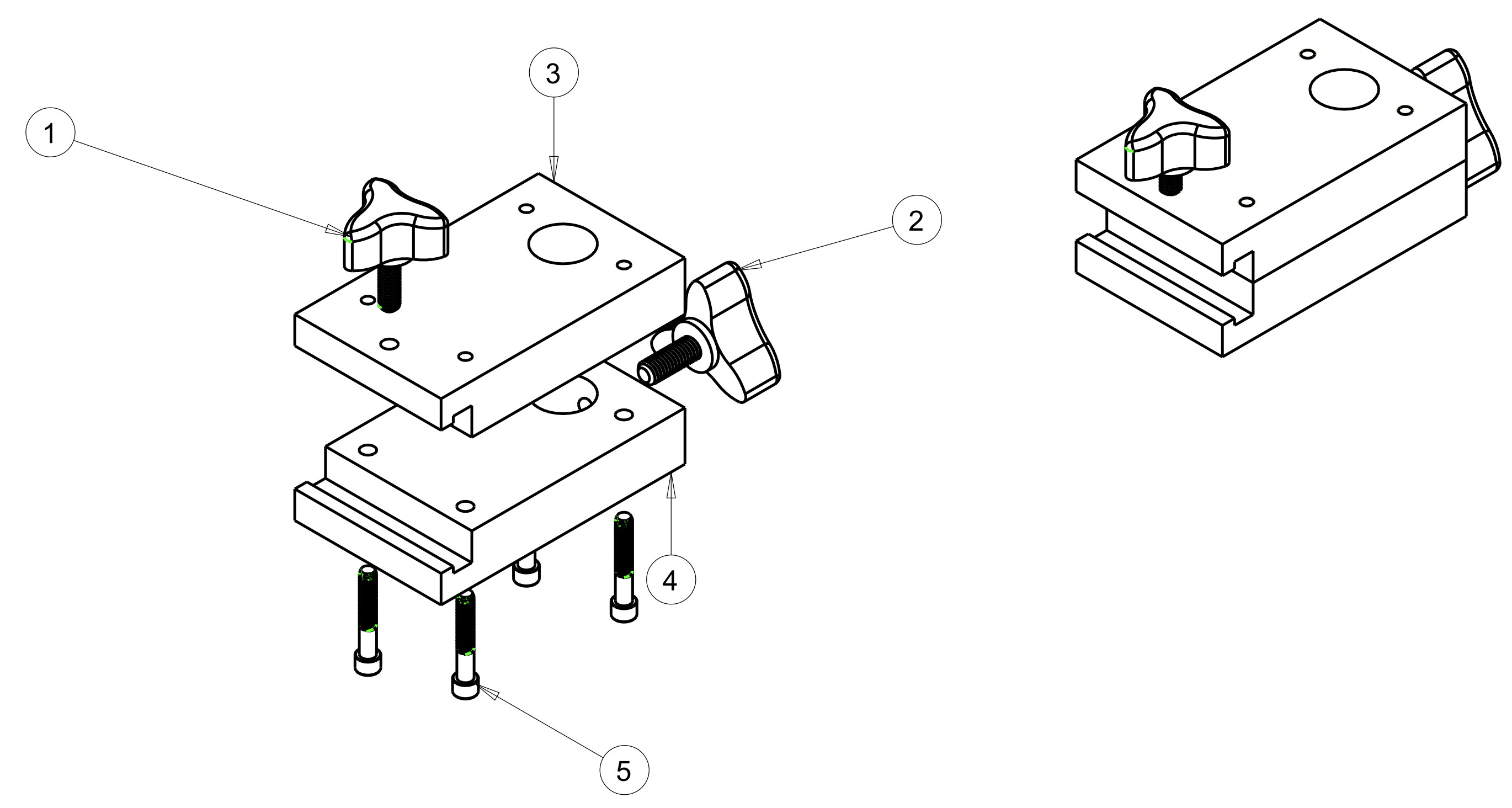

\begin{tabular}{|c|c|}
\hline BOM \# & DESCRIPTION \\
\hline 1 & $\begin{array}{c}\text { MCMASTER P/N } \\
2776 K 270\end{array}$ \\
\hline 2 & $\begin{array}{c}\text { MCMASTER P/N } \\
2776 K 250\end{array}$ \\
\hline 3 & RAIL CLAMP BOTTOM \\
\hline 4 & RAIL CLAMP TOP \\
\hline 5 & 4X MCMASTER P/N \\
& 93705 A546 \\
\hline
\end{tabular}

TITLE \begin{tabular}{|c|}
\hline FROM ASSEM \\
\hline MATERIAL \\
\hline COMPANY \\
\hline UNITS \\
\hline TOLERANCE
\end{tabular}
FEMORAL RAIL CLAMP N/A 

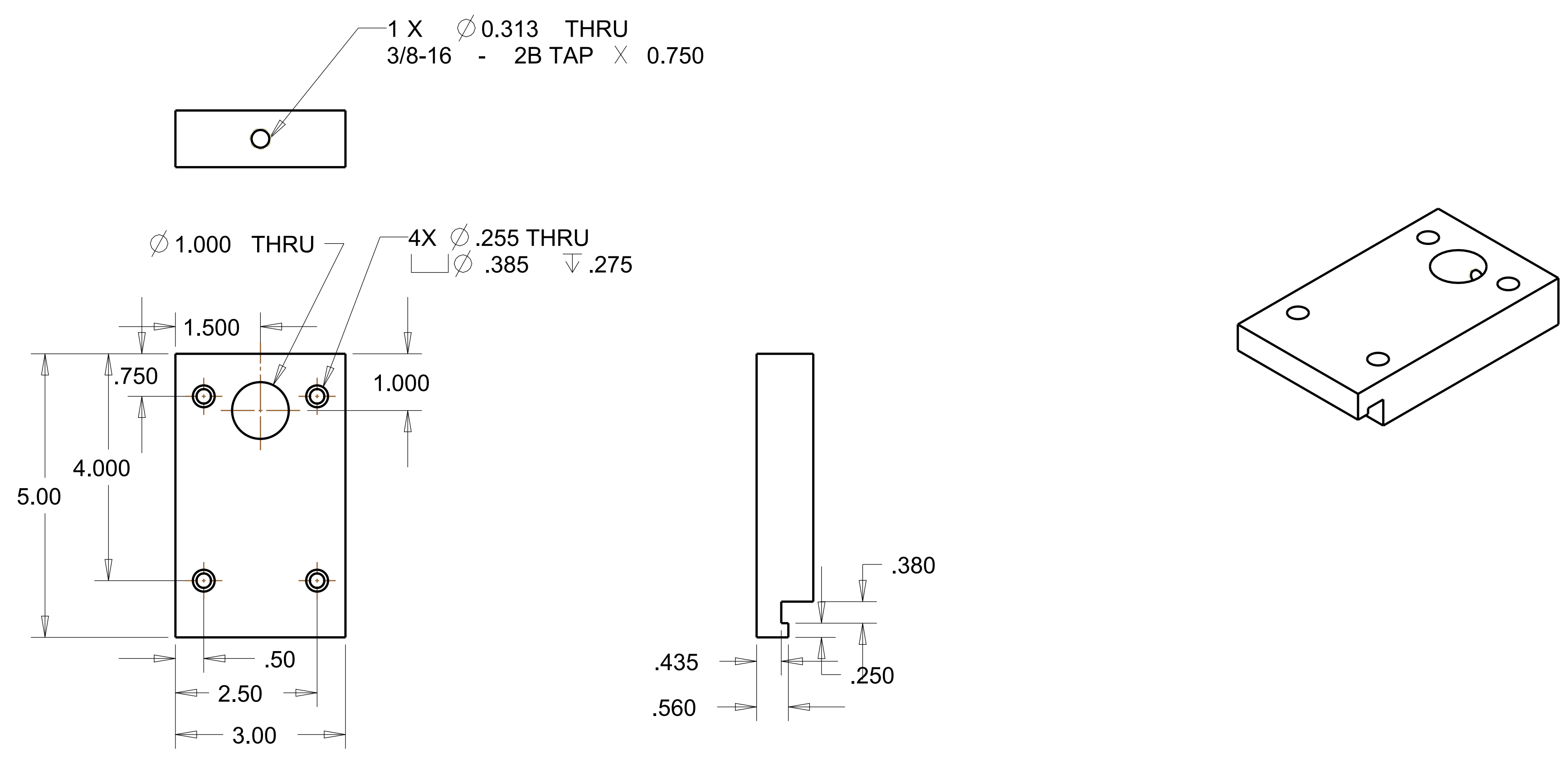

\begin{tabular}{|c|c|}
\hline TITLE & RAIL CLAMP TOP \\
\hline FROM ASSEMBLY & FEMORAL RAIL CLAMP \\
\hline MATERIAL & 6061 AL \\
\hline COMPANY & MECKANICAL DESIGN, LLC \\
\hline UNITS & INCHES \\
\hline TOLERANCE & $. X X= \pm \quad 0.01, . X X X= \pm 0.005$ \\
\hline
\end{tabular}


$4 X \quad 1 / 4-20$ UNC- 2B TAP $\vee 1.000$

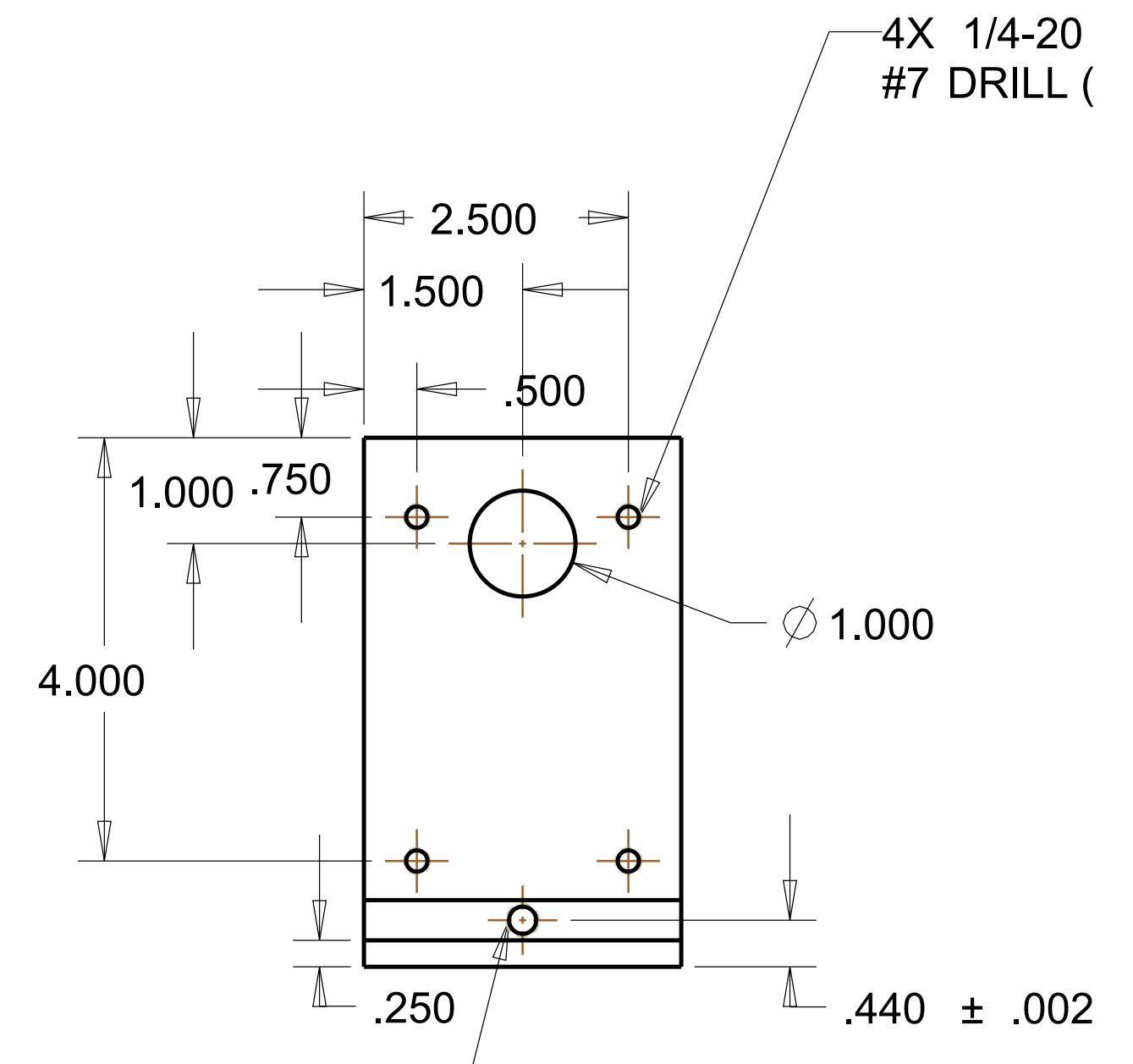

5/16-18 UNC- 2B TAP $\nabla 0.620$

F DRILL $\left(\begin{array}{cc}0.257 \\ 0\end{array}\right)$ THRU -( 1$)$ HOLE
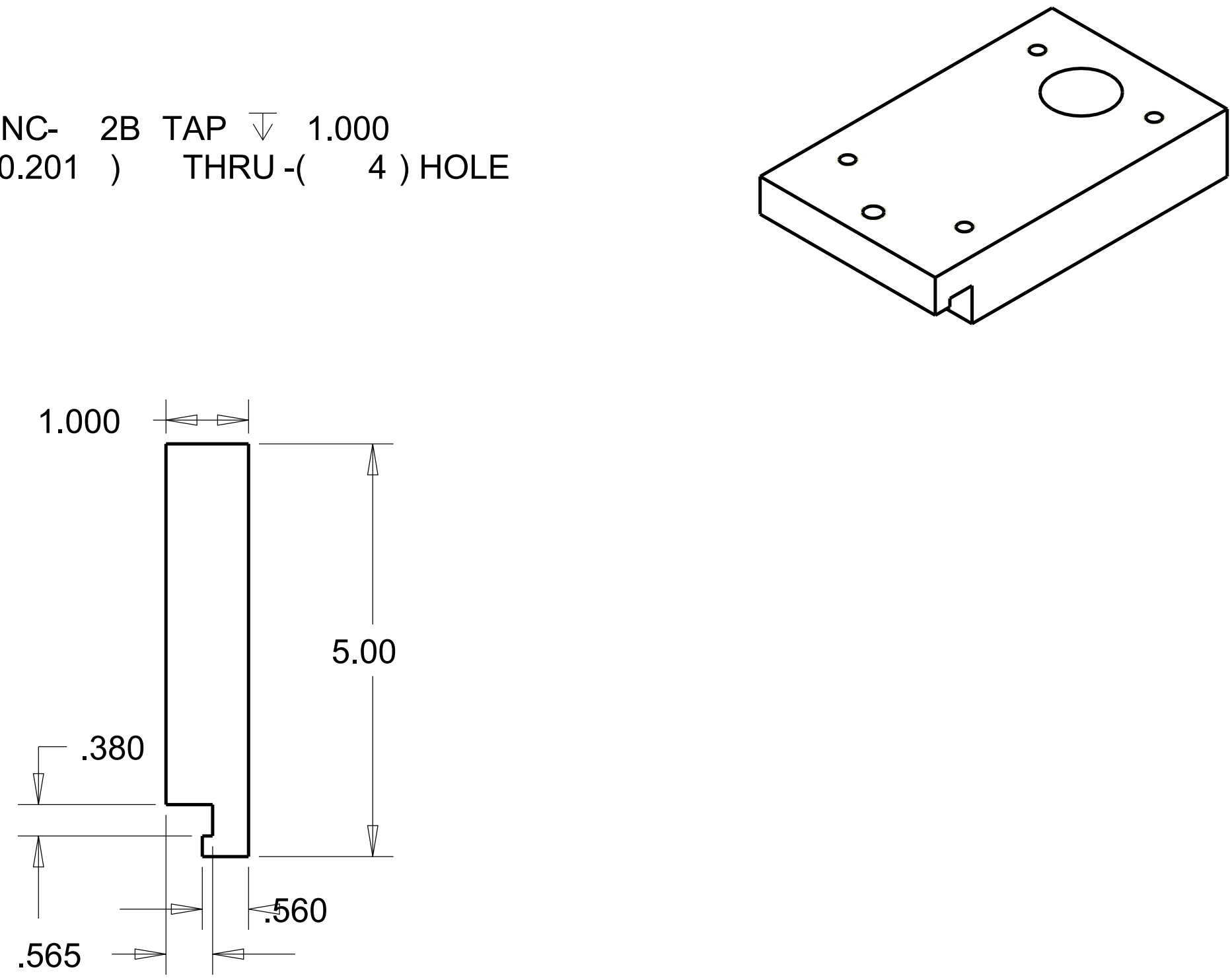

TITLE FROM ASSEMBLY MATERIAL COMPANY UNITS TOLERANCE
RAIL CLAMP BOTTOM FEMORAL RAIL CLAMP $6061 \mathrm{AL}$ MECKANICAL DESIGN, LLC INCHES

$0.01, X X X= \pm$ 
Appendix B - Manufacturing Cost Estimates

\section{Femoral Elevator Assembly}

Raw material cost - 6061 AL @ volume of 50.83in ${ }^{3}$ per assembly * $\$ 0.414 /$ in $^{3}$ (MetalsDepot.com price for quantity required for 1000 units $+10 \%$ for waste)

$=\$ \mathbf{2 1 . 0 4} / \mathbf{a s s e m b l y}$

316 SST - @ volume of 3.79in ${ }^{3}$ per assembly * \$1.115/in ${ }^{3}$ (MetalsDepot.com price for quantity required for $\$ 1000$ units $+10 \%$ for waste) $=\mathbf{\$ 4 . 2 3}$ /assembly

Hinge pin-\$4.97@ McMaster-Carr

Brass bushing - \$.90@ McMaster-Carr

Bolts $-4 X \$ .18 /$ bolt $=\$ .72 @$ McMaster-Carr

Screw knobs - 2X \$1.27/knob@ McMaster-Carr = \$2.54/assembly

Machine shop cost @ \$50/hr*12 hrs=\$600/assembly.

\section{Sum $=\$ 634.40$}

\section{Boot Assembly}

Raw material cost - 6061 AL@ volume of 36.84in ${ }^{3}$ per assembly * \$0.414/in ${ }^{3}$ (MetalsDepot.com price for quantity required for 1000 units $+10 \%$ for waste)

$=\$ 15.25$ /assembly

Brass bushing - \$.90@ McMaster-Carr

Screw knobs - 2 X \$1.27/knob @ McMaster-Carr = \$2.54/assembly

80/20 T-slot rail extrusion - \$23.54/rail (8020.net)

80/20 double flange linear bearing - \$55.39 (8020.net)

Bolts $-4 X \$ .16 /$ bolt $=\$ .64 @$ McMaster-Carr

Machine shop cost @ \$50/hr*11.5 hrs=\$575/assembly

Sum $=\$ 673.26$

Total Assembly cost $=\$ 1,307.66$ 